\title{
Structural plasticity of the serotonergic and dopaminergic systems : a multidisciplinary approach
}

Citation for published version (APA):

Jahanshahi, A. (2012). Structural plasticity of the serotonergic and dopaminergic systems : a multidisciplinary approach. [Doctoral Thesis, Maastricht University]. Maastricht University. https://doi.org/10.26481/dis.20120523aj

Document status and date:

Published: 01/01/2012

DOI:

10.26481/dis.20120523aj

Document Version:

Publisher's PDF, also known as Version of record

\section{Please check the document version of this publication:}

- A submitted manuscript is the version of the article upon submission and before peer-review. There can be important differences between the submitted version and the official published version of record.

People interested in the research are advised to contact the author for the final version of the publication, or visit the DOI to the publisher's website.

- The final author version and the galley proof are versions of the publication after peer review.

- The final published version features the final layout of the paper including the volume, issue and page numbers.

Link to publication

\footnotetext{
General rights rights.

- You may freely distribute the URL identifying the publication in the public portal. please follow below link for the End User Agreement:

www.umlib.nl/taverne-license

Take down policy

If you believe that this document breaches copyright please contact us at:

repository@maastrichtuniversity.nl

providing details and we will investigate your claim.
}

Copyright and moral rights for the publications made accessible in the public portal are retained by the authors and/or other copyright owners and it is a condition of accessing publications that users recognise and abide by the legal requirements associated with these

- Users may download and print one copy of any publication from the public portal for the purpose of private study or research.

- You may not further distribute the material or use it for any profit-making activity or commercial gain

If the publication is distributed under the terms of Article $25 \mathrm{fa}$ of the Dutch Copyright Act, indicated by the "Taverne" license above, 
Structural plasticity of the serotonergic and dopaminergic systems: a multidisciplinary approach

ALI JAHANSHAHI 


\section{Cover:}

The cover illustrates the main content of this thesis. A rat brain section containing the dorsal raphe nucleus stained for serotonergic and dopaminergic neurons.

(Jahanshahi et al., 2012)

Copyright: (C) Ali Jahanshahi, Maastricht 2012

All rights reserved. No part of this book may be reproduced in any form or by any means, without permission, in writing, from the copyright holder.

ISBN: 978-90-8570-835-3

Typesetting and design: Ali Jahanshahi 


\section{Structural plasticity of the serotonergic and dopaminergic systems: a multidisciplinary approach}

\section{Proefschrift}

Ter verkrijging van de graad van doctor aan

de Universiteit Maastricht, op gezag van

de Rector Magnificus, Prof. Mr. G.P.M.F. Mols volgens het besluit van het College van Decanen, in het openbaar te verdedigen op

Woensdag 23 Mei 2012 om 16.00 uur

door

Ali Jahanshahi

Geboren op 23 september 1978 te Bahar, Iran 


\section{Promoters:}

Prof. Dr. H. W. M. Steinbusch

Prof. Dr. Y. Temel

\section{Co-promoter:}

Dr. L. W. Lim

\section{Evaluation committee:}

Prof. Dr. J. J. van Overbeeke (Chairman); Maastricht, the Netherlands

Prof. Dr. T. Hökfelt; Stockholm, Sweden

Prof. Dr. D. Hopkins; Halifax, Canada

Prof. Dr. K.P. Lesch; Wurzburg, Germany

Prof. Dr. J. S. H. Vles; Maastricht, the Netherland 


\section{Contents}

General introduction

Buspirone-induced changes in the serotonergic and nonserotonergic cells in the dorsal raphe nucleus of rats. Jahanshahi A, Lim LW, Steinbusch HW, Visser-Vandewalle $\mathrm{V}$ and Temel $\mathrm{Y}$

Neurosci Lett, 2010 Apr 5;473(2):136-40

Chapter 3

Altered expression of neuronal tryptophan hydroxylase-2 mRNA in the dorsal and median raphe nuclei of three genetically modified mouse models relevant to depression and anxiety.

Jahanshahi A, Le Maitre E, Temel Y, Lanfumey L, Hamonf M, Lesch P, Tordera, RM, Del Río J, Aso E, Maldonado R, Hökfelt $\mathrm{T}$ and Steinbusch HW

J Chem Neuroanat, 2011 Jul;41(4):227-33

Hyperdopaminergic status in experimental Huntington's disease.

Jahanshahi A, Vlamings R, Hilmi Kaya A, Lim LW, Janssen M.L.F, Tan S.K, Visser-Vandewalle V, Steinbusch HW and Temel Y

J Neuropathol Exp Neurol, 2010 Sep;69(9):910-7

Chapter 5

Phenoconversion in experimental and clinical Huntington's disease.

Jahanshahi A, Vlamings R, van Roon-Mom W, Faull RLM, Waldvogel HJ, Steinbusch HW and Temel Y

Submitted

Close communication between the subependymal serotonergic plexus and the neurogenic subventricular zone.

Jahanshahi A, Temel Y, Lim LW, Hoogland G and Steinbusch HW

J Chem Neuroanat, 2011 Dec;42(4):297-303 
Chapter 7

In vivo brain repair? Electrical fields attract newborn brain cells

Jahanshahi A, Janssen ML, Steinbusch HW and Temel Y submitted

Chapter 8

Conclusion

Acknowledgment

Biography

List of publications 




\section{CHEIAP'T[ER 1}

\section{GENERAL INTRODUCTION}

Structural plasticity of the serotonergic and dopaminergic systems: a multidisciplinary approach 

For decades it was believed that the adult central nervous system (CNS) was a static network of cells and fibers without having the ability to reorganize neuronal communication. This belief was based on the assumption that changes in neurotransmission in the adult brain of higher vertebrates would interrupt the normal functioning of the brain and ultimately with physiological behavior.

It is now well accepted that these adaptive processes, generally referred to as neuronal plasticity, take place in the adult mammalian CNS when for instance new skills and memories are acquired. These changes give the CNS the capability of adapting to the new environment at functional and structural levels. Likewise, when the brain is damaged by trauma or affected by neurodegenerative disease, mechanisms of plasticity play an important role to limit the amount of damage and to enhance recovery processes. Examples are sprouting or shrinkage of dendrites and axons, neurochemical changes in neurons and synapses, and even more remarkable the generation of new neurons and glia.

In this thesis, we were mainly interested in the role of two monoaminergic neurotransmitters involved in neuronal plasticity: dopamine (DA) and 
serotonin (5-hydroxytryptamine, 5HT). These neurotransmitters play a major role in subcellular, cellular and supracellular processes involved in behavioral functions.

\section{The brainstem serotonergic and dopaminergic neurons}

The region responsible for the main serotonergic innervation of the forebrain, involved in behavioral functions, is the dorsal raphe nucleus $(\mathrm{DRN})$. The DRN is a large, distinct area situated in the brainstem tegmentum. It can be divided in four subdivisions: a dorsomedial cluster, a ventromedial division, the lateral sub nuclei (rostral subnucleus "B7") and the caudal subnucleus (B6) (Steinbusch and Nieuwenhuys, 1982). The DRN compromises the largest cluster of 5-HT-containing nerve cell bodies in the mammalian CNS (Descarries et al., 1982). Besides 5-HT, the DRN also contains neuronal cells which use other neurotransmitters, e.g., $\gamma$-aminobutyric acid (GABA) (Nanopoulos et al., 1982), enkephalin (Hokfelt et al., 1979) and substance- $p$ (Hokfelt et al., 1978). These neurons are known to innervate a great number of brain areas, e.g., the cerebral cortex (Yoshida et al., 1989), substantia nigra (SN) and the striatum (Vertes, 1991). Besides these ascending pathways, there are descending projections from the DRN, for instance to the locus coeruleus (LC) (Vertes and Kocsis, 1994) and cerebellum (Strazielle et al., 1996). The afferents of the DRN have been shown to originate from a great number of brain areas, e.g., cerebral cortex, the $\mathrm{SN}$ and the lateral habenular nucleus (LH) (Iversen and Iversen, 2007). Because the DRN is harboring a large subset of neurotransmitters and since it has a complex in and output pattern, the DRN is thought to participate in complex processes such as sensory perception, mood and affect, feeding and mating behavior, reward, sleep, aggression and cerebral blood flow (Mohammad-Zadeh et al., 2008). Because of its central position, it has also been implicated in different neurodegenerative diseases, e.g., Alzheimer disease (AD) (Michelsen et al., 2008) and Parkinson's disease (PD) (Kaya et al., 2008).

The main sources of DA in the mammalian brain, involved in 
behavior, arise from two main groups of mesotelencephalic neurons designated as areas A9 and A10, according to Dahlstrom and Fuxe (1964). The A9 group corresponds to the substantia nigra pars compacta ( $\mathrm{SNc}$ ), whereas the A10 group is located in the ventral tegmental area (VTA). Based on the morphological and neurochemical properties, midbrain dopaminergic neurons are divided into dorsal and ventral portions. Neurons of the dorsal part, consisting of the dorsal parts of the SNc and VTA, are strongly immunoreactive for calbindin and have relatively low levels of TH and DA transporters. The neurons located in the ventral portions, however, do not express calbindin and exert high levels of immunoreactivity for DA transporters (Gerfen et al., 1985; Haber et al., 1995). In rodents and primates it has been shown that, $50-70 \%$ of dopaminergic SNc and VTA neurons express calretinin (Isaacs and Jacobowitz, 1994; Rogers, 1992). In addition, a large proportion of dopaminergic neurons in the SNc and VTA are known to contain cholecystokinin and neurotensin (Crawley, 1991; Kalivas, 1985; Smith and Kieval, 2000). These regions are known to have reciprocal innervations with different brain regions including the neocortex, striatum and diencephalon (Haber and Fudge, 1997; Joel and Weiner, 2000). Beside these, the DRN is also known to contain dopaminergic neurons, which send efferent projections to different brain regions (Steinbusch et al., 1980; Stratford and Wirtshafter, 1990; Trulson et al., 1985).

\section{Neuroplasticity of the Serotonergic and Dopaminergic systems}

Regulation of many forms of neural plasticity is among the various functions of the neurotransmitters 5-HT and DA. The serotonergic system has plastic properties and plays a key role in the CNS homeostasis with the internal organs as well as the environment (Azmitia, 1999). It is well established that serotonergic fibers undergo degeneration and/or regeneration in different CNS areas (Frankfurt et al., 1985; Nobin et al., 1973) under control of serotonergic neurons at distance (Igarashi et al., 1995; Lima et al., 1994). Many studies have demonstrated that 5-HT 
regulates the shape and patterns of neuronal connectivity (Azmitia et al., 1996), synaptogenesis, (Azmitia et al., 1995; Chen et al., 1994; Okado et al., 1993), electrogenesis (Lessmann and Dietzel, 1991) and neurite outgrowth (Lieske et al., 1999), as well as survival of neuronal circuits and synapses in the adult brain (Moriizumi et al., 1994). In addition, there is increasing amount of evidence showing that the serotonergic system strongly controls neurogenesis in the neurogenic areas: the subgranular layer of the dentate gyrus of the hippocampal formations and the subventricular zone (Brezun and Daszuta, 1999; Cheng et al., 2010; Hitoshi et al., 2007; Momma et al., 2000).

When it comes to the plasticity of the dopaminergic system, most of the studies have focused on short term and long term synaptic regulations such as long term potentiation (LTP) and long term depression (LTD). These changes can lead to different neurological abnormalities in motor performance, emotional states, and cognitive functions. However, more permanent forms of plasticity such as sprouting or synaptogenesis have been demonstrated as well (Davis et al., 2007). It has also been shown that the dopaminergic system can regulate the neurogenesis in adult brain (Baker et al., 2004; Hoglinger et al., 2004). In addition, DA regulates as an endogenous factor synaptic strength during the formation and maintenance of reactive plasticity following injury in the adult brain (Davis et al., 2007).

\section{AIM OF THE PRESENT STUDY}

The aim of the studies presented in this thesis was to investigate the neuroplasticity of the serotonergic and dopaminergic systems in experimental and clinical models of pharmacological, genetic and electrical modulations. These investigations were performed using postmortem human brain tissues and genetically manipulated rodents. The aims of experiments are described in the following chapters.

In Chapter 2, we used a pharmacological modulation model and 
studied the intracellular content of 5-HT, DA and related neurotransmitters in the DRN. Chapter 3 aimed to find the consequence of genetic modulation on the serotonergic system in three different transgenic mouse models related to depression and anxiety. In Chapter 4, we continue with genetic modulation and investigate the change in the dopaminergic system within the different regions of the basal ganglia using the transgenic rat model of Huntington's disease. Following this, Chapter 5 tests the hypothesis that an increased number of dopaminergic cells in the basal ganglia is due to the change in the phenotype of non-dopaminergic (serotonergic), again using models of genetic modulation. In Chapter 6, we review the involvement of serotonin in neurogenesis and provide an extensive review on the histology, anatomy, and chemistry of the subependymal serotonergic plexus.

In Chapter 7 we use the electrical modulation model and report a novel method to deliver low electrical current to the motor cortex. Using this method we addressed the main hypothesis that neurogenesis is induced by chronic electrical stimulation of the brain and evaluated the involvement of the serotonergic system.

Finally, in Chapter 8, we provide an overall conclusion of our findings. 


\section{References}

Azmitia, E.C., Rubinstein, V.J., Strafaci, J.A., Rios, J.C., Whitaker-Azmitia, P.M., 1995. 5-HT1A agonist and dexamethasone reversal of para-chloroamphetamine induced loss of MAP-2 and synaptophysin immunoreactivity in adult rat brain. Brain Res. 677, 181-92.

Azmitia, E.C., Gannon, P.J., Kheck, N.M., Whitaker-Azmitia, P.M., 1996. Cellular localization of the 5-HT1A receptor in primate brain neurons and glial cells. Neuropsychopharmacology. 14, 35-46.

Azmitia, E.C., 1999. Serotonin neurons, neuroplasticity, and homeostasis of neural tissue. Neuropsychopharmacology. 21, 33S-45S.

Baker, S.A., Baker, K.A., Hagg, T., 2004. Dopaminergic nigrostriatal projections regulate neural precursor proliferation in the adult mouse subventricular zone. Eur $\mathbf{J}$ Neurosci. 20, 575-9.

Brezun, J.M., Daszuta, A., 1999. Depletion in serotonin decreases neurogenesis in the dentate gyrus and the subventricular zone of adult rats. Neuroscience. 89, 9991002.

Chen, L., Hamaguchi, K., Ogawa, M., Hamada, S., Okada, N., 1994. PCPA reduces both monoaminergic afferents and nonmonoaminergic synapses in the cerebral cortex. Neurosci Res. 19, 111-5.

Cheng, A., Scott, A.L., Ladenheim, B., Chen, K., Ouyang, X., Lathia, J.D., Mughal, M., Cadet, J.L., Mattson, M.P., Shih, J.C., 2010. Monoamine oxidases regulate telencephalic neural progenitors in late embryonic and early postnatal development. J Neurosci. 30, 10752-62.

Crawley, J.N., 1991. Cholecystokinin-dopamine interactions. Trends Pharmacol Sci. 12, 232-6.

Dahlstrom, A., Fuxe, K., 1964. Localization of monoamines in the lower brain stem. Experientia. 20, 398-9.

Davis, E.J., Coyne, C., McNeill, T.H., 2007. Intrastriatal dopamine D1 antagonism dampens neural plasticity in response to motor cortex lesion. Neuroscience. 146, 784-91.

Descarries, L., Watkins, K.C., Garcia, S., Beaudet, A., 1982. The serotonin neurons in nucleus raphe dorsalis of adult rat: a light and electron microscope radioautographic study. J Comp Neurol. 207, 239-54.

Frankfurt, M., Renner, K., Azmitia, E., Luine, V., 1985. Intrahypothalamic 5,7dihydroxytryptamine: temporal analysis of effects on 5-hydroxytryptamine content in brain nuclei and on facilitated lordosis behavior. Brain Res. 340, 127 33.

Gerfen, C.R., Baimbridge, K.G., Miller, J.J., 1985. The neostriatal mosaic: compartmental distribution of calcium-binding protein and parvalbumin in the basal ganglia of the rat and monkey. Proc Natl Acad Sci U S A. 82, 8780-4.

Haber, S.N., Ryoo, H., Cox, C., Lu, W., 1995. Subsets of midbrain dopaminergic neurons in monkeys are distinguished by different levels of mRNA for the dopamine transporter: comparison with the mRNA for the D2 receptor, tyrosine hydroxylase and calbindin immunoreactivity. J Comp Neurol. 362, 400-10. 
Haber, S.N., Fudge, J.L., 1997. The primate substantia nigra and VTA: integrative circuitry and function. Crit Rev Neurobiol. 11, 323-42.

Hitoshi, S., Maruta, N., Higashi, M., Kumar, A., Kato, N., Ikenaka, K., 2007. Antidepressant drugs reverse the loss of adult neural stem cells following chronic stress. J Neurosci Res. 85, 3574-85.

Hoglinger, G.U., Rizk, P., Muriel, M.P., Duyckaerts, C., Oertel, W.H., Caille, I., Hirsch, E.C., 2004. Dopamine depletion impairs precursor cell proliferation in Parkinson disease. Nat Neurosci. 7, 726-35.

Hokfelt, T., Ljungdahl, A., Steinbusch, H., Verhofstad, A., Nilsson, G., Brodin, E., Pernow, B., Goldstein, M., 1978. Immunohistochemical evidence of substance P-like immunoreactivity in some 5-hydroxytryptamine-containing neurons in the rat central nervous system. Neuroscience. 3, 517-38.

Hokfelt, T., Terenius, L., Kuypers, H.G., Dann, O., 1979. Evidence for enkephalin immunoreactive neurons in the medulla oblongata projecting to the spinal cord. Neurosci Lett. 14, 55-60.

Igarashi, M., Li, W.W., Sudo, Y., Fishman, M.C., 1995. Ligand-induced growth cone collapse: amplification and blockade by variant GAP-43 peptides. J Neurosci. 15, 5660-7.

Isaacs, K.R., Jacobowitz, D.M., 1994. Mapping of the colocalization of calretinin and tyrosine hydroxylase in the rat substantia nigra and ventral tegmental area. Exp Brain Res. 99, 34-42.

Iversen, S.D., Iversen, L.L., 2007. Dopamine: 50 years in perspective. Trends Neurosci. 30, 188-93.

Joel, D., Weiner, I., 2000. The connections of the dopaminergic system with the striatum in rats and primates: an analysis with respect to the functional and compartmental organization of the striatum. Neuroscience. 96, 451-74.

Kalivas, P.W., 1985. Interactions between neuropeptides and dopamine neurons in the ventromedial mesencephalon. Neurosci Biobehav Rev. 9, 573-87.

Kaya, A.H., Vlamings, R., Tan, S., Lim, L.W., Magill, P.J., Steinbusch, H.W., VisserVandewalle, V., Sharp, T., Temel, Y., 2008. Increased electrical and metabolic activity in the dorsal raphe nucleus of Parkinsonian rats. Brain Res. 1221, 93-7.

Lessmann, V., Dietzel, I.D., 1991. Development of serotonin-induced ion currents in identified embryonic Retzius cells from the medicinal leech (Hirudo medicinalis). J Neurosci. 11, 800-9.

Lieske, V., Bennett-Clarke, C.A., Rhoades, R.W., 1999. Effects of serotonin on neurite outgrowth from thalamic neurons in vitro. Neuroscience. 90, 967-74.

Lima, L., Matus, P., Urbina, M., 1994. Serotonin inhibits outgrowth of goldfish retina and impairs the trophic effect of taurine. J Neurosci Res. 38, 444-50.

Michelsen, K.A., Prickaerts, J., Steinbusch, H.W., 2008. The dorsal raphe nucleus and serotonin: implications for neuroplasticity linked to major depression and Alzheimer's disease. Prog Brain Res. 172, 233-64.

Mohammad-Zadeh, L.F., Moses, L., Gwaltney-Brant, S.M., 2008. Serotonin: a review. J Vet Pharmacol Ther. 31, 187-99.

Momma, S., Johansson, C.B., Frisen, J., 2000. Get to know your stem cells. Curr Opin Neurobiol. 10, 45-9. 
Moriizumi, T., Tsukatani, T., Sakashita, H., Miwa, T., 1994. Olfactory disturbance induced by deafferentation of serotonergic fibers in the olfactory bulb. Neuroscience. 61, 733-8.

Nanopoulos, D., Belin, M.F., Maitre, M., Vincendon, G., Pujol, J.F., 1982. Immunocytochemical evidence for the existence of GABAergic neurons in the nucleus raphe dorsalis. Possible existence of neurons containing serotonin and GABA. Brain Res. 232, 375-89.

Nobin, A., Baumgarten, H.G., Bjorklund, A., Lachenmayer, L., Stenevi, U., 1973. Axonal degeneration and regeneration of bulbo-spinal indolamine neurons after 5,6-dihydroxytryptamine treatment. Brain Res. 56, 1-24.

Okado, N., Cheng, L., Tanatsugu, Y., Hamada, S., Hamaguchi, K., 1993. Synaptic loss following removal of serotoninergic fibers in newly hatched and adult chickens. J Neurobiol. 24, 687-98.

Rogers, J.H., 1992. Immunohistochemical markers in rat brain: colocalization of calretinin and calbindin-D28k with tyrosine hydroxylase. Brain Res. 587, 20310.

Smith, Y., Kieval, J.Z., 2000. Anatomy of the dopamine system in the basal ganglia. Trends Neurosci. 23, S28-33.

Steinbusch, H.W., van der Kooy, D., Verhofstad, A.A., Pellegrino, A., 1980. Serotonergic and non-serotonergic projections from the nucleus raphe dorsalis to the caudate-putamen complex in the rat, studied by a combined immunofluorescence and fluorescent retrograde axonal labeling technique. Neurosci Lett. 19, 137-42.

Steinbusch, H.W.M., Nieuwenhuys, R., 1982. Localization of serotonin-like immunoreactivity in the central nervous system and pituitary of the rat, with special references to the innervation of the hypothalamus. In: Serotonin: Current Aspects of Neurochemistry and Function. Vol., B. Haber, S. Gabay, ed.^eds. Plenum Press, New York, pp. 7-35.

Stratford, T.R., Wirtshafter, D., 1990. Ascending dopaminergic projections from the dorsal raphe nucleus in the rat. Brain Res. 511, 173-6.

Strazielle, C., Lalonde, R., Riopel, L., Botez, M.I., Reader, T.A., 1996. Regional distribution of the 5-HT innervation in the brain of normal and lurcher mice as revealed by [H-3]citalopram quantitative autoradiography. J Chem Neuroanat. 10, 157-171.

Trulson, M.E., Cannon, M.S., Raese, J.D., 1985. Identification of dopamine-containing cell bodies in the dorsal and median raphe nuclei of the rat brain using tyrosine hydroxylase immunochemistry. Brain Res Bull. 15, 229-34.

Vertes, R.P., 1991. A PHA-L analysis of ascending projections of the dorsal raphe nucleus in the rat. J Comp Neurol. 313, 643-68.

Vertes, R.P., Kocsis, B., 1994. Projections of the dorsal raphe nucleus to the brainstem: PHA-L analysis in the rat. J Comp Neurol. 340, 11-26.

Yoshida, M., Shirouzu, M., Tanaka, M., Semba, K., Fibiger, H.C., 1989. Dopaminergic neurons in the nucleus raphe dorsalis innervate the prefrontal cortex in the rat: a combined retrograde tracing and immunohistochemical study using antidopamine serum. Brain Res. 496, 373-6. 




\title{
CHHAPP'TIER 2
}

\section{Buspirone-induced changes in the serotonergic and non- serotonergic cells in the dorsal raphe nucleus of rats}

Jahanshahi A, Lim LW, Steinbusch HW, Visser-Vandewalle V and Temel Y

\begin{abstract}
Buspirone, a 5-HT (5-hydroxytryptamine, serotonin) 1A partial agonist, is being used as an anxiolytic drug. The mechanism of action is explained by an effect on the 5-HT system. The main source of 5-HT in the forebrain is the dorsal raphe nucleus (DRN). However, there are also other populations of non-5-HT neurons in the DRN. Here, we investigated the effect of acute and chronic buspirone treatments on the 5-HT and non5-HT cells, the neuronal nitric oxide synthase (nNOS) and tyrosine hydroxylase $(\mathrm{TH})$ cells, in the DRN. Rats received either an acute or chronic administration of buspirone or saline. Hereafter, the brains were processed for 5-HT, nNOS, and TH immunohistochemistry. We found that acute and chronic buspirone treatments significantly lowered the mean optical density of nNOS in the DRN as compared to controls. Meanwhile only the chronic buspirone treatment reduced the mean density of 5-HT and $\mathrm{TH}$ immunoreactivity but not the acute buspirone as compared to saline treated animals. Our findings suggest that buspirone treatment affects not only the intracellular content of 5-HT but also nNOS and TH. Therefore, the cellular effect of buspirone is more complex than thought.
\end{abstract}





\section{Introduction}

Buspirone, a 5-HT (5-hydroxytryptamine, serotonin) 1A partial agonist, is used to treat generalized anxiety disorder clinically (Goodman, 2004; Kane et al., 2002) and has profound effects on anxiety-related behavior in animal models (Lim et al., 2008b; Liu et al., 2007). At the cellular level, buspirone produces a dose-dependent reduction in the firing rate of 5-hydroxytryptamine (5-HT; serotonin) neurons in the dorsal raphe nucleus (DRN). The DRN is the major source of 5-HT in the forebrain (Stark et al., 2007). This inhibition is most probably mediated by the presynaptic (somatodendritic) 5-HT1A autoreceptors, similarly to the effect of selective serotonin reuptake inhibitors (Blier and Ward, 2003). It has been shown that systemic administration of 5-HT1A receptor agonist decreases the DRN 5-HT concentrations (Matos et al., 1996), and also a reduction in the number of c-fos immunoreactive cells in the DRN (Rioja et al., 2006). The therapeutic effect of buspirone is therefore, at least partially, mediated by modulating the 5-HT system.

5-HT1A receptors are also present on dopaminergic cells, which are present in the DRN, and activation of them can inhibit dopamine (DA) synthesis (Johnson et al., 1993; Johnson et al., 1996). Nitric oxide (NO) containing cells are present in the DRN. NO synthase (NOS) has also been implicated in anxiety-like behavior (Faria et al., 1997; Garthwaite et al., 1989; Garthwaite and Boulton, 1995). Interestingly, neuronal NOS (nNOS) is colocalized with 5-HT in some DRN neurons. Here, we have evaluated the effects of acute and chronic buspirone treatments on 5-HT containing, tyrosine hydroxylase containing, and nNOS containing cells in the DRN of rats with acute and chronic buspirone treatment.

\section{Experimental procedures}

Twenty-four male albino Wistar rats (Harlan, Horst, The Netherlands) weighing approximately 350-400g were used in this study. They were housed individually in standard transparent polypropylene 
cages on sawdust bedding in an air-ventilated room under a 12/12-h reversed light/dark cycle with the room temperature at $20-22{ }^{\circ} \mathrm{C}$ and a humidity of $60-70 \%$. Food, standard laboratory chow (Hopefarms, Woerden, the Netherlands), and water were available ad libitum. All animals were handled daily to habituate them. The experimental protocol was approved by the Animal Experiments and Ethics Committee of Maastricht University.

Animals were divided randomly into the following four experimental groups: acute saline treatment $(A S, n=5)$, acute buspirone treatment $(A B$, $\mathrm{n}=5$ ), chronic saline treatment $(\mathrm{CS}, \mathrm{n}=5)$, and chronic buspirone treatment $(\mathrm{CB}, \mathrm{n}=5)$. Rats with acute treatment received only one injection, whereas the rats in the chronic treatment group were injected continuously for twenty one days with either saline or buspirone hydrochloride, respectively.

Buspirone hydrochloride (TOCRIS Cookson Inc., Missouri, USA) was dissolved in saline solution and injected subcutaneously. A dose of 3 $\mathrm{mg} / \mathrm{kg}$ was used based on previous experiences (Hashimoto et al., 1992; Lim et al., 2008a; Lim et al., 2008b). One week before the actual experimental injection, all animals received $1 \mathrm{ml}$ saline injection on alternating days to habituate the animals to the injection procedure. Chronic treatment with saline and buspirone consisted of 21 daily routine injections. The acute treatment with saline or buspirone (one time injection) was performed at day 21 .

At the end of the experiments, animals were deeply anesthetized with Nembutal $(75 \mathrm{mg} / \mathrm{kg})$ and perfused transcardially with Tyrode $(0.1$ M) followed by fixative containing paraformaldehyde, picric acid and glutaraldehyde in phosphate buffer ( $\mathrm{pH}$ 7.6). Brains were removed, postfixed and cryoprotected with sucrose treatment. Brain tissue was then quickly frozen with $\mathrm{CO} 2$ and stored at $-80^{\circ} \mathrm{C}$. Subsequently, the brains were cut serially on a cryostat into $30 \mu \mathrm{m}$ frontal sections and again stored at $-80{ }^{\circ} \mathrm{C}$. One series was taken for 5 -HT immunohistochemistry which 
was carried out by using an anti-5-HT rabbit antibody (1:50000, kindly provided by Dr. HWM Steinbusch, Maastricht University, The Netherlands), diluted in $0.1 \%$ Bovine Serum Albumin (BSA) and Tris Buffered Solution (TBS)-Triton (TBS-T) solution. After three-night incubation, sections were incubated with the secondary antibody (donkey anti-rabbit biotine, Jackson Immunoresearch Laboratories Inc., Westgrove, USA) for $90 \mathrm{~min}$. Meanwhile, another two series were also taken for nNOS (1:10000, rabbit anti-neuronal NOS, Sigma), and TH (1:100, mouse anti-TH antibody, kindly supplied by Dr. C. Cuello, Canada) immunohistochemistry. Both primary antibodies (nNOS and $\mathrm{TH}$ ) were diluted in $0.1 \%$ Bovine Serum Albumin (BSA) and TBS-T solution, respectively. After an overnight incubation, sections were incubated with the secondary antibodies (donkey anti-rabbit biotine for nNOS sections, 1:400, Jackson Immunoresearch Laboratories Inc., Westgrove, USA; and donkey anti-mouse for $\mathrm{TH}$ sections, 1:400, Jackson Immunoresearch Laboratories Inc., Westgrove, USA). Subsequently, all 5-HT, TH, nNOS sections were incubated with an avidin-biotin-peroxidase complex (Elite ABC-kit, Vectastatin; Burlingame, USA) for $2 \mathrm{~h}$, respectively. To visualize the immune complex of horseradish peroxide reaction product, sections were incubated with 3,3'-diaminobenzidine tetrahydrochloride/ nickel chloride solution. This reaction was stopped after $10 \mathrm{~min}$ by rinsing thoroughly all sections with TBS. All sections were then mounted, dehydrated, and coverslipped with Pertex (Histolab Products ab, Goteborg, Sweden).

\section{Results}

By qualitative examination, we observed marked differences in the optical density (OD = mean Gray value) of the 5-HT, TH and nNOS cells in the DRN of $\mathrm{CB}$ treated animals as compared to other groups. We measured the optical densities quantitatively. For this, the mean Gray values of respectively $205-\mathrm{HT}$, TH, and nNOS immunoreactive neurons in the DRN of each animal, were assessed at $40 \mathrm{X}$ magnification using an Olympus AX70 bright field microscope (analySIS; Imaging System, 
Münster, Germany) connected to a digital camera (F-view; Olympus, Tokyo, Japan),. These neurons were selected from the same area in all animals (median part of the DRN). Each cell was analyzed using the Image J software (NIH, http://rsbweb.nih.gov/ij/) and the light intensity and threshold conditions were similar for all sections. The density of pixels ranged from 0 (black) to 255 (white) for an 8-bit digital signal.

All data are presented as means \pm S.E.M and were analyzed using a two-way Analysis of Variance (ANOVA) using Treatment (saline vs. buspirone) and Duration of Treatment (acute and chronic) as betweensubjects factors. All statistical analyses were performed with SPSS 16.0 version for Windows. Fisher's Least Significant Difference (LSD) post hoc test was used to analyze group differences in more detail. P-values lower than 0.05 were considered significant.

We found that acute and chronic buspirone treatment significantly lowered the OD of nNOS $(\mathrm{P}<0.001)$ in the DRN as compared to the saline groups. Only chronic buspirone treatment reduced the OD of 5-HT $(\mathrm{P}<0.001)$ and $\mathrm{TH}(\mathrm{P}<0.01)$ cells when compared to the other groups.
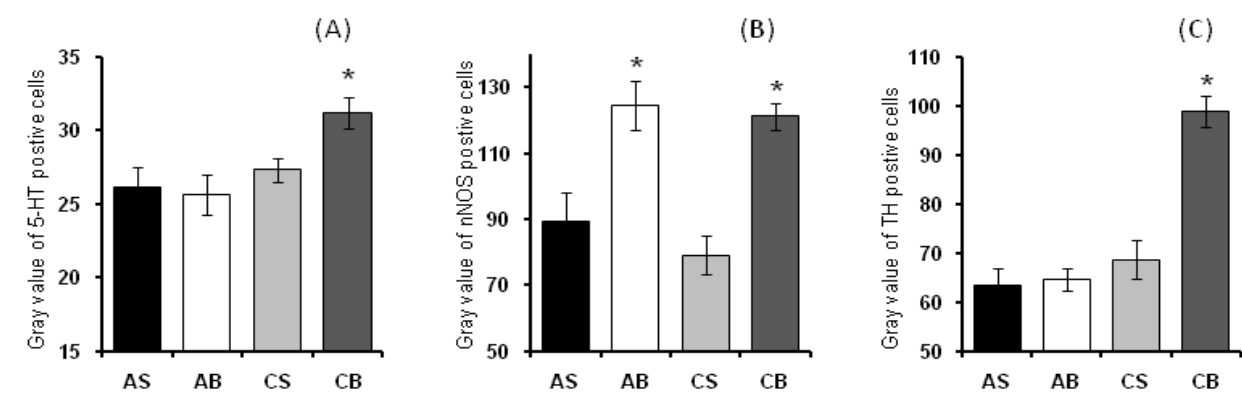

Figure1. The graphs represent means \pm S.E.M. of animals treated with either saline or buspirone, acutely or chronically, respectively. (A) Mean gray value of 5-HT positive cells. (B) Mean gray value of nNOS positive cells. (C) Mean gray value of TH positive cells. * Indicates significant difference compared with saline treated animals. 


\section{Discussion}

Here, we have shown that $\mathrm{CB}$ treatment reduced the immunoreactivity level of 5-HT and TH in DRN cells, indicative of low 5HT and TH concentrations in the cells. Interestingly, the clinical anxiolytic effect of buspirone takes also place after 2 to 3 weeks (Goldberg and Finnerty, 1979; Rickels et al., 1982; Sramek et al., 2002). AB treatment had no effect on the OD of DRN 5-HT and TH containing cells. However, the OD of nNOS containing cells was decreased by both acute and chronic buspirone treatments.

The effectiveness of $\mathrm{CB}$ treatment was also found in other experimental studies. CB administration (3 weeks) decreased the 5-HT1A receptor binding by approximately $25 \%-30 \%$ in the DRN (Sim-Selley et al., 2000). In addition, CB treatment decreased the 5-HT1A receptor immunoreactivity and 5-HT levels in the DRN (Khan and Haleem, 2006), as well as modulated 5-HT1A receptors in forebrain structures (Bosker et al., 1997; Ceci et al., 1994). Nevertheless, it is now becoming wellestablished that the anxiolytic effect of $\mathrm{CB}$ administration depends on the DRN where the (somatodendritic) presynaptic 5-HT1A autoreceptors are located. Interestingly, a recent study by Nishi et al. (2009) using the animal model of "Flinders Sensitive Line", demonstrated that CB treatment reduced 5-HT synthesis particularly in the DRN (Nishi et al., 2009). Besides, electrophysiological studies showed that desensitization of 5-HT1A autoreceptors in the DRN was also induced by chronic administration with analogues of buspirone, gepirone, and ipsapirone (Schechter et al., 1990). In view of these findings, CB treatment could eventually desensitize 5-HT1A autoreceptors by inhibiting 5-HT cell firing. However, on the basis of the current study, CB treatment probably enhances the bioavailability of 5-HT levels in the extracellular space by depleting the 5-HT content intracellularly.

The present study demonstrated the decrease of OD of $\mathrm{TH}$ containing cells after chronic buspirone treatment, indicating a direct interaction of buspirone with DRN dopaminergic cells (Konig et al., 
1988). Peroutka has shown in a radioligand binding study that buspirone displays a high affinity for 5-HT1A, D2 receptors, and moderate affinity for histamine, alpha-adrenergic2, and 5-HT2 receptors (Peroutka, 1985). It was previously reported that systemic administration of 5-HT1A receptor agonist 8-OH-DPAT increased acetylcholine release in the frontal cortex, and this effect of 8-OH-DPAT was then inhibited by the 5-HT1A antagonist WAY 100635 (Consolo et al., 1996; Somboonthum et al., 1997). It is important to note that chronic treatment (14, 21 days) with citalopram, a selective serotonin reuptake inhibitor (SSRI) decreased the firing activity of noradrenergic (NA) neurons in locus coeruleus (LC) but not with the short-term treatment (Szabo et al., 2000). A wealth of evidence also showed that the NA neurons modulate the 5-HT system in the DRN that receive its projection from the LC (Baraban and Aghajanian, 1980b; Clement et al., 1992). On the other hand, chronic systemic administration of mirtazapine, an $\alpha 2$-adrenergic antagonist increased the 5-HT and NA neurons firing activity, indicating that this compound affects both the NA and 5-HT systems (Haddjeri et al., 1997). Other studies also demonstrated that SSRIs putatively involve in the NA system (Szabo et al., 1999; Szabo et al., 2000), that NA receptor antagonists directly influence the activity of DRN 5-HT neurons (Baraban and Aghajanian, 1980a; Baraban and Aghajanian, 1980b; Costain and Green, 1978). Taken together, the latter studies have clearly shown that these two systems, 5HT and NA or dopamine, are remarkably interconnected in the pathophysiology of mood disorders; and it is of ultimate importance to understand the other neurotransmitter systems that act within this underlying mechanism. Several studies have reported the colocalisation of nNOS with 5-HT and TH containing cells in the DRN and other mesencephalic structures (Johnson and Ma, 1993; Kauffman et al., 1974; Panzica et al., 1996). It has been shown that approximately $70 \%$ of 5-HT neurons contain nNOS (Wotherspoon et al., 1994; Xu and Hokfelt, 1997), which allows NO to act as an intracellular messenger (Garthwaite, 1991; Vincent and Kimura, 1992). nNOS in DRN has been implicated in the regulation of sleep (Monti et al., 1999), conditioned fear (Grahn, 2000) 

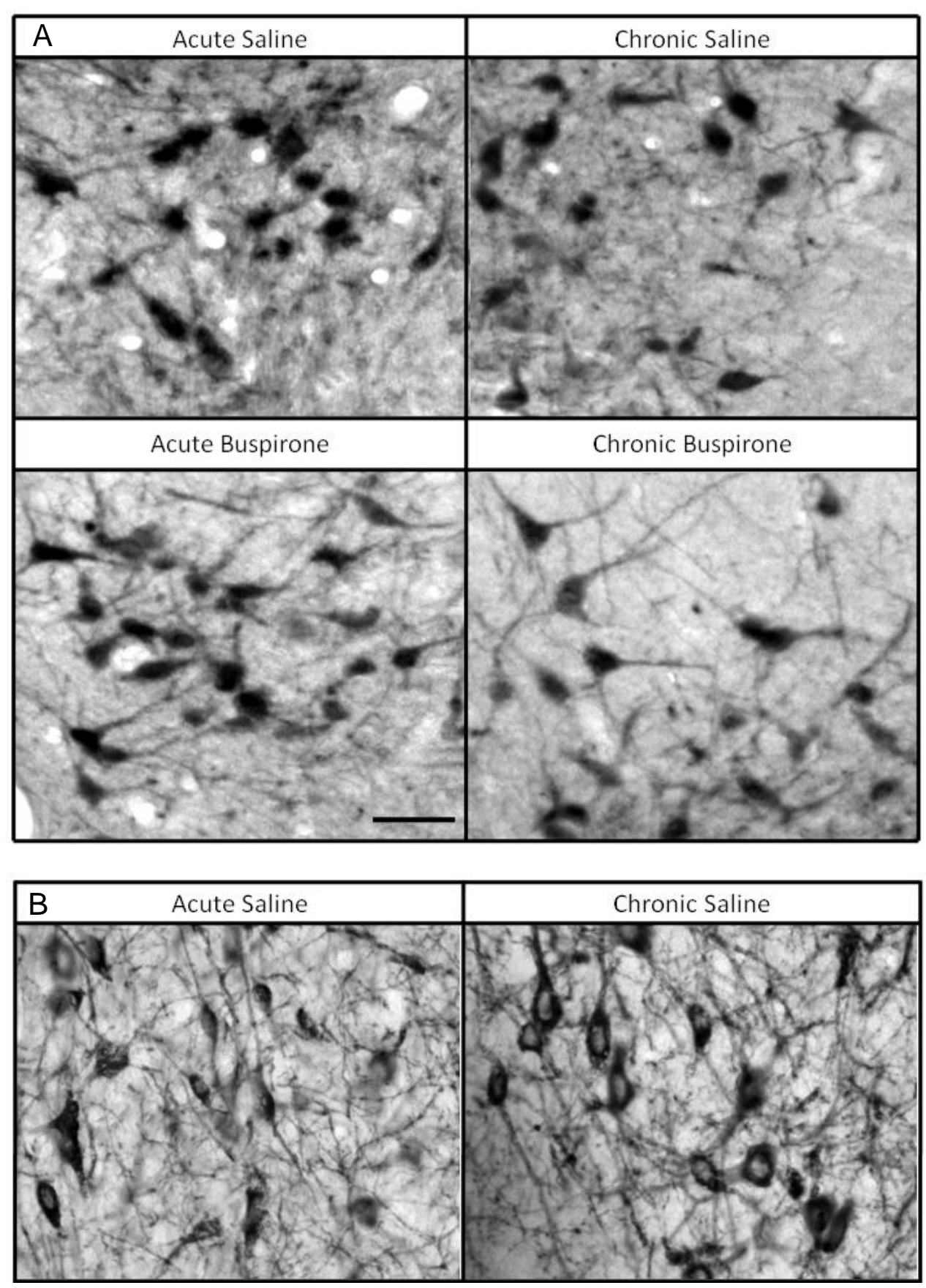

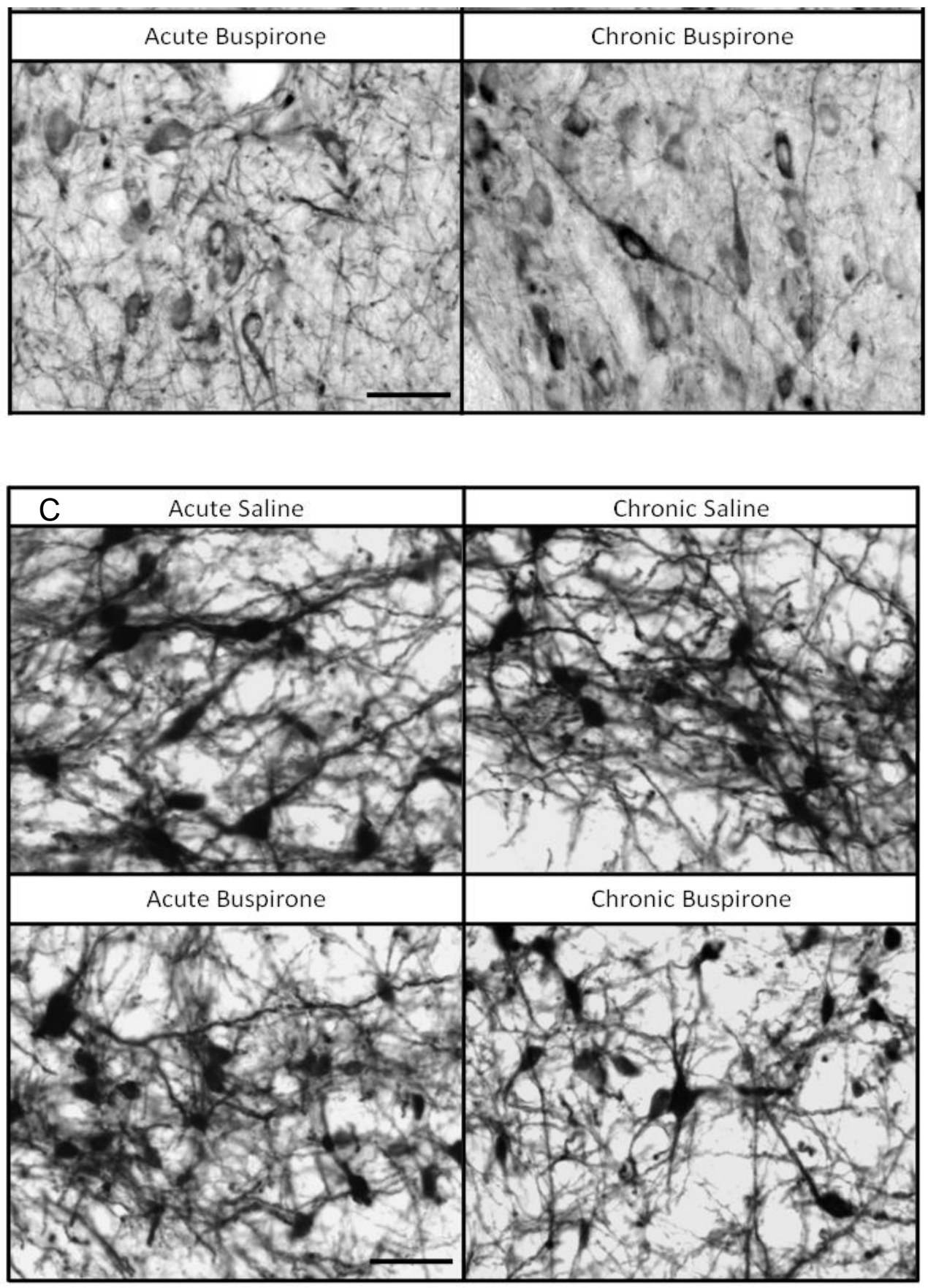
Figure 2. The figures represent high-power photomicrographs (40X) of a $30 \mu \mathrm{m}$-think section from the DRN of animals treated with either acute or chronic saline/buspirone, respectively. Fig. 2 (A): 5-HT containing cells. Fig. 2 (B): nNOS containing cells. Fig. 2 (C): TH containing cells. Note that effect of $\mathrm{AB}$ and $\mathrm{CB}$ treatment induced a remarkable reduction of optical density of nNOS containing cells; while only $\mathrm{CB}$ treatment decreased the optical density of 5-HT and TH containing cells. Optical density indication: the brightness of pixels ranged from 0 (black) to 255 (white) for an 8-bit digital signal. Scale bar: $50 \mu \mathrm{m}$.

(Grahn et al., 2000), and mood and anxiety disorders (Guimaraes et al., 2005; Spiacci et al., 2008). Interestingly, our findings of acute and chronic effects of nNOS, is in line with precious findings that this enzyme responsible for NO production is active in serotonergic cells during any moment of physiological response to the stimuli.

In conclusion, we have shown that buspirone has an effect on different neurotransmitter systems in the DRN.

\section{Acknowledgment}

This research was supported by a grant from the FP6 Marie Curie Fellowship (MEST-CT-2005-020589) and by a grant from The Netherlands Organization for Scientific Research (NWO-Veni No: 016.096.032). 


\section{References}

Baraban, J.M., Aghajanian, G.K., 1980a. Suppression of serotonergic neuronal firing by alpha-adrenoceptor antagonists: evidence against GABA mediation. Eur J Pharmacol. 66, 287-94.

Baraban, J.M., Aghajanian, G.K., 1980b. Suppression of firing activity of 5-HT neurons in the dorsal raphe by alpha-adrenoceptor antagonists. Neuropharmacology. 19, 355-63.

Blier, P., Ward, N.M., 2003. Is there a role for 5-HT1A agonists in the treatment of depression? Biol Psychiatry. 53, 193-203.

Bosker, F.J., Klompmakers, A., Westenberg, H.G., 1997. Postsynaptic 5-HT1A receptors mediate 5-hydroxytryptamine release in the amygdala through a feedback to the caudal linear raphe. Eur J Pharmacol. 333, 147-57.

Ceci, A., Baschirotto, A., Borsini, F., 1994. The inhibitory effect of 8-OH-DPAT on the firing activity of dorsal raphe serotoninergic neurons in rats is attenuated by lesion of the frontal cortex. Neuropharmacology. 33, 709-13.

Clement, H.W., Gemsa, D., Wesemann, W., 1992. Serotonin-norepinephrine interactions: a voltammetric study on the effect of serotonin receptor stimulation followed in the N. raphe dorsalis and the Locus coeruleus of the rat. J Neural Transm Gen Sect. 88, 11-23.

Consolo, S., Ramponi, S., Ladinsky, H., Baldi, G., 1996. A critical role for D1 receptors in the 5-HT1A-mediated facilitation of in vivo acetylcholine release in rat frontal cortex. Brain Res. 707, 320-3.

Costain, D.W., Green, A.R., 1978. beta-Adrenoceptor antagonists inhibit the behavioural responses of rats to increased brain 5-hydroxytryptamine. Br J Pharmacol. 64, 193-200.

Faria, M.S., Muscara, M.N., Moreno Junior, H., Teixeira, S.A., Dias, H.B., De Oliveira, B., Graeff, F.G., De Nucci, G., 1997. Acute inhibition of nitric oxide synthesis induces anxiolysis in the plus maze test. Eur J Pharmacol. 323, 37-43.

Garthwaite, J., Garthwaite, G., Palmer, R.M., Moncada, S., 1989. NMDA receptor activation induces nitric oxide synthesis from arginine in rat brain slices. Eur $\mathbf{J}$ Pharmacol. 172, 413-6.

Garthwaite, J., 1991. Glutamate, nitric oxide and cell-cell signalling in the nervous system. Trends Neurosci. 14, 60-7.

Garthwaite, J., Boulton, C.L., 1995. Nitric oxide signaling in the central nervous system. Annu Rev Physiol. 57, 683-706.

Goldberg, H.L., Finnerty, R.J., 1979. The comparative efficacy of buspirone and diazepam in the treatment of anxiety. Am J Psychiatry. 136, 1184-7.

Goodman, W.K., 2004. Selecting pharmacotherapy for generalized anxiety disorder. J Clin Psychiatry. 65 Suppl 13, 8-13.

Grahn, R.E., Watkins, L.R., Maier, S.F., 2000. Impaired escape performance and enhanced conditioned fear in rats following exposure to an uncontrollable stressor are mediated by glutamate and nitric oxide in the dorsal raphe nucleus. Behav Brain Res. 112, 33-41. 
Guimaraes, F.S., Beijamini, V., Moreira, F.A., Aguiar, D.C., de Lucca, A.C., 2005. Role of nitric oxide in brain regions related to defensive reactions. Neurosci Biobehav Rev. 29, 1313-22.

Haddjeri, N., Blier, P., de Montigny, C., 1997. Effects of long-term treatment with the alpha 2-adrenoceptor antagonist mirtazapine on 5-HT neurotransmission. Naunyn Schmiedebergs Arch Pharmacol. 355, 20-9.

Hashimoto, T., Hamada, C., Wada, T., Fukuda, N., 1992. Comparative study on the behavioral and EEG changes induced by diazepam, buspirone and a novel anxioselective anxiolytic, DN-2327, in the cat. Neuropsychobiology. 26, 89-99.

Johnson, E.A., Tsai, C.E., Shahan, Y.H., Azzaro, A.J., 1993. Serotonin 5-HT1A receptors mediate inhibition of tyrosine hydroxylation in rat striatum. J Pharmacol Exp Ther. 266, 133-41.

Johnson, E.A., Fox, J.L., Azzaro, A.J., 1996. The anxiolytic serotonin 5-HT1A receptor agonists buspirone, ipsapirone and gepirone are inhibitors of tyrosine hydroxylation in rat striatum. Behav Brain Res. 73, 331-5.

Johnson, M.D., Ma, P.M., 1993. Localization of NADPH diaphorase activity in monoaminergic neurons of the rat brain. J Comp Neurol. 332, 391-406.

Kane, J.M., Carson, W.H., Saha, A.R., McQuade, R.D., Ingenito, G.G., Zimbroff, D.L., Ali, M.W., 2002. Efficacy and safety of aripiprazole and haloperidol versus placebo in patients with schizophrenia and schizoaffective disorder. J Clin Psychiatry. 63, 763-71.

Kauffman, F.C., Pickel, V.M., Sims, K.L., Bloom, F.E., 1974. Localization of nicotinamide adenine dinucleotide phosphate-dependent dehydrogenases in catecholamine-containing neurons of rat brain. Studies on the nucleus locus ceruleus. J Histochem Cytochem. 22, 20-8.

Khan, A., Haleem, D.J., 2006. 5-HT-1A receptor responsiveness following subchronic administration of buspirone. Pak J Pharm Sci. 19, 333-7.

Konig, N., Wilkie, M.B., Lauder, J.M., 1988. Tyrosine hydroxylase and serotonin containing cells in embryonic rat rhombencephalon: a whole-mount immunocytochemical study. J Neurosci Res. 20, 212-23.

Lim, L.W., Temel, Y., Sesia, T., Vlamings, R., Visser-Vandewalle, V., Steinbusch, H.W., Blokland, A., 2008a. Buspirone induced acute and chronic changes of neural activation in the periaqueductal gray of rats. Neuroscience. 155, 164-173.

Lim, L.W., Temel, Y., Visser-Vandewalle, V., Steinbusch, H., Schruers, K., Hameleers, R., Esquivel, G., Griez, E., Blokland, A., 2008b. Effect of buspirone on the behavioral regulation of rats in low versus high anxiety conditions. Arzneimittelforschung. 58, 269-76.

Liu, G.X., Cai, G.Q., Cai, Y.Q., Sheng, Z.J., Jiang, J., Mei, Z., Wang, Z.G., Guo, L., Fei, J., 2007. Reduced anxiety and depression-like behaviors in mice lacking GABA transporter subtype 1. Neuropsychopharmacology. 32, 1531-9.

Matos, F.F., Urban, C., Yocca, F.D., 1996. Serotonin (5-HT) release in the dorsal raphe and ventral hippocampus: raphe control of somatodendritic and terminal 5-HT release. J Neural Transm. 103, 173-90.

Monti, J.M., Hantos, H., Ponzoni, A., Monti, D., Banchero, P., 1999. Role of nitric oxide in sleep regulation: effects of L-NAME, an inhibitor of nitric oxide synthase, on sleep in rats. Behav Brain Res. 100, 197-205. 
Nishi, K., Kanemaru, K., Hasegawa, S., Watanabe, A., Diksic, M., 2009. Both acute and chronic buspirone treatments have different effects on regional 5-HT synthesis in Flinders Sensitive Line rats (a rat model of depression) than in control rats. Neurochem Int. 54, 205-14.

Panzica, G.C., Garzino, A., Garcia Ojeda, E., 1996. Coexistence of NADPH-diaphorase and tyrosine hydroxylase in the mesencephalic catecholaminergic system of the Japanese quail. J Chem Neuroanat. 11, 37-47.

Peroutka, S.J., 1985. Selective interaction of novel anxiolytics with 5hydroxytryptamine1A receptors. Biol Psychiatry. 20, 971-9.

Rickels, K., Weisman, K., Norstad, N., Singer, M., Stoltz, D., Brown, A., Danton, J., 1982. Buspirone and diazepam in anxiety: a controlled study. J Clin Psychiatry. 43, 81-6.

Rioja, J., Santin, L.J., Dona, A., de Pablos, L., Minano, F.J., Gonzalez-Baron, S., Aguirre, J.A., 2006. 5-HT1A receptor activation counteracts c-Fos immunoreactivity induced in serotonin neurons of the raphe nuclei after immobilization stress in the male rat. Neurosci Lett. 397, 190-5.

Schechter, L.E., Bolanos, F.J., Gozlan, H., Lanfumey, L., Haj-Dahmane, S., Laporte, A.M., Fattaccini, C.M., Hamon, M., 1990. Alterations of central serotoninergic and dopaminergic neurotransmission in rats chronically treated with ipsapirone: biochemical and electrophysiological studies. J Pharmacol Exp Ther. 255, 133547.

Sim-Selley, L.J., Vogt, L.J., Xiao, R., Childers, S.R., Selley, D.E., 2000. Region-specific changes in 5-HT(1A) receptor-activated G-proteins in rat brain following chronic buspirone. Eur J Pharmacol. 389, 147-53.

Somboonthum, P., Matsuda, T., Asano, S., Sakaue, M., Baba, A., 1997. MKC-242, a novel 5-HT1A receptor agonist, facilitates cortical acetylcholine release by a mechanism different from that of 8-OH-DPAT in awake rats. Neuropharmacology. 36, 1733-9.

Spiacci, A., Jr., Kanamaru, F., Guimaraes, F.S., Oliveira, R.M., 2008. Nitric oxidemediated anxiolytic-like and antidepressant-like effects in animal models of anxiety and depression. Pharmacol Biochem Behav. 88, 247-55.

Sramek, J.J., Zarotsky, V., Cutler, N.R., 2002. Generalised anxiety disorder: treatment options. Drugs. 62, 1635-48.

Stark, A.D., Jordan, S., Allers, K.A., Bertekap, R.L., Chen, R., Mistry Kannan, T., Molski, T.F., Yocca, F.D., Sharp, T., Kikuchi, T., Burris, K.D., 2007. Interaction of the novel antipsychotic aripiprazole with 5-HT1A and 5-HT 2A receptors: functional receptor-binding and in vivo electrophysiological studies. Psychopharmacology (Berl). 190, 373-82.

Szabo, S.T., de Montigny, C., Blier, P., 1999. Modulation of noradrenergic neuronal firing by selective serotonin reuptake blockers. Br J Pharmacol. 126, 568-71.

Szabo, S.T., de Montigny, C., Blier, P., 2000. Progressive attenuation of the firing activity of locus coeruleus noradrenergic neurons by sustained administration of selective serotonin reuptake inhibitors. Int J Neuropsychopharmacol. 3, 1-11.

Vincent, S.R., Kimura, H., 1992. Histochemical mapping of nitric oxide synthase in the rat brain. Neuroscience. $46,755-84$. 
CHAPTER 2

Wotherspoon, G., Albert, M., Rattray, M., Priestley, J.V., 1994. Serotonin and NADPHdiaphorase in the dorsal raphe nucleus of the adult rat. Neurosci Lett. 173, 31-6.

$\mathrm{Xu}$, Z.Q., Hokfelt, T., 1997. Expression of galanin and nitric oxide synthase in subpopulations of serotonin neurons of the rat dorsal raphe nucleus. J Chem Neuroanat. 13, 169-87. 



\title{
CHHAPP'TIEIR 3,
}

\section{Altered expression of neuronal tryptophan hydroxylase-2 mRNA in the dorsal and median raphe nuclei of three genetically modified mouse models relevant to depression and anxiety}

\begin{abstract}
Jahanshahi A, Le Maitre E, Temel Y, Lanfumey L, Hamonf M, Lesch P, Tordera RM,
\end{abstract} Del Río J, Aso E, Maldonado R, Hökfelt T and Steinbusch HW

\begin{abstract}
Depression and anxiety are among the leading causes of societal burden. Abnormalities in 5-hydroxytryptamine (5-HT; serotonin) neurotransmission are known to be associated with depressive and anxiety symptoms. The rostral projections of brainstem dorsal (DRN) and median $(\mathrm{MRN})$ raphe nuclei are the main sources of forebrain 5-HT. The expression, turnover and distribution of tryptophan hydroxylase 2 (TPH2), the rate-limiting enzyme in 5-HT biosynthesis in the DRN and MRN are complex, in keeping with the existence of different subpopulations of 5HT neurons in this area. In the present study, we measured the expression of TPH2 mRNA in the DRN and MRN using in situ hybridization in three genetically modified mouse models, all relevant to depression and anxiety, and matched wild-type controls. Our results show quantitative modifications in TPH 2 mRNA expression in the three main subregions of the DRN as well as the MRN in relation to changes in serotonergic, glutamatergic and endocannabinoid neurotransmission systems. Thus, there were significant decreases in TPH2 transcript levels in 5-HT transporter (5-HTT) -/- mutant mice, whereas increases were observed in
\end{abstract}


the vesicular glutamate transporter 1 hemi knock out (VGLUT1+/-) and cannabinoid receptor 1 mutant (CB1R-/-)mice.

Based on these findings, we suggest that TPH2 mRNA expression is under the influence of multiple messenger systems in relation to presynaptic and/or postsynaptic feedback control of 5-HT synthesis that, 5-HTT, VGLUT1 and CB1R seem to be involved in these feedback mechanisms. Finally, our data are in line with previous reports suggesting that $\mathrm{TPH} 2$ activity within different raphe subregions is differentially regulated under specific conditions.

Journal of Chemical Neuroanatomy, 2011 


\section{Introduction}

Depression is a leading cause of disability worldwide and a serious health problem (Greenberg et al., 2003), but the exact mechanisms underlying its pathophysiology are still not well understood. One line of evidence suggests that abnormalities in 5-hydroxytryptamine (5-HT; serotonin) neurotransmission are associated with depressive and anxiety symptoms (Cowen, 2008).

The brainstem dorsal (DRN) and median (MRN) raphe nuclei, cell groups B7 and B8, respectively, according to Dahlström and Fuxe (1964), are the main source of forebrain serotonergic innervation and subsequently 5-HT release (Steinbusch, 1981, 1984; Steinbusch and Nieuwenhuys, 1983; Michelsen et al., 2007, 2008). The DRN and MRN project heavily to several forebrain areas that modulate emotional and cognitive processes (Kosofsky and Molliver, 1987). The DRN can be subdivided anatomically into ventromedial (DRV) and dorsomedial (DRD) subregions over much of its length, and dorsolateral wings (DRL) in the mid-regions (Steinbusch et al., 1981a). Each of these subregions has been shown to project to specific parts of the cerebral cortex and subcortical regions, and consequently, may differentially regulate 5-HT neurotransmission (O'Hearn and Molliver, 1984; Steinbusch and De Vente, 1997). Moreover, these brainstem nuclei receive descending projections from forebrain regions such as prefrontal cortex (Hajos et al., 1998; Peyron et al., 1998; Celada et al., 2001).

Tryptophan hydroxylase (TPH) is the rate-limiting enzyme in 5-HT biosynthesis. The discovery of a neuronal isoform, TPH2, by Walther and Bader (2003) opened up a new way to reliably map brain 5-HT neurons with immunohistochemistry and in situ hybridization. Results confirm a wide expression, including cell bodies in DRN and MRN (Zhang et al., 2004; Clark et al., 2008). In fact, it is now established that TPH2 is the predominant isoform in the rodent brain (Gutknecht et al., 2008, Gutknecht et al., 2009). However, early studies have previously reported 
that TPH expression, turnover and distribution in DRN are complex, in line with the existence of different subpopulations of 5-HT neurons in this area (Weissmann et al., 1990).

Changes in TPH2 gene and/or protein expression in the brain have been reported in various mood disorders and have been validated in animal models (Hiroi et al., 2006; Bach-Mizrachi et al., 2008, Bonkale and Austin, 2008). TPH2 genetic variants have also been extensively reported to be associated with major depression (Zill et al., 2004; Van Den Bogaert et al., 2006; Haghighi et al., 2008). However, whether these changes might reflect alterations in possible modulatory effects of other neurotransmitter systems on 5-HT systems is still largely unknown. To address this question directly, we measured TPH 2 mRNA expression in three different transgenic mouse models, all related to pathological states of depression and anxiety, but caused by mutations affecting different neurotransmitter systems.

One of the models is a 5-HT transporter-deficient mouse (5-HTT -/-) (Bengel et al., 1998; for review see Murphy and Lesch, 2008). By mediating the 5-HT reuptake in the nerve terminal (and other parts of the 5-HT neuron), 5-HTT fine-tunes the magnitude and duration of serotonergic signaling (Canli and Lesch, 2007) which makes it the target for many antidepressant drugs, including the selective 5-HT reuptake inhibitors (SSRIs) (Owens and Nemeroff, 1998). They exhibit major adaptive changes in 5-HT neurotransmission, when compared with their wild-type controls. It has been shown that lack of 5-HTT depletes 5-HT and its metabolite 5-hydroxyindoleacetic acid by $60-80 \%$ in several brain areas such as the brainstem, striatum, hippocampus and frontal cortex (Bengel et al., 1998; Fabre et al., 2000). Functional desensitization of 5HT1A, 5-HT1B autoreceptors has been reported in the DRN of the 5-HTT -/- mutants as a consequence of high extracellular 5-HT levels in the vicinity of the serotonergic cells in the DRN. However, in terms of their target areas such as hippocampus and forebrain increased or no changes were observed in expression of these receptors. (Fabre et al., 2000; 
Mannoury la Cour et al., 2001). Autoradiographic labeling of 5-HT2A receptors has also revealed a 30 to $40 \%$ reduction in the density of these receptors in the cerebral cortex and lateral striatum of 5-HTT-/- in comparison to the wild type mice (Rioux et al., 1999). In addition, anxiolytic- and antidepressant-like responses have been observed in 5HTT -/- mice in behavioral test paradigms such as the elevated plus maze, tail suspension and forced swim test (Holmes et al., 2003a; Holmes et al., 2003b; Renoir et al., 2008).

The second model consists of mice heterozygous for the vesicular glutamate transporter 1 (VGLUT1+/-) (Wojcik et al., 2004). As the first of three vesicular glutamate transporters (VGLUT1, VGLUT2 and VGLUT3) (Takamori et al., 2000), VGLUT1 has been shown to have a high level of expression in glutamatergic neurons in the cerebral cortex (Hisano, 2003). By concentrating glutamate in synaptic vesicles, VGLUT1 mediates glutamate release from synaptic terminals and facilitates efficient glutamatergic transmission (Fremeau et al., 2004; Wilson et al., 2005). Recent studies have demonstrated that VGLUT1+/- mice exhibit deficient glutamate transmission (Balschun et al., 2009), depressive-like behavior and neurochemical changes, which are related to depression and anxiety (Tordera et al., 2007; Garcia-Garcia et al., 2009). Aberrations in glutamate synthesis and its dysregulation also appear to play a relevant role in major depression (Krystal et al., 2002). In keeping with this, recent post-mortem studies showing decreased cortical VGLUT1 in depressed subjects (Uezato et al., 2009) together with clinical findings of an excitatory inhibitory imbalance in the cortex of depressed patients (Sanacora et al., 2004; Bhagwagar et al., 2007) suggest that decreased VGLUT1 levels may have clinical implications.

Finally, mice with targeted disruption of the gene encoding the cannabinoid 1 receptor (CB1R -/-) (Ledent et al., 1999) were used as an additional model of mood disorders. The endocannabinoid system is a major neuromodulatory system that contributes to the control of emotional behavior (Maldonado et al., 2006). The pharmacological and genetic 
blockade of the CB1R induces a behavioral state analogous to depression in experimental animals (Hill and Gorzalka, 2005). Thus, CB1R -/- mice exhibit depressive-like symptoms, such as reduced responsiveness to reward stimuli (Sanchis-Segura et al., 2004; Maldonado et al., 2006) and enhanced anxiety levels and sensitivity to stress (Martin et al., 2002; Aso et al., 2008). Moreover, the chronic absence of CB1R activity induces alterations in 5-HT-dependent negative feedback. In particular, enhanced extracellular 5-HT levels in the prefrontal cortex decreased 5-HTT binding site density and caused functional desensitization of the 5-HT1A autoreceptors. As well reduced 5-HT2C receptor expression in different brain regions has previously been described in these mutants (Aso et al., 2009). In addition, according to Mato et al., (2007) mice lacking CB1R exert impaired post-synaptic serotonergic signaling, suggesting that CB1R -/- mice are useful models to reveal more regarding the nature of cannabinoid-5-HT interactions in mood disorders.

\section{Experimental procedures}

\section{Animals}

The experiments were carried out on 8-12- week-old male 5-HTT -/-, VGLUT1 +/- and CB1R -/- mice. Corresponding wild-type littermates were used as controls for each genetic model. All animals used in a given experiment were matched for age and weight. Mice were housed five per cage in a temperature $\left(21 \pm 1^{\circ} \mathrm{C}\right)$ - and humidity-controlled $(55 \pm 10 \%)$ room with a 12:12-h light/dark cycle (light on 08:00) with food and water ad libitum. Animal procedures were conducted according to European ethical guidelines (European Communities Council Directive 86/609/EEC) and approved by the respective local Ethical Committees (PRBB) .

Homozygous male 5-HTT -/- mice and wild-type (WT) littermates (obtained from Pierre \& Marie Curie, Paris, France) born from heterozygous mutants at the tenth generation (F10) of backcrossing with C57BL/6J mice were used (Renoir et al., 2008). Genotyping was performed as described by Bengel et al. (1998). 
Heterozygous VGLUT1 mice (VGLUT1+/-; C57BL/6N) were obtained from S. Wojcik (Göttingen, Germany). The targeted knockout allele was generated by truncation of the coding region of the VGLUT1 gene between the start codon and a BglII site in the fifth coding exon through homologous recombination in embryonic stem cells (129/ola background). A colony of WT and VGLUT1 +/- mice was bred in the animal house of the University of Navarra from heterozygous fathers and WT mothers (Harlan, France). In this laboratory, mice were weaned and genotyped at the age of 3 weeks. The first heterozygous generation has already been bred for more than 20 generations in the C57BL/6N background. VGLUT1+/- mice were studied and compared to their WT littermates. Heterozygous mice exhibited no apparent phenotypic abnormalities during development and adulthood.

Mice lacking CB1R (obtained from PRBB, Barcelona, Spain) were generated as previously described by Ledent et al. (1999). In order to obtain homogeneous genetic background, the first heterozygous generation was bred for 30 generations on a CD1 background, with selection for the mutant CB1R gene at each generation. After the 30th generation of backcross, heterozygote-heterozygote mating of CB1R knockout mice produced WT and CB1R -/- littermates for subsequent experiments. All mice were sacrificed between 9:00 and 10:00 am, alternating between WT and KO mice excluding all bias linked to the circadian cycle. Frozen brains from all three mouse models were sent on dry ice from the respective collaborating university to the Karolinska Institute (Stockholm).

\section{In situ hybridization}

\section{Tissue preparation}

Mice were sacrificed by decapitation, and the brains were rapidly removed, frozen in isopentane and stored at $-80{ }^{\circ} \mathrm{C}$ until use. Mice brainstem were cut into $20 \mu \mathrm{m}$ thick sections through the rostro-caudal extent of the DRN and MRN using cryostat, thaw-mounted on Superfrost 
slides (Fisher Scientific) and stored at $-20 \circ \mathrm{C}$. From the series of 50 sections through the rostro-caudal extent of DRN and MRN, first of every four sections (12 in total) were subjected to in situ hybridization (ISH). Therefore, optical density measurements for each subregion were carried out using 12 sections taken from each brain and average value used for statistics.

\section{Oligoprobes}

Antisense oligoprobes complementary to mouse TPH2 mRNA (5'TCC GTC CAA ATG TTG TCA GGT GGA TCC AGC CTC ACA ATG GTG GTC3', position 505; accession \#NM-173391) were synthesized by CyberGene AB (Huddinge, Sweden). The oligonucleotides were labeled at the 3' end using terminal deoxynucleotidyl-transferase (Amersham, Buckinghamshire, UK) with [ $\alpha-33 \mathrm{P}]$ dATP (NEN, Boston, MA, USA) to a specific activity of 1-4 x $106 \mathrm{cpm} / \mathrm{ng}$ oligonucleotide. The labeled oligoprobes were purified using ProbeQuant G-50 Micro Columns (Amersham). Sections were hybridized as described previously (Schalling et al., 1988, Dagerlind et al., 1992). Briefly, air dried sections were incubated in a hybridization cocktail $(50 \%$ formamide, $4 \times \mathrm{SSC}$, 1xDenhardt's solution 1\% sarcosyl, $0.02 \mathrm{M}$ phosphate buffer, PH 7.6, 10\% dextran sulfate, $500 \mu \mathrm{g} / \mathrm{ml}$ heat-denatured salmon sperm DNA, 1x107 $\mathrm{cpm} / \mathrm{ml}$ of the labeled probe) in a humidified chamber for $16-18 \mathrm{~h}$ at $42{ }^{\circ} \mathrm{C}$. After hybridization, the sections were washed in $1 \mathrm{xSSC}$ for $4 \mathrm{x} 15 \mathrm{~min}$ at $55^{\circ} \mathrm{C}$ and for $30 \mathrm{~min}$ at RT, then air-dried and dipped into Kodak NTB 2 emulsion (Kodak, Rochester, NY) diluted 1:1 with water. After exposure at $4{ }^{\circ} \mathrm{C}$ for $72 \mathrm{~h}$, the slides were developed in Kodak D19, fixed in Kodak Unifix and mounted in glycerol-phosphate buffer. For specificity control, adjacent sections were incubated with an excess (x100) of unlabelled probe.

Quantitative analysis of the TPH2 $\mathrm{mRNA}$ expression levels in the dorsal and median raphe nuclei

The expression levels of TPH2 mRNA in the DRD, DRV, DRL and MRN were quantified using an image analysis system (Nikon Microphot- 
MX microscope equipped with a dark-field condenser) from digital photos taken with a digital camera, DXM1200 (Nikon). Densitometric measurements (Image J software version 1.38x; NIH, Bethesda, USA) were obtained from the DRN after delineation of DRD, DRV and DRL and from the MRN based on a mouse brain atlas (Paxinos and Franklin, 2001). The data are expressed as optical density ratios.

\section{Statistical analyses}

For all experiments, samples from transgenic and wild type mice were treated in parallel. Data are presented as means and standard errors of means (S.E.M.). The quantitative data of the TPH2 mRNA expression levels in the DRD, DRV, DRL and the MRN were analyzed using twoway ANOVA and statistically significant differences were evaluated further by a Tukey's post hoc test. All statistical analyses were performed with SPSS 15.0 version for Windows. P-values lower than 0.05 were considered significant.

In all of the experiments, there were no significant differences between the right and left sides of the DRL in any of the groups. Therefore, the data were pooled for these subregions. Note that the ISH for each strain of mice and corresponding controls was carried out independently at separate times. Therefore, the baseline of the optical density signal differs in different sets of experiments.

\section{Results}

Decreased TPH2 mRNA expression in the dorsal and median raphe nuclei of mice deficient in 5-HT transporter

Quantitative optical density measurements of in situ hybridization labeling showed that TPH2 mRNA expression was significantly decreased in the DRD and DRV subregions of the DRN as well as in the MRN ( $\mathrm{p}<0.01, \mathrm{p}<0.05$ and $\mathrm{p}<0.05$, respectively) of homozygous 5-HTT-/- mice $(n=4)$ compared with WT counterparts $(n=4)$. Although a decrease was 
also noted in the DRL, the difference between 5-HTT -/- and WT genotypes did not reach the critical level of statistical significance in this DRN subregion (Figure 1).

Enhanced TPH2 mRNA expression in the dorsal and median raphe nuclei of heterozygous VGLUT1+/- mice and CB1R knock out mutants

A significant increase of TPH2 mRNA expression in the DRD, DRV, DRL and MRN ( $\mathrm{p}<0.01, \mathrm{p}<0.01, \mathrm{p}<0.05$ and $\mathrm{p}<0.05$, respectively) was observed in VGLUT1 +/- mice $(\mathrm{n}=4)$ in comparison to wild-type littermates $(n=3)$ (Figure 2).

Similarly, ISH labeling of TPH2 mRNA in the DRD, DRV, DRL and MRN was at a significantly higher density $(\mathrm{p}<0.05)$ in homozygous CB1R -/- mutants $(n=5)$ than in paired wild-type controls $(n=5)$ (Figure 3).

Interestingly, in the three different lines of wild-type mice (C57BL/6J, C57BL/6N, CD1) investigated for these studies, the same heterogeneous distribution of TPH2 mRNA was observed within the DRN. Thus, in all cases, ISH labeling showed a higher (+10-40\%) expression of TPH2 mRNA in the dorsomedial and ventromedial portions than in the dorsolateral portion of this region (Figures 1-3). Similar data have been previously reported in the rat (Clark et al., 2006).

\section{Discussion}

Using three genetically modified mouse models, all characterized by altered behaviors in depression-related paradigms, our results show quantitative differences in TPH2 mRNA expression in the three main subregions of the DRN as well as in the MRN. These changes are related to serotonergic or glutamatergic neurotransmission and to endocannabinoid systems. Thus, there were significant decreases in TPH2 
mRNA expression in the 5-HTT-/- mutant mice, whereas increases in TPH2 mRNA expression were observed in the VGLUT1+/- and CB1R-/mutant mice.
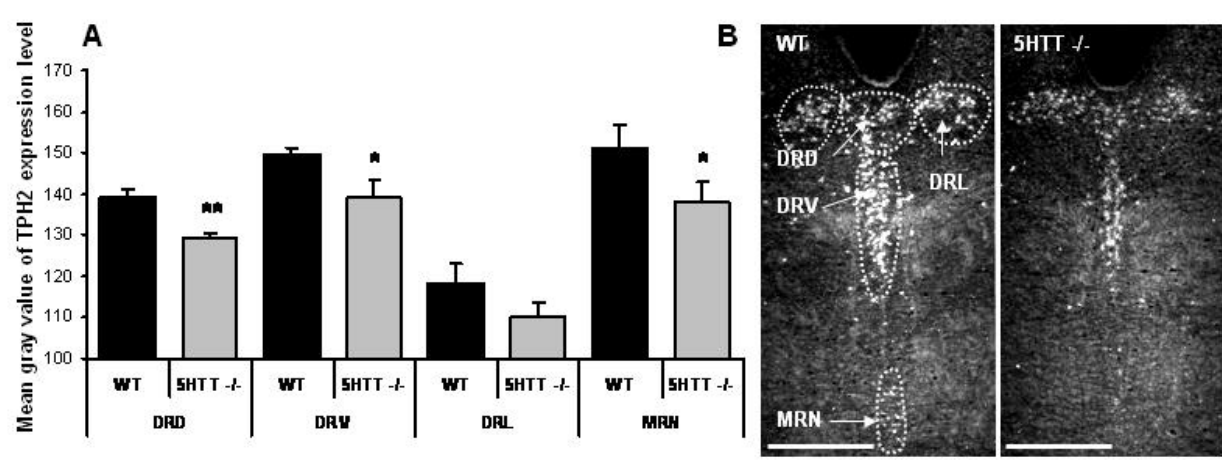

Figure 1. A) Optical densitometry of TPH2 mRNA levels in the dorsomedial (DRD), ventromedial (DRV), and dorsolateral (DRL) parts of the dorsal raphe nucleus (DRN) and the median raphe nucleus (MRN) of wild-type (WT) controls and 5-HTT knock-out (5-HTT -/-) mice. B) Representative photomicrographs of $20 \mu \mathrm{m}$-thick sections at the level of the DRN and the MRN from a WT and a 5-HTT -/- mouse. Note that 5-HTT -/- mice show a reduction of TPH2 mRNA expression. Each bar is the mean + S.E.M. from 4 mice of each genotype. scale bar: $500 \mu \mathrm{m},{ }^{*} \mathrm{p}<0.05$ and ${ }^{* *} \mathrm{p}<0.01$.

\section{The 5-HTT -/- mouse}

It has previously been shown that TPH mRNA levels and activity can be regulated by the end-product 5-HT. For example, lower 5-HT levels result in higher TPH mRNA expression in vivo (Park et al., 1994). There is evidence that 5-HTT -/- mice exhibit marked changes in 5-HT synthesis and turn-over. In particular, lack of 5-HTT is associated with a $60-80 \%$ depletion of 5-HT and its metabolite 5-hydroxyindoleacetic acid in several brain areas such as the brain stem, striatum, hippocampus and frontal cortex as compared with wild-type controls (Bengel et al., 1998; Fabre et al., 2000). Desensitization of 5-HT1A, 5-HT1B autoreceptors has been reported in 5-HTT -/- mutants as a consequence of high extracellular 
5-HT levels in the DRN (Fabre et al., 2000; Mannoury la Cour et al., 2001). Interestingly, such changes were also observed in mice after longterm SSRI administration (Landgrebe et al,, 2002), which are accompanied by decreased expression of TPH2 mRNA in DRN and MRN in rodents (Abumaria et al., 2007). In view of behavioral and biochemical evidence of similar alterations of serotonergic neurotransmission in mice lacking 5-HTT and in mice receiving long-term SSRI therapy, it can be proposed that high concentrations of 5-HT in the extracellular space of 5HTT-/- mice are also causally related to the reduced TPH2 mRNA expression in these mutants. Conversely, high TPH2 protein and mRNA levels have been reported in the DRN of depressed patients compared to control subjects, possibly due to a compensatory response to counteract deficits in extracellular 5-HT concentrations (Bach-Mizrachi et al., 2006). Increased TPH 2 mRNA levels in the DRN have also been observed in rats after adverse experiences during early life and adulthood (Gardner et al., 2009). However, further investigations are needed in order to elucidate the precise relationships between extracellular levels of 5-HT and TPH2 mRNA expression because changes opposite to those noted above in SSRI-treated rodents (i.e., increased TPH2 mRNA expression) have also been reported (Shishkina et al., 2007).

The lack of a significant decrease of TPH2 mRNA level in the DRL in 5HTT-/- mice in comparison with the other subregions of the DRN, known to contain fewer serotonergic neurons (Steinbusch, 1981), suggests that the DRL may be less involved in this model. In agreement with our data, previous studies already reported a heterogeneous distribution of TPH2 mRNA in the DRN with the greatest number of TPH2 mRNApositive neurons in the DRD and DRV subnuclei (Austin and O'Donnell, 1999; Clark et al., 2006). Perhaps, the DRL exhibits a lower sensitivity to extracellular 5-HT levels and consequently does not display any alteration in $\mathrm{TPH} 2$ expression. Accordingly, changes in $\mathrm{TPH} 2$ expression in the ventromedial and dorsomedial DRN might play a more predominant role in modulating serotonergic neurotransmission and depressive behavior (Bonkale et al., 2006; Lowry et al., 2008). Nevertheless, it must be taken 
in account that due to the sample sizes $(n=4)$ the statistical analysis might not have sufficient power to detect a decrease in TPH2 expression in the DRL of 5-HTT-/- mice.

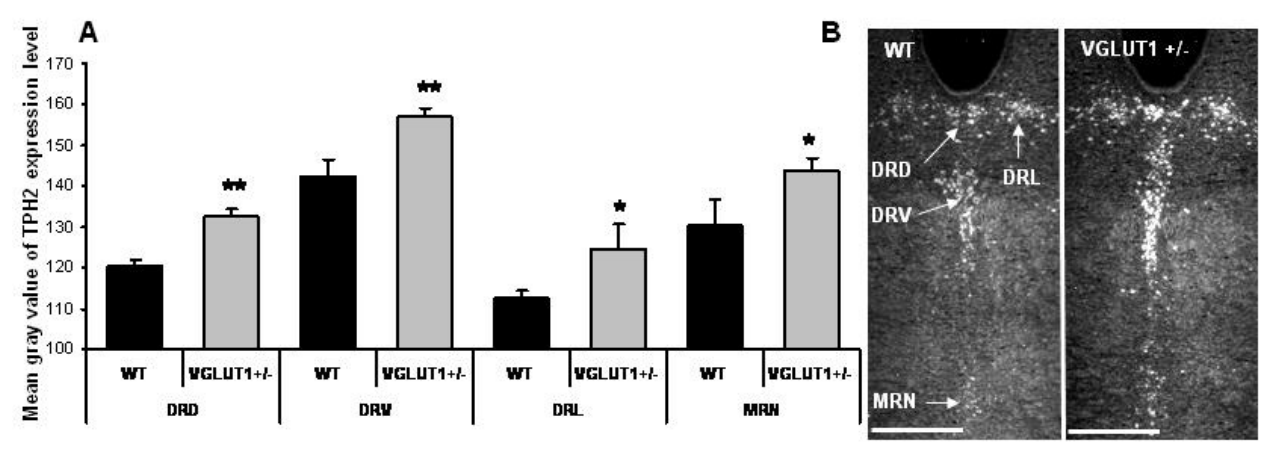

Figure 2. A) Optical densitometry of TPH2 mRNA levels in the dorsomedial (DRD), ventromedial (DRV), and dorsolateral (DRL) parts of the dorsal raphe nucleus (DRN) and the median raphe nucleus (MRN) of wild-type (WT) mice and paired heterozygous VGLUT1 +/- mice. B) Representative photomicrographs of the DRN and the MRN from a WT and a VGLUT1 +/- mouse. VGLUT1 +/- mice show increased TPH2 mRNA expression compared to WT. Each bar is the mean + S.E.M. of independent

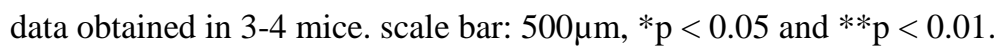

\section{The VGLUT1 +/- mouse}

Alterations in glutamate and GABA neurotransmission appear to play a key role in depression (Krystal et al., 2002). In addition to high TPH2 mRNA levels in the raphe nuclei (Bach-Mizrachi et al., 2008), marked changes in glutamatergic and GABA-ergic neurotransmission have been observed in depressed patients, e.g., increased glutamate and decreased GABA at cortical and hippocampal levels (Bhagwagar et al., 2007). However, the underlying molecular mechanisms responsible for the abnormal glutamate neurotransmission in the brain of depressed patients remain to be elucidated. 
Interestingly, the VGLUT1+/- mice also exhibit changes in cortical and hippocampal release of glutamate and GABA together with increased anxiogenic/depressive-like responses (Tordera et al., 2007; Garcia-Garcia et al., 2009). VGLUT1 plays a critical role in refilling synaptic glutamate vesicles (Wilson et al., 2005; Takamori, 2006) and indeed, a recent study has demonstrated that VGLUT1+/- mice exhibit deficient glutamate transmission (Balschun et al., 2009). Moreover, the lack of VGLUT1 in glial cells also increases the probability of excitotoxic effects of excessive extracellular glutamate in brain, which in turn can lead to more disturbed glutamatergic neurotransmission (Valentine and Sanacora, 2009).

The present study demonstrates that the glutamatergic system through VGLUT1 affects TPH2 mRNA expression. In particular, VGLUT1+/- mice exhibited increased TPH2 mRNA levels in the DRN and MRN that may be related to alterations in the glutamatergic/GABAergic-5-HT negative feedback system. Specifically, it has been established that forebrain glutamatergic neurons send projections to the ventral periaqueductal grey, stimulating local GABA neurons, which in turn inhibit 5-HT neurons (Arnsten and Goldman-Rakic, 1984; Sharp et al., 2007). Compromised glutamatergic signaling due to the reduced VGLUT1s in cortical prefrontal descending projections to the brainstem, as expected in VGLUT1+/- mice, would lead to attenuated stimulation of GABA neurons, and decreased inhibition of the 5-HT neurons and presumably, increased TPH2 mRNA levels. Moreover, the altered 5-HT function could contribute to explain the increased vulnerability of these mice to depressive like-behavior after exposure to chronic mild stress (Garcia-Garcia et al., 2009). With regard to the ascending component of the circuitry, 5-HT modulates the magnitude of responses in many cortical glutamatergic and GABA-ergic neurons (Araneda and Andrade, 1991; Aghajanian and Marek, 1999; Zhou and Hablitz, 1999). In addition, it has been reported that 5-HT controls, in turn, the activity of descending excitatory inputs through the activation of pyramidal cortical neurons (Amargos-Bosch et al., 2004). Since the neurochemical pathways regulating glutamate and GABA signaling are 
closely related (Choudary et al., 2005), changes in the levels and the activity of these neurotransmitters can lead to altered excitation-inhibition ratios in the cortex (Bhagwagar et al., 2007).
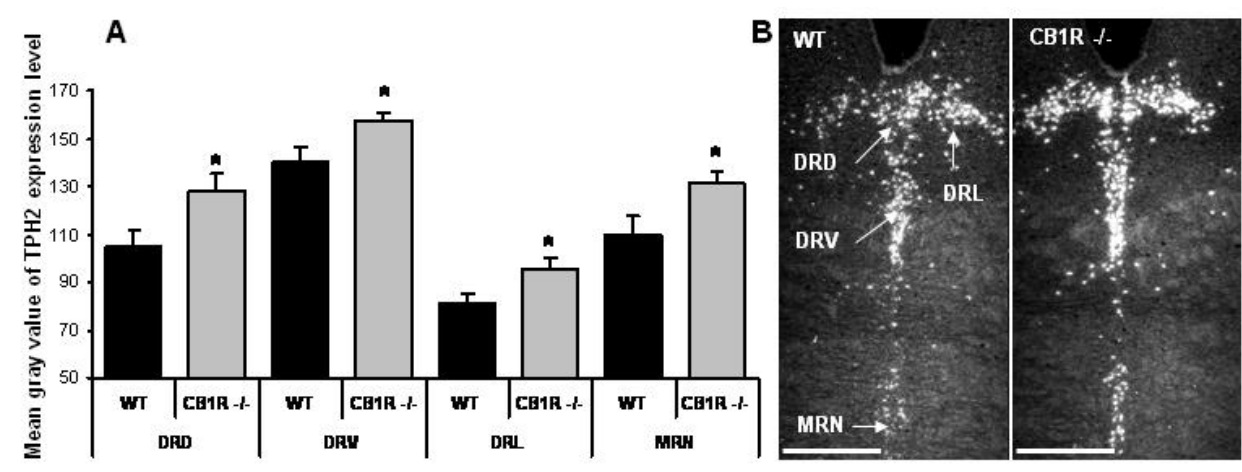

Figure 3. A) Optical densitometry of TPH2 mRNA levels in the dorsomedial (DRD), ventromedial (DRV), and dorsolateral (DRL) parts of the dorsal raphe nucleus (DRN) and the median raphe nucleus (MRN) in wild-type (WT) mice and paired CB1R knock-out (CB1R -/-). B) Representative photomicrographs at the level of DRN and MRN from a WT and a CB1R -/- mouse. A significant increase of TPH2 mRNA expression is observed in CB1R -/- compared to WT mice. Each bar is the mean + S.E.M. from 5 mice of each genotype. Scale bar: $500 \mu \mathrm{m}$. *p $<0.05$.

\section{The CB1R -/- mouse}

Previous evidence demonstrates that the endocannabinoid system through CB1R regulates the activity of the serotonergic system by modulating different components of serotonergic feedback (Hill et al., 2006; Bambico et al., 2007; Aso et al., 2009). In the present study, our data reveal additional alterations in the serotonergic activity at the levels of 5-HT synthesis in the absence of the CB1R. Mice lacking CB1R exhibit increased TPH2 mRNA expression in the MRN and all subregions of the DRN compared to wild-type littermates. Considering the role of TPH2 in 5-HT synthesis and the reciprocal innervation between the prefrontal cortex and DRN (Jankowski and Sesack, 2004), the increased expression 
of TPH2 in the DRN of CB1R -/- mice could contribute to the enhanced extracellular 5-HT levels in the prefrontal cortex of these mutants (Aso et al., 2009). Similarly, the alterations of different components involved in 5HT dependent negative feedback, such as enhanced extracellular 5-HT levels in the prefrontal cortex, decreased 5-HTT binding site density, functional desensitization of the 5-HT1A receptors and reduced 5-HT2C receptors have been described in CB1R-/- mice (Aso et al., 2009), as well as the enhancement of the 5-HT2A receptor excitatory effect on DRN and MRN produced by the lack of CB1R activity (Gorzalka et al., 2005), could also contribute to the increased 5-HT extracellular levels in the prefrontal cortex in CB1R-/- mutants. The synergistic alteration of these multiple serotonergic components modulated by CB1R on 5-HT signaling might be a reason for the robust up-regulation of TPH2 mRNA in all subregions of the DRN/MRN complex in CB1R-/- mice.

In contrast to the expected consequence of the enhanced serotonergic release, the genetic and pharmacological blockade of the CB1R induces a depressive-like phenotype (Hill and Gorzalka, 2005). This could be explained by the impairment of other mechanisms controlling emotional homeostasis beyond 5-HT neurotransmission in the absence of CB1R, such as the effects of stress on glucocorticoids and neurotrophic factor levels (Aso et al., 2008). The alterations observed on 5-HT neurotransmission have been proposed to be a substrate for counteracting the stress-induced emotional impairment in mice lacking CB1R since similar changes have been described after antidepressant treatments (Lanfumey et al., 2000; Le Poul et al., 2000; Gould et al., 2006). Nevertheless, an impaired post-synaptic serotonergic signaling has been reported in CB1R-/- mice (Mato et al., 2007), which could lead to a reduction in the efficacy of 5-HT for ameliorating their depressive-like phenotype.

Taken together, these data suggest that the CB1R gene knock out should lead to a reduction of the inhibitory effect exerted through 5-HT1A and 5-HT2C receptors and enhancement of the excitatory effect through 5HT2A receptors on DRN and MRN 5-HT neurons, possibly leading to 
increased expression of TPH2 mRNA. Additionally, CB1R -/- mice are characterized by impaired serotonergic negative feedback (Aso et al., 2009), and CB1R stimulation in the cortex directly inhibits 5-HT release (Nakazi et al., 2000), whereas a CB1R antagonist exerts the opposite effect (Tzavara et al., 2003). Therefore, changes in negative feedback input to the raphe nuclei from medial prefrontal cortex (Hajos et al., 1999) due to the absence of CB1R in DRN could compromise the feedback mechanisms in the raphe nuclei. The synergistic attenuation of the multiple actions mediated by $\mathrm{CB} 1 \mathrm{R}$ on 5 -HT signaling might be a reason why CB1R-/- mice show such a robust up regulation of TPH2 mRNA in all parts of the DRN/MRN complex.

\section{Conclusion}

In conclusion, based on the findings of the present study, we suggest that TPH2 mRNA expression is under the influence of multiple messenger systems in relation with presynaptic and/or postsynaptic feedback control of 5-HT synthesis. 5-HTT, VGLUT1 and CB1R seem to be involved in the execution of these feedback mechanisms. Finally, our data are consistent with previous reports suggesting that TPH2 activity within different raphe subregions are differentially regulated under specific conditions.

\section{Acknowledgements}

This study was supported by an EC grant (Newmood; LHSM-CT2003-503474), the Swedish Research Council (2887), The Marianne and Marcus Wallenberg Foundation, a FP6 Marie Curie Early Stage Training Fellowship (MEST-CT-2005-020589), the French Institute National de la Santé et de la Recherche Médicale (INSERM), the University Pierre \& Marie Curie, and the German Research Foundation (SFB 581, SFB TRR 58).

We are grateful to Professor S. Wojcik, University of Göttingen, Germany for supplying the original VGLUT1 heterozygous mice. We are grateful to Prof. D. A. Hopkins, Dalhousie University, Halifax and Visiting Professor Maastricht University for his comments. 


\section{References}

Abumaria, N., Rygula, R., Hiemke, C., Fuchs, E., Havemann-Reinecke, U., Ruther, E., Flugge, G., 2007. Effect of chronic citalopram on serotonin-related and stressregulated genes in the dorsal raphe nucleus of the rat. Eur Neuropsychopharmacol. 17, 417-429.

Aghajanian, G.K., Marek, G.J., 1999. Serotonin, via 5-HT2A receptors, increases EPSCs in layer $\mathrm{V}$ pyramidal cells of prefrontal cortex by an asynchronous mode of glutamate release. Brain Res. 825, 161-171.

Amargos-Bosch, M., Bortolozzi, A., Puig, M.V., Serrats, J., Adell, A., Celada, P., Toth, M., Mengod, G., Artigas, F., 2004. Co-expression and in vivo interaction of serotonin1 A and serotonin2A receptors in pyramidal neurons of prefrontal cortex. Cereb Cortex. 14, 281-299.

Araneda, R., Andrade, R., 1991. 5-Hydroxytryptamine2 and 5-hydroxytryptamine 1A receptors mediate opposing responses on membrane excitability in rat association cortex. Neuroscience. 40, 399-412.

Arnsten, A.F., Goldman-Rakic, P.S., 1984. Selective prefrontal cortical projections to the region of the locus coeruleus and raphe nuclei in the rhesus monkey. Brain Res. 306, 9-18.

Aso, E., Ozaita, A., Valdizan, E.M., Ledent, C., Pazos, A., Maldonado, R., Valverde, O., 2008. BDNF impairment in the hippocampus is related to enhanced despair behavior in CB1 knockout mice. J Neurochem. 105, 565-572.

Aso, E., Renoir, T., Mengod, G., Ledent, C., Hamon, M., Maldonado, R., Lanfumey, L., Valverde, O., 2009. Lack of CB1 receptor activity impairs serotonergic negative feedback. J Neurochem. 109, 935-944.

Austin, M.C., O'Donnell, S.M., 1999. Regional distribution and cellular expression of tryptophan hydroxylase messenger RNA in postmortem human brainstem and pineal gland. J Neurochem. 72, 2065-2073.

Bach-Mizrachi, H., Underwood, M.D., Kassir, S.A., Bakalian, M.J., Sibille, E., Tamir, H., Mann, J.J., Arango, V., 2006. Neuronal tryptophan hydroxylase mRNA expression in the human dorsal and median raphe nuclei: major depression and suicide. Neuropsychopharmacology. 31, 814-824.

Bach-Mizrachi, H., Underwood, M.D., Tin, A., Ellis, S.P., Mann, J.J., Arango, V., 2008. Elevated expression of tryptophan hydroxylase-2 mRNA at the neuronal level in the dorsal and median raphe nuclei of depressed suicides. Mol Psychiatry. 13, 507-513.

Balschun, D., Moechars, D., Callaerts-Vegh, Z., Vermaercke, B., Van Acker, N., Andries, L., D'Hooge, R., 2009. Vesicular glutamate transporter VGLUT1 has a role in hippocampal long-term potentiation and spatial reversal learning. Cereb Cortex. 20, 684-693.

Bambico, F.R., Katz, N., Debonnel, G., Gobbi, G., 2007. Cannabinoids elicit antidepressant-like behavior and activate serotonergic neurons through the medial prefrontal cortex. J Neurosci. 27, 11700-11711.

Bengel, D., Murphy, D.L., Andrews, A.M., Wichems, C.H., Feltner, D., Heils, A., Mossner, R., Westphal, H., Lesch, K.P., 1998. Altered brain serotonin homeostasis and locomotor insensitivity to 3, 4- 
methylenedioxymethamphetamine ("Ecstasy") in serotonin transporter-deficient mice. Mol Pharmacol. 53, 649-655.

Bhagwagar, Z., Wylezinska, M., Jezzard, P., Evans, J., Ashworth, F., Sule, A., Matthews, P.M., Cowen, P.J., 2007. Reduction in occipital cortex gamma-aminobutyric acid concentrations in medication-free recovered unipolar depressed and bipolar subjects. Biol Psychiatry. 61, 806-812.

Bonkale, W.L., Turecki, G., Austin, M.C., 2006. Increased tryptophan hydroxylase immunoreactivity in the dorsal raphe nucleus of alcohol-dependent, depressed suicide subjects is restricted to the dorsal subnucleus. Synapse. 60, 81-85.

Bonkale, W.L., Austin, M.C., 2008. 3,4-Methylenedioxymethamphetamine induces differential regulation of tryptophan hydroxylase 2 protein and mRNA levels in the rat dorsal raphe nucleus. Neuroscience. 155, 270-276.

Canli, T., Lesch, K.P., 2007. Long story short: the serotonin transporter in emotion regulation and social cognition. Nature Neurosci. 10, 1103-1109.

Celada, P., Puig, M.V., Casanovas, J.M., Guillazo, G., Artigas, F., 2001. Control of dorsal raphe serotonergic neurons by the medial prefrontal cortex: Involvement of serotonin-1A, GABA(A), and glutamate receptors. J Neurosci. 21, 9917-9929.

Choudary, P.V., Molnar, M., Evans, S.J., Tomita, H., Li, J.Z., Vawter, M.P., Myers, R.M., Bunney, W.E., Jr., Akil, H., Watson, S.J., Jones, E.G., 2005. Altered cortical glutamatergic and GABAergic signal transmission with glial involvement in depression. Proc Natl Acad Sci. U S A. 102, 15653-15658.

Clark, J.A., Flick, R.B., Pai, L.Y., Szalayova, I., Key, S., Conley, R.K., Deutch, A.Y., Hutson, P.H., Mezey, E., 2008. Glucocorticoid modulation of tryptophan hydroxylase-2 protein in raphe nuclei and 5-hydroxytryptophan concentrations in frontal cortex of C57/B16 mice. Mol Psychiatry. 13, 498-506.

Clark, M.S., McDevitt, R.A., Neumaier, J.F., 2006. Quantitative mapping of tryptophan hydroxylase-2, 5-HT1A, 5-HT1B, and serotonin transporter expression across the anteroposterior axis of the rat dorsal and median raphe nuclei. J Comp Neurol. 498, 611-623.

Cowen, P.J., 2008. Serotonin and depression: pathophysiological mechanism or marketing myth? Trends Pharmacol Sci. 29, 433-436.

Dagerlind, A., Friberg, K., Bean, A.J., Hokfelt, T., 1992. Sensitive mRNA detection using unfixed tissue: combined radioactive and non-radioactive in situ hybridization histochemistry. Histochemistry. 98, 39-49.

Dahlstrom, A., Fuxe, K., 1964. Localization of monoamines in the lower brain stem. Experientia. 20. 398-399.

Fabre, V., Beaufour, C., Evrard, A., Rioux, A., Hanoun, N., Lesch, K.P., Murphy, D.L., Lanfumey, L., Hamon, M., Martres, M.P., 2000. Altered expression and functions of serotonin 5-HT1A and 5-HT1B receptors in knock-out mice lacking the 5-HT transporter. Eur J Neurosci. 12, 2299-2310.

Fremeau, R.T., Jr., Kam, K., Qureshi, T., Johnson, J., Copenhagen, D.R., Storm-Mathisen, J., Chaudhry, F.A., Nicoll, R.A., Edwards, R.H., 2004. Vesicular glutamate transporters 1 and 2 target to functionally distinct synaptic release sites. Science. 304, 1815-1819.

Garcia-Garcia, A.L., Elizalde, N., Matrov, D., Harro, J., Wojcik, S.M., Venzala, E., Ramirez, M.J., Del Rio, J., Tordera, R.M., 2009. Increased vulnerability to 
depressive-like behavior of mice with decreased expression of VGLUT1. Biol Psychiatry. 66, 275-282.

Gardner, K.L., Hale,M.W., Oldfield, S., Lightman, S.L., Plotsky, P.M., Lowry, C.A., 2009. Adverse experience during early life and adulthood interact to elevate tph2 mRNA expression in serotonergic neurons within the dorsal raphe nucleus. Neuroscience. 163, 991-1001.

Gorzalka, B.B., Hill, M.N., Sun, J.C., 2005. Functional role of the endocannabinoid system and AMPA/kainate receptors in 5-HT2A receptor-mediated wet dog shakes. Eur J Pharmacol. 516, 28-33.

Gould, G.G., Altamirano, A.V., Javors, M.A., Frazer, A., 2006. A comparison of the chronic treatment effects of venlafaxine and other antidepressants on serotonin and norepinephrine transporters. Biol Psychiatry. 59, 408-414.

Greenberg, P.E., Kessler, R.C., Birnbaum, H.G., Leong, S.A., Lowe, S.W., Berglund, P.A., Corey-Lisle, P.K., 2003. The economic burden of depression in the United States: how did it change between 1990 and 2000? J Clin Psychiatry. 64, 14651475.

Gutknecht, L., Waider, J., Kraft, S., Kriegebaum, C., Holtmann, B., Reif, A., Schmitt, A., Lesch, K.P., 2008. Deficiency of brain 5-HT synthesis but serotonergic neuron formation in Tph2 knockout mice. J Neural Transm. 115, 1127-1132.

Gutknecht, L., Kriegebaum, C., Waider, J., Schmitt, A., Lesch, K.P., 2009. Spatiotemporal expression of tryptophan hydroxylase isoforms in murine and human brain: convergent data from Tph2 knockout mice. Eur Neuropsychopharmacol. $19,266-282$

Haghighi, F., Bach-Mizrachi, H., Huang, Y.Y., Arango, V., Shi, S., Dwork, A.J., Rosoklija, G., Sheng, H.T., Morozova, I., Ju J Russo, J.J., Mann J.J., 2008. Genetic architecture of the human tryptophan hydroxylase 2 Gene: existence of neural isoforms and relevance for major depression. Mol Psychiatry. 13, 813820.

Hajos, M., Richards, C.D., Szekely, A.D., Sharp, T., 1998. An electrophysiological and neuroanatomical study of the medial prefrontal cortical projection to the midbrain raphe nuclei in the rat. Neuroscience. 87, 95-108.

Hajos, M., Hajos-Korcsok, E., Sharp, T., 1999. Role of the medial prefrontal cortex in 5HT1A receptor-induced inhibition of 5-HT neuronal activity in the rat. Br J Pharmacol. 126, 1741-1750.

Hill, M.N., Gorzalka, B.B., 2005. Is there a role for the endocannabinoid system in the etiology and treatment of melancholic depression? Behav Pharmacol. 16, 333352.

Hill, M.N., Sun, J.C., Tse, M.T., Gorzalka, B.B., 2006. Altered responsiveness of serotonin receptor subtypes following long-term cannabinoid treatment. Int $\mathbf{J}$ Neuropsychopharmacol. 9, 277-286.

Hiroi, R., McDevitt, R.A., Neumaier, J.F., 2006. Estrogen selectively increases tryptophan hydroxylase-2 mRNA expression in distinct subregions of rat midbrain raphe nucleus: association between gene expression and anxiety behavior in the open field. Biol Psychiatry. 60, 288-295.

Hisano, S., 2003. Vesicular glutamate transporters in the brain. Anat Sci Int. 78, 191-204. 
Holmes, A., Yang, R.J., Lesch, K.P., Crawley, J.N., Murphy, D.L., 2003a. Mice lacking the serotonin transporter exhibit 5-HT1A receptor-mediated abnormalities in tests for anxiety-like behavior. Neuropsychopharmacology. 28, 2077-2088

Holmes, A., Murphy, D.L., Crawley, J.N., 2003b. Abnormal behavioral phenotypes of serotonin transporter knockout mice: parallels with human anxiety and depression. Biol Psychiatry. 54, 953-959.

Jankowski, M.P., Sesack, S.R., 2004. Prefrontal cortical projections to the rat dorsal raphe nucleus: ultrastructural features and associations with serotonin and gamma-aminobutyric acid neurons. J Comp Neurol. 468, 518-529.

Kosofsky, B.E., Molliver, M.E., 1987. The serotoninergic innervation of cerebral cortex: different classes of axon terminals arise from dorsal and median raphe nuclei. Synapse. 1, 153-168.

Krystal, J.H., Sanacora, G., Blumberg, H., Anand, A., Charney, D.S., Marek, G., Epperson, C.N., Goddard, A., Mason, G.F., 2002. Glutamate and GABA systems as targets for novel antidepressant and mood-stabilizing treatments. Mol Psychiatry. 7 Suppl 1, S71-80.

Landgrebe, J., Welzl, G., Metz, T., van Gaalen, M.M., Ropers, H., Wurst, W., Holsboer, F., 2002. Molecular characterisation of antidepressant effects in the mouse brain using gene expression profiling. J Psychiatr Res. 36, 119-129.

Lanfumey, L., Mannoury La Cour, C., Froger, N., Hamon, M., 2000. 5-HT-HPA interactions in two models of transgenic mice relevant to major depression. Neurochem Res. 25, 1199-1206.

Le Poul, E., Boni, C., Hanoun, N., Laporte, A.M., Laaris, N., Chauveau, J., Hamon, M., Lanfumey, L., 2000. Differential adaptation of brain 5-HT1A and 5-HT1B receptors and 5-HT transporter in rats treated chronically with fluoxetine. Neuropharmacology. 39, 110-122.

Ledent, C., Valverde, O., Cossu, G., Petitet, F., Aubert, J.F., Beslot, F., Bohme, G.A., Imperato, A., Pedrazzini, T., Roques, B.P., Vassart, G., Fratta, W., Parmentier, M., 1999. Unresponsiveness to cannabinoids and reduced addictive effects of opiates in CB1 receptor knockout mice. Science. 283, 401-404.

Lesch, K.P., Mossner, R., 2006. Inactivation of 5HT transport in mice: modeling altered 5HT homeostasis implicated in emotional dysfunction, affective disorders, and somatic syndromes. Handb Exp Pharmacol. 417-456.

Li, Q., Wichems, C., Heils, A., Van De Kar, L.D., Lesch, K.P., Murphy, D.L., 1999. Reduction of 5-hydroxytryptamine $(5-\mathrm{HT})(1 \mathrm{~A})$-mediated temperature and neuroendocrine responses and 5-HT(1A) binding sites in 5-HT transporter knockout mice. J Pharmacol Exp Ther. 291, 999-1007.

Lowry, C.A., Hale, M.W., Evans, A.K., Heerkens, J., Staub, D.R., Gasser, P.J., Shekhar, A., 2008. Serotonergic systems, anxiety, and affective disorder: focus on the dorsomedial part of the dorsal raphe nucleus. Ann. N. Y. Acad. Sci. 1148, 86-94.

Maldonado, R., Valverde, O., Berrendero, F., 2006. Involvement of the endocannabinoid system in drug addiction. Trends Neurosci. 29, 225-232.

Mannoury la Cour, C., Boni, C., Hanoun, N., Lesch, K.P., Hamon, M., Lanfumey, L., 2001. Functional consequences of 5-HT transporter gene disruption on 5-HT(1a) receptor-mediated regulation of dorsal raphe and hippocampal cell activity. $\mathbf{J}$ Neurosci. 21, 2178-2185. 
Martin, M., Ledent, C., Parmentier, M., Maldonado, R., Valverde, O., 2002. Involvement of CB1 cannabinoid receptors in emotional behaviour. Psychopharmacology (Berl). 159, 379-387.

Mato, S., Aso, E., Castro, E., Martin, M., Valverde, O., Maldonado, R., Pazos, A., 2007. CB1 knockout mice display impaired functionality of 5-HT1A and 5-HT2A/C receptors. J Neurochem. 103, 2111-2120.

Michelsen, K.A., Schmitz, C., Steinbusch, H.W.M., 2007. The dorsal raphe nucleus-from silver stainings to a role in depression. Brain Res Rev. 55, 329-342.

Michelsen, K.A., Prickaerts, J., Steinbusch, H.W.M., 2008. The dorsal raphe nucleus and serotonin: implications for neuroplasticity linked to major depression and Alzheimer's disease. Prog Brain Res. 172, 233-264.

Murphy, D.L., Lesch, K.P., 2008. Targeting the murine serotonin transporter: insights into human neurobiology. Nat Rev Neurosci. 9(2), 85-96.

Nakazi, M., Bauer, U., Nickel, T., Kathmann, M., Schlicker, E., 2000. Inhibition of serotonin release in the mouse brain via presynaptic cannabinoid CB1 receptors. Naunyn Schmiedebergs Arch Pharmacol. 361, 19-24.

O'Hearn, E., Molliver, M.E., 1984. Organization of raphe-cortical projections in rat: a quantitative retrograde study. Brain Res Bull. 13, 709-726.

Owens, M.J., Nemeroff, C.B., 1998. The serotonin transporter and depression. Depress Anxiety. 8 Suppl 1, 5-12.

Park, D.H., Stone, D.M., Baker, H., Kim, K.S., Joh, T.H., 1994. Early induction of rat brain tryptophan hydroxylase (TPH) mRNA following parachlorophenylalanine (PCPA) treatment. Brain Res Mol Brain Res. 22, 20-28.

Paxinos, G., Franklin, K.B.J., 2001. The mouse brain atlas in stereotaxic coordinates. Academic Press, San Diego.

Peyron, C., Petit, J.M., Rampon, C., Jouvet, M., Luppi, P.H., 1998. Forebrain afferents to the rat dorsal raphe nucleus demonstrated by retrograde and anterograde tracing methods. Neuroscience. 82, 443-468.

Renoir, T., Paizanis, E., El Yacoubi, M., Saurini, F., Hanoun, N., Melfort, M., Lesch, K.P., Hamon, M., Lanfumey, L., 2008. Differential long-term effects of MDMA on the serotoninergic system and hippocampal cell proliferation in 5-HTT knock-out vs. wild-type mice. Int J Neuropsychopharmacol. 11, 1149-1162.

Rioux, A., Fabre, V., Lesch, K.P., Moessner, R., Murphy, D.L., Lanfumey, L., Hamon, M., Martres, M.P., 1999. Adaptive changes of serotonin 5-HT2A receptors in mice lacking the serotonin transporter. Neurosci Lett. 262, 113-116.

Sanacora, G., Gueorguieva, R., Epperson, C.N., Wu, Y.T., Appel, M., Rothman, D.L., Krystal, J.H., Mason, G.F., 2004. Subtype-specific alterations of gammaaminobutyric acid and glutamate in patients with major depression. Arch Gen Psychiatry. 61, 705-713.

Sanchis-Segura, C., Cline, B.H., Marsicano, G., Lutz, B., Spanagel, R., 2004. Reduced sensitivity to reward in CB1 knockout mice. Psychopharmacology (Berl). 176, 223-232.

Schalling, M., Seroogy, K., Hokfelt, T., Chai, S.Y., Hallman, H., Persson, H., Larhammar, D., Ericsson, A., Terenius, L., Graffi, J., 1988. Neuropeptide tyrosine in the rat adrenal gland--immunohistochemical and in situ hybridization studies. Neuroscience. 24, 337-349. 
Sharp, T., Boothman, L., Raley, J., Queree, P., 2007. Important messages in the 'post': recent discoveries in 5-HT neurone feedback control. Trends Pharmacol Sci. 28, 629-636.

Shishkina, G.T., Kalinina, T.S., Dygalo, N.N., 2007. Up-regulation of tryptophan hydroxylase- 2 mRNA in the rat brain by chronic fluoxetine treatment correlates with its antidepressant effect. Neuroscience. 150, 404-412.

Steinbusch, H.W.M., 1984. Distribution of serotonin-immunoreactive neurons and their projections in the central nervous system of the rat. In: Björklund, A., Hökfelt, T., Kuhar, M.J. (Eds.), Classical Transmitters and Transmitter Receptors in the CNS, part II, The Handbook of Chemical Neuroanatomy. Elsevier, Amsterdam, Vol. 3, pp. 68-125.

Steinbusch, H.W., 1981. Distribution of serotonin-immunoreactivity in the central nervous system of the rat-cell bodies and terminals. Neuroscience. 6, 557-618.

Steinbusch, H.W.M., de Vente, J. 1997. New vistas on the neurobiology of depression: Colocalization of serotonin-, dopamine- and nitric oxide synthase-containing neurons in the dorsal raphe nucleus. In: Honig, A., Praag, H.M. (Eds.) Depression: Neurobiological, Psychopathological and Therapeutic Advances. John Wiley and Sons, pp. 179 - 196.

Steinbusch, H.W.M., Nieuwenhuys, R., 1983. The raphe nuclei of the rat brain stem: a cytoarchitectonic and immunohistochemical study using antibodies to serotonin, In: Emson, P. (Ed) Chemical Neuroanatomy. Raven Press., New York, pp. 131-207.

Steinbusch, H.W., Nieuwenhuys, R., Verhofstad, A.A., Van der Kooy, D., 1981. The nucleus raphe dorsalis of the rat and its projection upon the caudatoputamen. A combined cytoarchitectonic, immunohistochemical and retrograde transport study J Physiol (Paris). 77, 157-174.

Takamori, S., Rhee, J.S., Rosenmund, C., Jahn, R., 2000. Identification of a vesicular glutamate transporter that defines a glutamatergic phenotype in neurons. Nature. 407, 189-194.

Takamori, S., 2006. VGLUTs: 'exciting' times for glutamatergic research? Neurosci Res $55,343-351$.

Tordera, R.M., Totterdell, S., Wojcik, S.M., Brose, N., Elizalde, N., Lasheras, B., Del Rio, J., 2007. Enhanced anxiety, depressive-like behaviour and impaired recognition memory in mice with reduced expression of the vesicular glutamate transporter 1 (VGLUT1). Eur J Neurosci. 25, 281-290.

Tzavara, E.T., Davis, R.J., Perry, K.W., Li, X., Salhoff, C., Bymaster, F.P., Witkin, J.M., Nomikos, G.G., 2003. The CB1 receptor antagonist SR141716A selectively increases monoaminergic neurotransmission in the medial prefrontal cortex: implications for therapeutic actions. Br J Pharmacol. 138, 544-553.

Uezato, A., Meador-Woodruff, J.H., McCullumsmith, R.E., 2009. Vesicular glutamate transporter mRNA expression in the medial temporal lobe in major depressive disorder, bipolar disorder, and schizophrenia. Bipolar Disord. 11, 711-725.

Valentine, G.W., Sanacora, G., 2009. Targeting glial physiology and glutamate cycling in the treatment of depression. Biochem Pharmacol. 78, 431-9.

Van Den Bogaert, A., Sleegers, K., De Zutter, S., Heyrman, L., Norrback, K.F., Adolfsson, R., Van Broeckhoven, C., Del-Favero, J., 2006. Association of brain- 
specific tryptophan hydroxylase, TPH2, with unipolar and bipolar disorder in a Northern Swedish, isolated population. Arch Gen Psychiatry 63, 1103-1110.

Walther, D.J., Bader, M., 2003. A unique central tryptophan hydroxylase isoform. Biochem. Pharmacol. 66, 1673-1680.

Weissmann, D., Chamba, G., Debure, L., Rousset, C., Richard, F., Maitre, M., Pujol, J.F., 1990. Variation of tryptophan-5-hydroxylase concentration in the rat raphe dorsalis nucleus after p-chlorophenylalanine administration. II. Anatomical distribution of the tryptophan-5-hydroxylase protein and regional variation of its turnover rate. Brain Res. 536, 46-55.

Wilson, N.R., Kang, J., Hueske, E.V., Leung, T., Varoqui, H., Murnick, J.G., Erickson, J.D., Liu, G., 2005. Presynaptic regulation of quantal size by the vesicular glutamate transporter VGLUT1. J Neurosci. 25, 6221-6234.

Wojcik, S.M., Rhee, J.S., Herzog, E., Sigler, A., Jahn, R., Takamori, S., Brose, N., Rosenmund, C., 2004. An essential role for vesicular glutamate transporter 1 (VGLUT1) in postnatal development and control of quantal size. Proc Natl Acad Sci. U S A. 101, 7158-7163.

Zhang, X., Beaulieu, J.M., Sotnikova, T.D., Gainetdinov, R.R., Caron, M.G., 2004. Tryptophan hydroxylase-2 controls brain serotonin synthesis. Science. 305, 217.

Zhou, F.M., Hablitz, J.J., 1999. Activation of serotonin receptors modulates synaptic transmission in rat cerebral cortex. J Neurophysiol. 82, 2989-2999.

Zill, P., Baghai, T.C., Zwanzger, P., Schule, C., Eser, D., Rupprecht, R., Moller, H.J., Bondy, B., Ackenheil, M., 2004. SNP and haplotype analysis of a novel tryptophan hydroxylase isoform (TPH2) gene provide evidence for association with major depression. Mol Psychiatry 9, 1030-1036. 




\title{
CHEAPPTIEIR 4H
}

\section{Hyperdopaminergic status in experimental Huntington's disease}

\author{
Jahanshahi A, Vlamings R, Hilmi Kaya A, Lim LW, Janssen ML, Tan SK, Visser-
}

Vandewalle V, Steinbusch HW and Temel Y

\begin{abstract}
Huntington's disease chorea has been linked to an increased dopaminergic neurotransmission in the striatum. In this respect, clinical studies have demonstrated that the chorea can be treated with dopamine antagonist or dopamine depleting drugs. However, the origin of this hyperdopaminergic status remains unknown. In a recently generated transgenic rat model of Huntington's disease, which exhibits progressive striatal neurodegeneration and chorea, we have found evidence for increased levels of dopamine in the striatum which is in line with postmortem human studies. In addition, we have demonstrated that the origin of increased levels of dopamine is the presence of more dopaminergic cells in the ventral tegmental area and the substantia nigra pars compacta of transgenic Huntington's disease rats, the two main nuclei providing the striatum with dopamine.
\end{abstract}

Journal of Neuropathology and Experimental Neurology, 2010 



\section{Introduction}

Huntington's disease (HD) is an autosomal dominant inherited progressive neurodegenerative disorder (HuntingtonStudyGroup, 1993; Vonsattel and DiFiglia, 1998). The mutation involves the expansion of the CAG trinucleotide repeat within exon one of the HD gene on chromosome four. This mutation encodes an extended polyglutamine stretch in the $\mathrm{N}$ terminal domain of the huntingtin protein, whose function is actually still poorly understood (Bauer et al., 2005). Huntingtin accumulates in the brain and can have either toxic (Weiss et al., 2009; Yang et al., 2002) or protective effects (Ravikumar et al., 2004). The prevalence of HD in Europe and both American continents is reported to be approximately 1 in 100,000 and affects both sexes with the same frequency (Walker, 2007). HD can become symptomatic in principle at any age, but the peak incidence is at mid-adult life.

Histopathologically, HD is characterized by loss of striatal projection neurons, striatal interneurons being relatively spared, and striatal atrophy (Huot et al., 2007; Sharp et al., 1995; Vonsattel et al., 1985). The striatal projection neurons, also known as medium spiny neurons, can be divided into two groups based on their connectivity and neurochemistry. Degeneration takes place in both populations, but the medium spiny neurons expressing the dopamine 2 (D2) receptors and enkephalin are more affected (Reiner et al., 1988). Besides the profound neuron death in the striatum (Levesque et al., 2003), the neuropathology of HD comprises atrophy of the cerebral cortex and thinning of the underlying white matter (Rosas et al., 2008). Neuronal loss in other brain structures such as the hippocampus, cerebellum and thalamus has been reported as well (de la Monte et al., 1988; Schmitz et al., 1999).

Clinically, HD is characterized by motor and non-motor symptoms. The predominant motor symptom is the chorea, and to a lesser extent hypokinesia. The non-motor symptoms consist of cognitive dysfunction leading to dementia and emotional instability. The chorea can be defined 
as an abrupt, rapid, brief, irregular and unsustained movement. The pathoanatomical basis for the chorea is not well known, but a link with the dopaminergic system has been suggested by human post-mortem studies and clinical therapy studies. Early post-mortem studies showed that striatal dopamine levels, both in the dorsal and ventral striatum were significantly higher in HD patients compared to controls (Bird, 1980; Bird et al., 1980; Spokes, 1980). In addition, clinical studies have shown that the chorea can be treated with dopamine antagonist or dopamine depleting drugs (Mason and Barker, 2009).

The origin of elevated dopamine levels in the dorsal and ventral striatum in HD remains unknown. Here, we tested the hypothesis that elevated striatal dopamine levels are caused by changes in the substantia nigra pars compacta $(\mathrm{SNc})$ and the ventral tegmental area (VTA), since these regions are the main source of striatal dopamine (Haber and Fudge, 1997; Joel and Weiner, 2000). We used antibodies raised against tyrosine hydroxylase (TH), the rate-limiting enzyme in the synthesis of dopamine. By means of stereological counting methods, we analyzed the number of TH containing cells in the SNc and VTA, in the only experimental model of HD with chorea, the transgenic rat model of HD ( $\operatorname{tgHD})(\mathrm{Cao}$ et al., 2006. Thus far, no other rodent model of HD has shown choreiform movements (Cao et al., 2006). This model has recently been created (von Horsten et al., 2003), and carries a truncated huntingtin cDNA fragment with $51 \mathrm{CAG}$ repeats under control of the native rat Huntington promoter. These animals show slowly progressive clinical and pathological phenotypes (Cao et al., 2006; Nguyen et al., 2006). In previous work we have shown that the clinical symptoms include choreiform movements and cognitive and emotional alterations (Cao et al., 2006; Temel et al., 2005) and that tgHD rats suffer from a progressive striatal cell loss, striatal atrophy and cortical cell damage (Nguyen et al., 2006).

\section{Materials and Methods}

\section{Subjects}


Three groups of male subjects were investigated: homozygous transgenic HD (tgHD) rats $(n=5)$, hemizygous tgHD rats $(n=5)$, and wildtype littermates $(n=4)$, of approximately 11 months old. After genotyping, all rats were transferred from the Friedrich-AlexanderUniversity Animal Facilities (Erlangen-Nürnberg, Germany) to the Central Animal Facilities of Maastricht University (Maastricht, The Netherlands) and housed there during the experiments in standard Makrolon ${ }^{\mathrm{TM}}$ cages on sawdust bedding in an air-conditioned room (about $20^{\circ} \mathrm{C}$ ). Food, standard laboratory chow (Hopefarms, Woerden, The Netherlands), and water were available ad libitum. All experimental procedures were approved by the Animal Experiments and Ethics Committee of Maastricht University, Maastricht, The Netherlands.

\section{Tissue collection}

The subjects were sacrificed after deep anesthesia with Nembutal $(75 \mathrm{mg} / \mathrm{kg})$ and the brains were immediately dissected, followed by immersion-fixation with $4 \%$ paraformaldehyde in $0.1 \mathrm{M}$ sodium phosphate buffer ( $\mathrm{pH}$ : 7.6). The duration of immersion-fixation was 48 hours, followed by overnight immersion in $15 \%$ sucrose for cryoprotection. Hereafter, selected regions of the brains were cut serially in $30-\mu \mathrm{m}$-thick coronal sections on a cryostat (MICROM HM 520, Neuss, Germany) and stored at $-80{ }^{\circ} \mathrm{C}$ until processing for $\mathrm{TH}$ immunocytochemistry.

\section{Immunocytochemistry}

To evaluate the number of TH containing cells in the SNc and VTA, and the level of expression of $\mathrm{TH}$ in the dorsal and ventral striatum, we processed sections containing the SNc, VTA, and striatum for immunocytochemistry. This was carried out using mouse anti-TH (diluted 1:100, kindly supplied by Dr. C. Cuello, Canada) as primary antibody (Temel et al., 2006b). After rinsing steps with Tris-buffered solution and Triton X-100, and incubation with the secondary antibody (diluted 1:400 donkey anti-mouse biotin; Jackson Immunoresearch Laboratories, West Grove, USA), the sections were incubated with an avidin-biotinperoxidase complex (diluted 1:800, Elite ABC-kit, Vestastatin, 
Burlingame, USA). To visualize the horseradish peroxide reaction product, the sections were incubated with 3,3' -diaminobenzidine tetrahydrochloride with nickel chloride enhancement.. Finally, the sections were mounted and coverslipped using Permount (Fisher Scientific, USA).

Quantitative analysis of TH containing cells in the SNc and VTA

The immunocytochemically processed sections were used to evaluate the total number and volumes of $\mathrm{TH}$ immunoreactive (THir) cells within the SNc and VTA. All stereological investigations were carried out with a stereological computer microscopy system (Stereo Investigator, Microbrightfield Bioscience, Williston, USA). In all sections showing the SNc and VTA, the region comprising the TH containing cells within the SNc and VTA, respectively, was delineated and total numbers of $\mathrm{TH}$ containing cells and the cell volumes were estimated with the optical fractionator and nucleator, respectively (Schmitz and Hof, 2000; Schmitz and Hof, 2005; West et al., 1991). More details of the stereological counting method has been described before (Temel et al., 2006c).

Quantitative analysis of the TH levels in the dorsal and ventral striatum

The expression levels of $\mathrm{TH}$ in the dorsal and ventral striatum (nucleus accumbens and olfactory tubercle) were quantified using an image analysis system (analySIS Imaging System, Münster, Germany) from digital photos taken by an Olympus U-CMAD-2 digital camera connected to an Olympus AX 70 microscope (Olympus, Zoeterwoude, the Netherlands). Densitometric measurements (Image J software version $1.38 \mathrm{x}$; NIH, Bethesda, USA) were obtained at two anteroposterior levels for the dorsal and one level for the ventral striatum rat, for the right and left hemispheres. The coordinates were from bregma for the dorsal striatum +0.28 and +1.00 , and for the ventral striatum +1.70 (Paxinos and Watson, stereotactic atlas of the rat brain, 1998). The data are expressed as optical density ratios.

\section{Statistical analysis}


Data are presented as means and standard errors of means (S.E.M.). The quantitative data of the total number of $\mathrm{TH}$ containing cells, the volumes of the $\mathrm{TH}$ containing cells in the SNc and VTA, and the $\mathrm{TH}$ expression levels in the dorsal and ventral striatum were analyzed using one-way ANOVA with a Bonferroni post-hoc multiple comparisons test. All statistical analyses were performed with SPSS 15.0 version for Windows. P-values less than 0.05 were considered significant.

\section{Results}

TH containing cells in the SNC

Qualitative inspection of the stained sections showed clearly more $\mathrm{TH}$ containing cells in the SNc of tgHD rats when compared to the wildtype littermates (Figure 1). Quantitative analysis revealed that there were no significant differences between the right and left $\mathrm{SNc}$ in all the groups, and therefore the data were pooled.

The mean number of TH containing cells was 9745 in the wildtype littermates, 15351 in the hemizygous tgHD rats, and 14180 in the homozygous tgHD rats (Figure 2). The number of TH containing cells in the hemizygous and homozygous tgHD rats were significantly higher than in the wildtype littermates $(\mathrm{F}=9.43, \mathrm{P}<0.01)$. There were no significant differences between the hemizygous and homozygous animals.

The volumes of the $\mathrm{TH}$ containing cells of the right and left SNc were not statistically different in all the groups and therefore this data set was pooled. The mean volumes of TH containing cells were $2939 \mu \mathrm{m} 3$ in the wildtype littermates, $2681 \mu \mathrm{m} 3$ in the hemizygous tgHD rats, and $3072 \mu \mathrm{m} 3$ in the homozygous tgHD rats. There were no significant differences between the groups (Figure 2).

TH containing cells in the VTA 

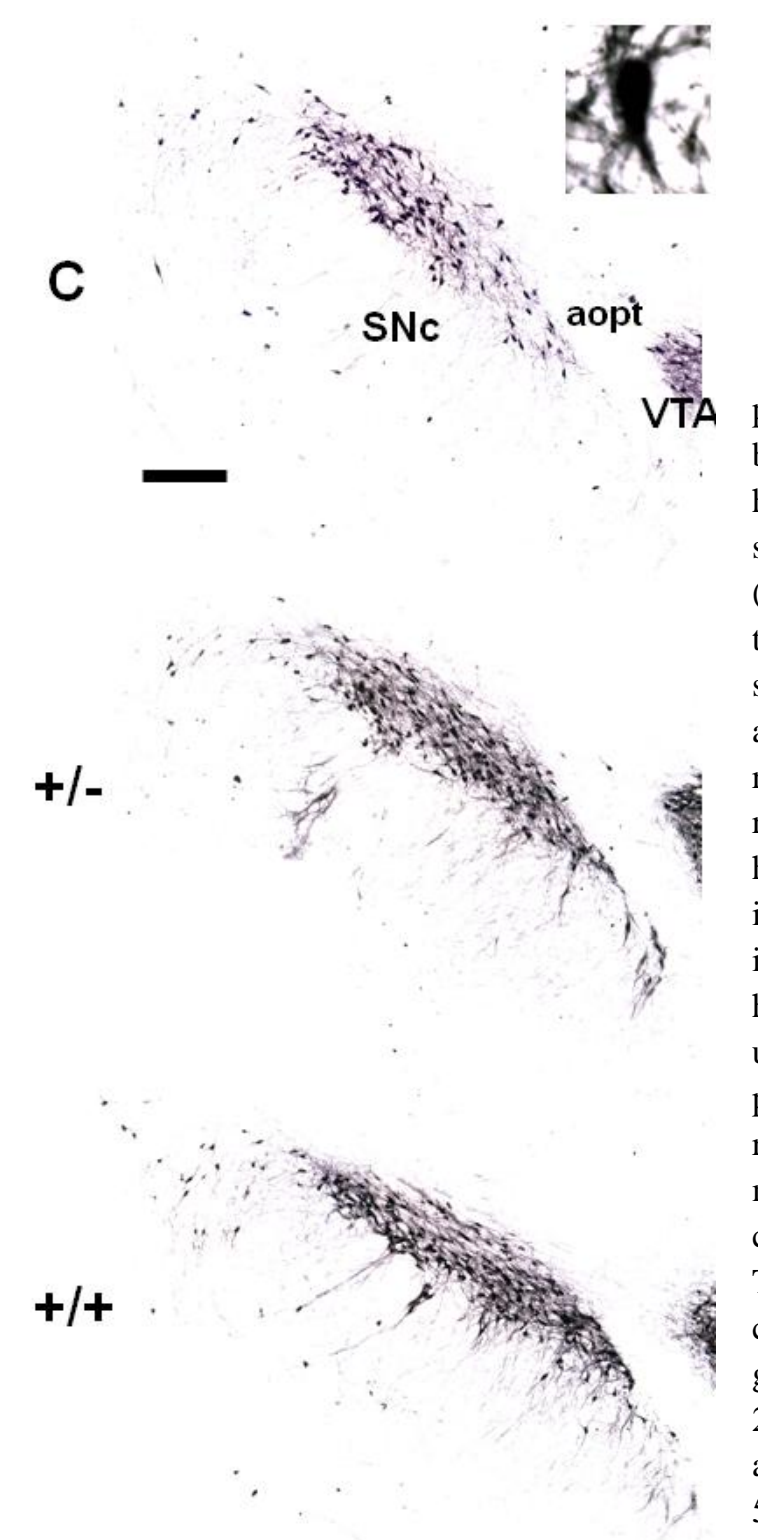
the Paxinos and Watson atlas of 1998.

Figure 1. Representative lowpower photomicrographs of coronal brain sections stained for tyrosine hydroxylase (TH) showing the substantia nigra pars compacta $(\mathrm{SNc})$, medial terminal nucleus of the accessory optic tract (aopt) and a small part of the ventral tegmental area (VTA) of a wildtype littermate rat (C), hemizygous transgenic HD rat (-/-) and a transgenic HD homozygous $(+/+)$ rat. Note the increased TH containing cell density in the SNc of the hemizygous and homozygous transgenic HD rats upon close inspection. The high power photomicrograph inset in the right upper corner shows a magnification of a $\mathrm{TH}$ containing cells of a transgenic homozygous rat. The volumes of the TH containing cells were not different between the groups. Scale bar is approximately $250 \mu \mathrm{m}$. The anatomical level is approximately anteroposterior $5.2 \mathrm{~mm}$ from Bregma according to

Similarly to the SNc, qualitative evaluation of the stained sections showed clearly more TH containing cells in the VTA of tgHD rats when compared 
to the wildtype littermates (Figure 3). Again, quantitative analysis revealed no significant differences between the right and left VTA in all the groups, and consequently the data were pooled.
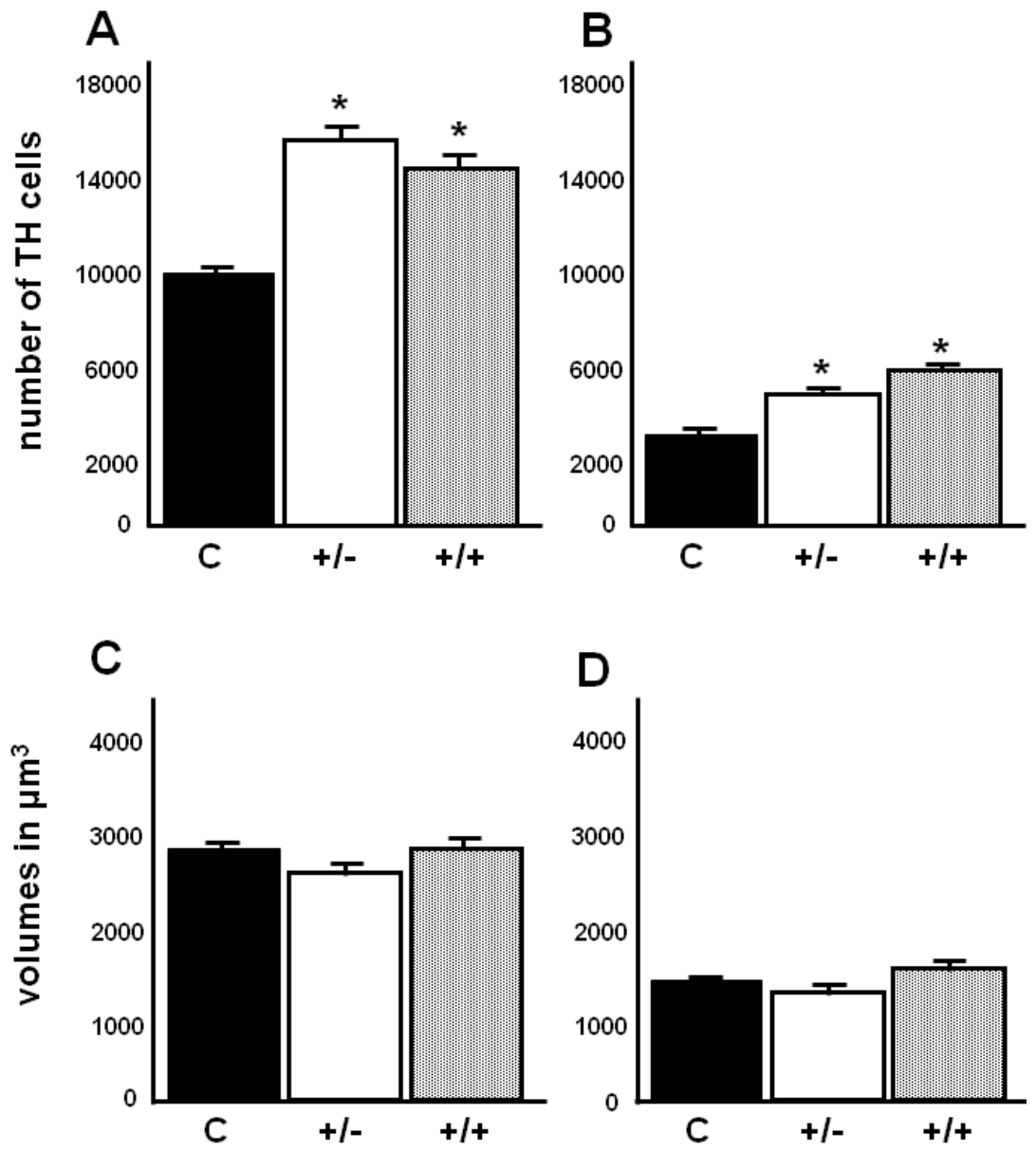

Figure 2. Cumulative data showing the means and SEM's of the number of TH containing cells in the substantia nigra pars compacta (A) and ventral tegmental area (B). Note that both the homozygous $(+/+)$ and the hemizygous transgenic HD rats have more TH containing neurons than the wildtype littermates (C). A significant difference $(\mathrm{P}<0.05)$ is indicated by an $\left(^{*}\right)$. The cumulative results of the measurements of the volumes of the TH containing cells in the SNc and the VTA are shown in figures $\mathrm{C}$ and $\mathrm{D}$, respectively. There were no significant differences between the groups. 
The mean number of TH containing cells in the VTA was 3901 in the wildtype littermates, 5056 in the hemizygous tgHD rats, and 5726 in the homozygous tgHD rats (Figure 2). The number of TH containing cells in the $\operatorname{tgHD}$ rats was significantly higher as compared to the wildtype littermates $(\mathrm{F}=9.09, \mathrm{P}<0.01)$. There were no significant differences between the hemizygous and homozygous animals.

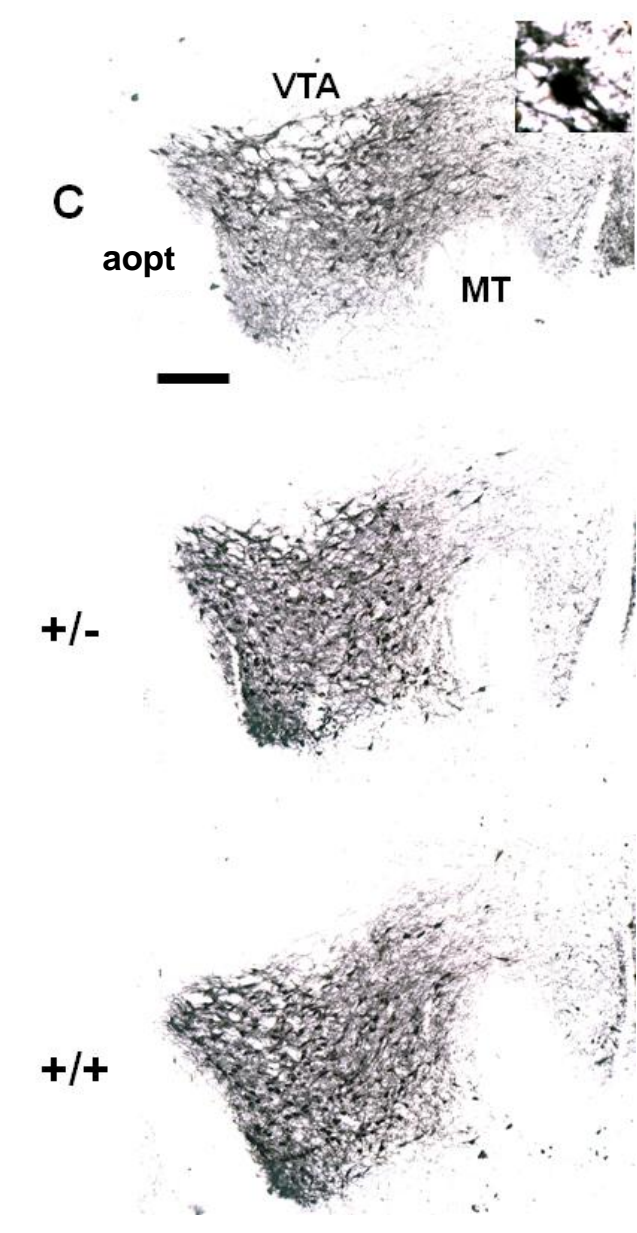

Figure 3. Representative lowpower photomicrographs of coronal brain sections stained for $\mathrm{TH}$ showing the ventral tegmental area (VTA), medial terminal nucleus of the accessory optic tract (aopt) and the mamillary tubercle (MT) of a wildtype littermate rat (C), hemizygous transgenic HD rat (-/-) and a transgenic HD homozygous $(+/+)$ rat. Note the increased TH containing cell density in the VTA of the hemizygous and homozygous transgenic HD rats upon close inspection, while the background staining (fiber staining) is comparable. The high-power photomicropgraph inset in the right upper corner shows a magnification of a TH containing cells of a transgenic homozygous rat. The volumes of the TH containing cells were not different between the groups. Scale bar is approximately $150 \mu \mathrm{m}$. The anatomical level is approximately anteroposterior $-5.6 \mathrm{~mm}$ from Bregma according to the Paxinos and Watson atlas of 1998.

The volumes of the TH containing cells of the right and left VTA were also not statistically different in all the groups and therefore these data were pooled (Figure 1). The mean volumes of TH containing cells 
were $1546 \mu \mathrm{m} 3$ in the wildtype littermates, $1376 \mu \mathrm{m} 3$ in the hemizygous $\operatorname{tgHD}$ rats, and $1667 \mu \mathrm{m} 3$ in the homozygous tgHD rats. There were no significant differences between the groups.
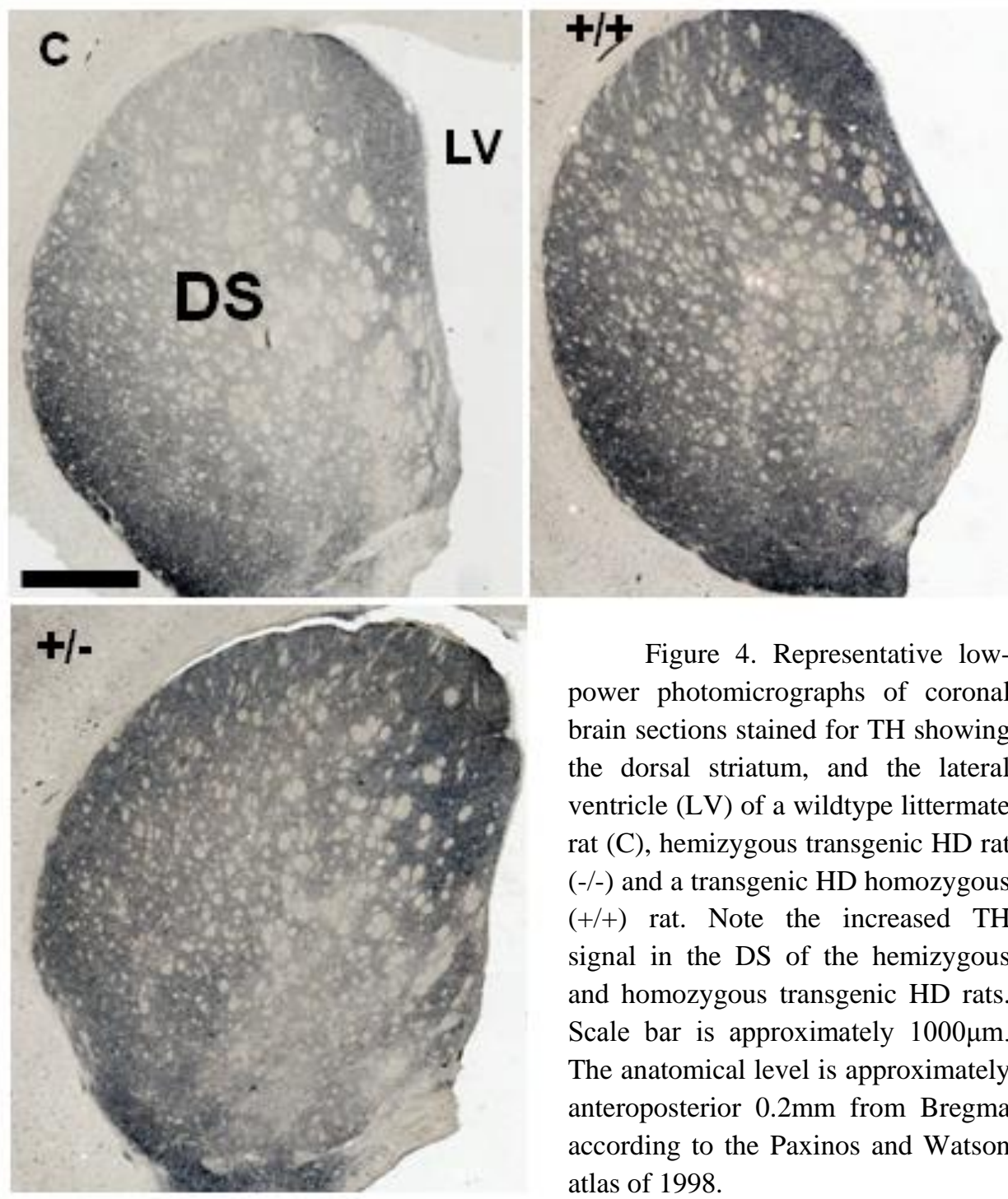

Figure 4. Representative lowpower photomicrographs of coronal brain sections stained for TH showing the dorsal striatum, and the lateral ventricle (LV) of a wildtype littermate rat $(\mathrm{C})$, hemizygous transgenic HD rat $(-/-)$ and a transgenic HD homozygous $(+/+)$ rat. Note the increased $\mathrm{TH}$ signal in the DS of the hemizygous and homozygous transgenic HD rats. Scale bar is approximately $1000 \mu \mathrm{m}$. The anatomical level is approximately anteroposterior $0.2 \mathrm{~mm}$ from Bregma according to the Paxinos and Watson atlas of 1998. 


\section{TH expression levels in the dorsal and ventral striatum}

Qualitative examination of the TH expression showed again clear differences between the tgHD rats and wildtype littermates in both the dorsal and ventral striatum (Figures 4 and 5). Quantitative analysis revealed no differences between the right and left striatum, and also not between the two anteroposterior levels of the dorsal striatum, and therefore the data were pooled.
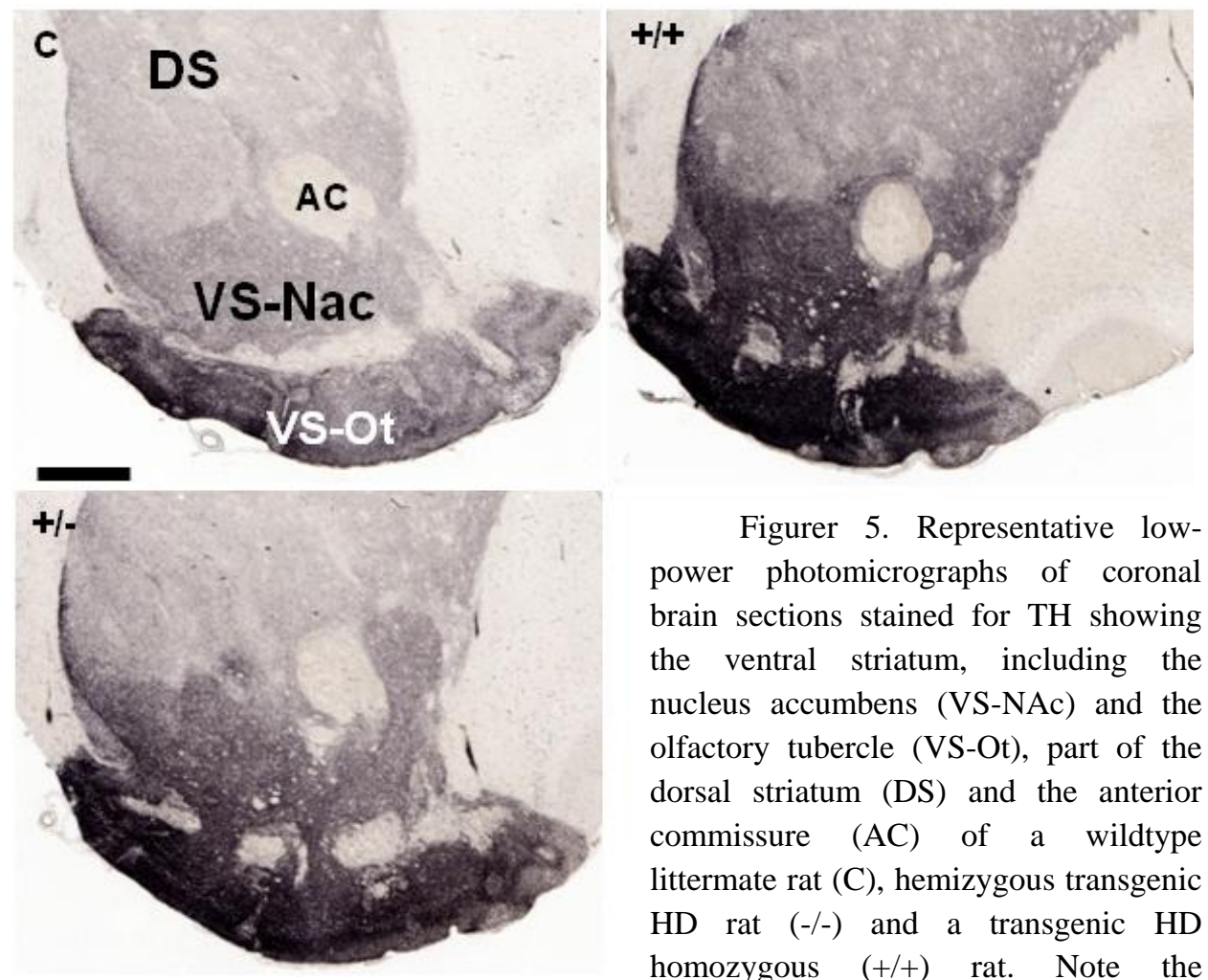

Figurer 5. Representative lowpower photomicrographs of coronal brain sections stained for TH showing the ventral striatum, including the nucleus accumbens (VS-NAc) and the olfactory tubercle (VS-Ot), part of the dorsal striatum (DS) and the anterior commissure (AC) of a wildtype littermate rat $(\mathrm{C})$, hemizygous transgenic $\mathrm{HD}$ rat (-/-) and a transgenic HD homozygous $(+/+)$ rat. Note the increased TH signal in the VS-NAc and

VS-Ot of the hemizygous and homozygous transgenic HD rats. Scale bar is approximately $600 \mu \mathrm{m}$. The anatomical level is approximately anteroposterior $1.6 \mathrm{~mm}$ from Bregma according to the Paxinos and Watson atlas of 1998. 
Measurements of the optical densities showed that the THexpression in the dorsal striatum was significantly higher in the tgHD rats as compared to the wildtype littermates $(\mathrm{F}=8.90, \mathrm{P}>0.01)$. There were no differences between the hemizygous and homozygous rats. Similarly, the expression of $\mathrm{TH}$ in the ventral striatum was significantly higher in the $\operatorname{tg} \mathrm{HD}$ rats than in the wildtype littermates $(\mathrm{F}=4.56, \mathrm{P}>0.05)$. Again, there were no differences between the hemizygous and homozygous rats (Figure 6).
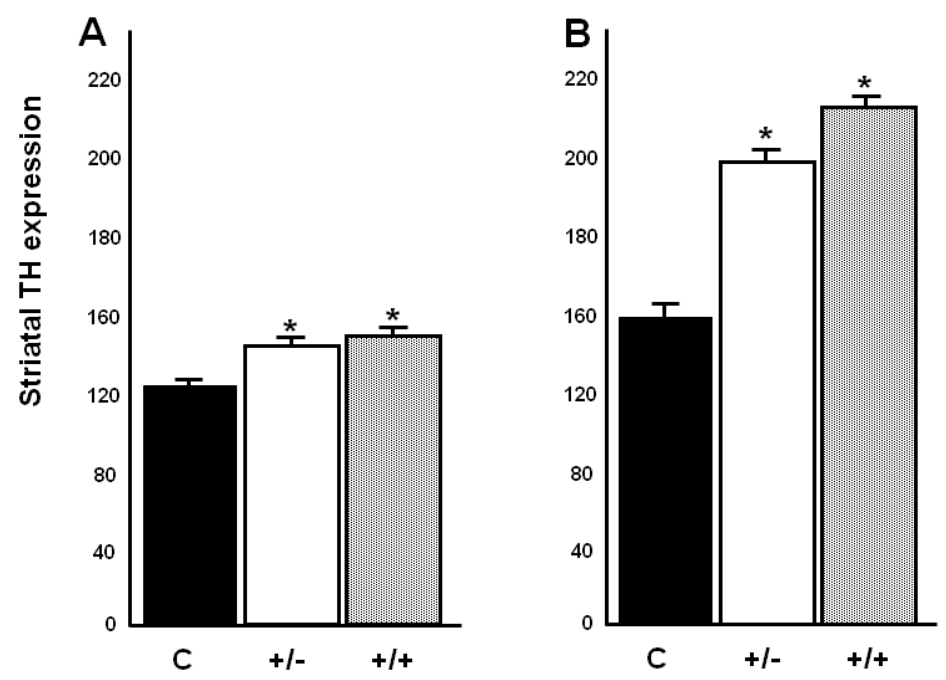

Figure 6. Cumulative data showing the means and SEM's of the level of TH expression in the dorsal (A) and ventral striatum (B), measured by calculating the optical density ratios. Higher value indicates lower TH expression, and lower values indicate more TH expression. Note that the levels of TH expression in both the dorsal and ventral striatum are higher in the tgHD animals. A significant difference $(\mathrm{P}<0.05)$ is indicated by an $(*)$.

The SNc-dorsal striatum (nigrostriatal) versus the VTA-ventral striatum (mesolimbic) dopaminergic system

Although the dopaminergic efferents from the $\mathrm{SNc}$ innervate predominantly the dorsomedial striatum, the medial part also innervates the ventral striatum (Haber and Fudge, 1997). The dopaminergic efferents 
from the VTA innervate the rest of the ventromedial striatum. To study the differences between the groups and the anatomical subregions in more detail, we calculated and analyzed the difference scores for all the groups. This was performed in order to evaluate whether there was a difference in the changes in the VTA-ventral striatum dopaminergic system when compared to the SNc-dorsal striatum dopaminergic system. The amount of increases in the number of $\mathrm{TH}$ containing cells and the level of $\mathrm{TH}$ expression was similar for both systems.

\section{Increase in cell density}

While semi-quantitative volumetric analysis of the VTA and SNc revealed no differences between the groups, we found an obvious increase in the density of TH containing neurons in these regions (Figure 7).

\section{Discussion}

Our results clearly show an increased expression of $\mathrm{TH}$ in the striatum of tgHD rats. This reflects increased striatal dopamine levels, since TH enzymatic activity highly corresponds to the cellular levels of dopamine (Yohrling et al., 2003). This is in line with post-mortem human studies in the 1980s reporting higher levels of dopamine in HD brains. Using a radioenzymatic detection method, Spokes found increased levels of dopamine in the striatum $(69 \%$ increase in the putamen and $32 \%$ in the caudate nucleus), NAc (87\% increase) and the SNc (34\%) in post-mortem material of $56 \mathrm{HD}$ patients, when compared to control tissue (Spokes, 1980). While another study with much less subjects, found no changes in dopamine levels in post-mortem HD patients (Bernheimer et al., 1973), Bird reported increased tyrosine hydroxylase activity in the striatum, NAc and substantia nigra (Bird, 1980), supporting the findings of Spokes (Spokes, 1980). Higher levels of striatal dopamine were explained by a higher density of dopaminergic terminals in the striatum which is undergo- 

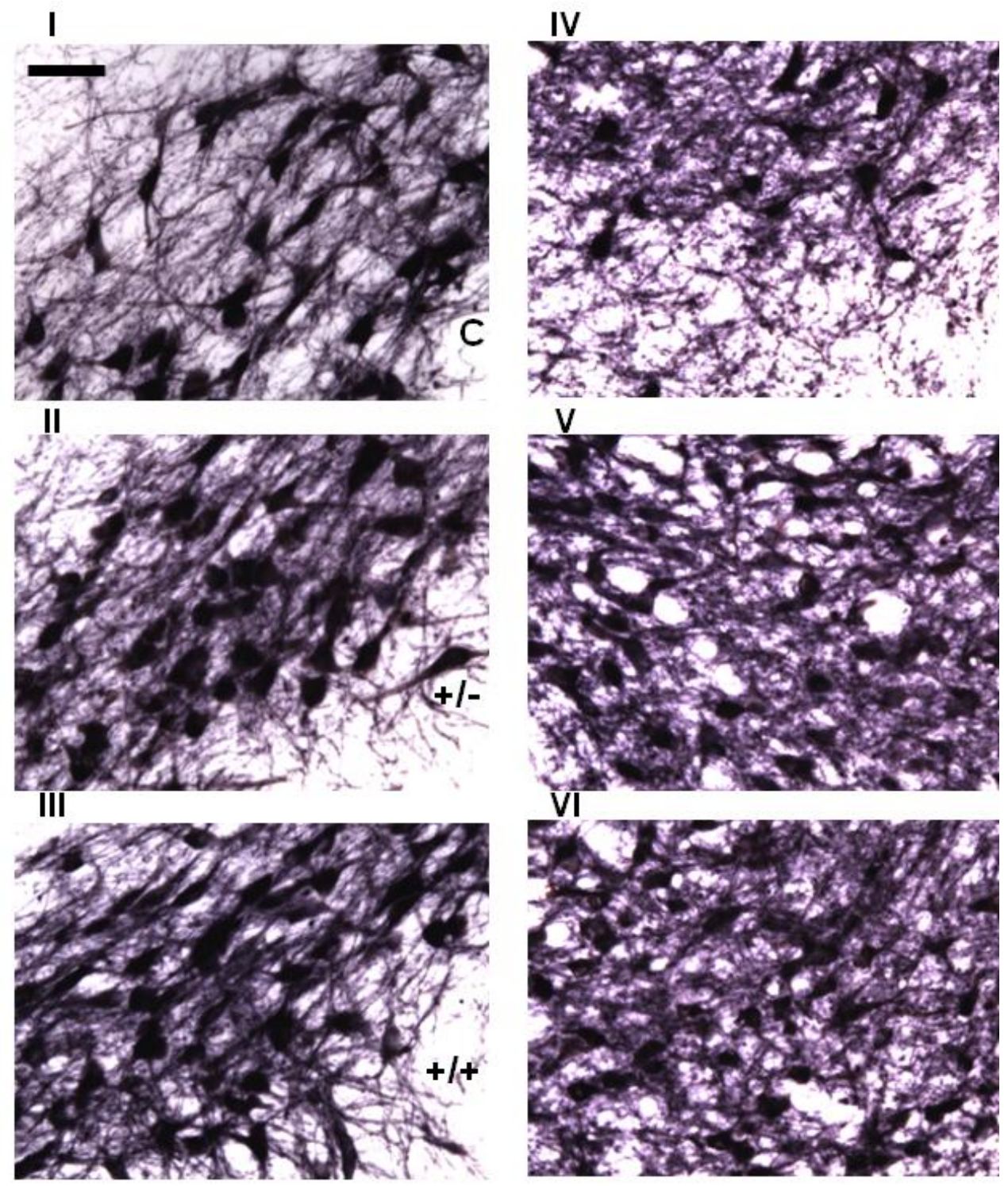

Figure 7. Representative high-power photomicrographs of coronal brain sections stained for TH showing the SNc (I-III) and the VTA (IV-VI) of a wildtype littermate rat (C), hemizygous transgenic HD rat (-/-) and a transgenic HD homozygous (+/+) rat. Note the increased density of $\mathrm{TH}$ containing cells in the hemizygous and homozygous transgenic HD rats. Scale bar is approximately $50 \mu \mathrm{m}$. 
-ing shrinkage. However, this could not explain the increase in the NAc and the substantia nigra, which do not show clear shrinkage in HD (Bird, 1980; Spokes, 1980). Indirect evidence for increased striatal dopamine levels is also derived from receptor studies. In tgHD rats (Bauer et al., 2005) and in HD patients (Augood et al., 1997), it has been shown that D1 and D2 receptors in the striatum are significantly decreased..

Our findings suggest that the origin of the increased dopamine in the striatum comes from the two main nuclei supplying the striatum with dopamine, the SNc for the nigrostriatal dopamine pathway and the VTA for the mesolimbic dopamine pathway, and is therefore not likely to be related to shrinkage of the striatum. Stereological counts of $\mathrm{TH}$ containing cells revealed a substantial increase in the number of $\mathrm{TH}$ containing cells in both regions in the tgHD rats when compared to controls. Since it has been demonstrated that the total number of cells in the substantia nigra in postmortem HD brains were not different from age-matched controls (Mann, 1989), it is possible that the increased number of TH containing cells in the SNc and VTA is the result of a change in phenotype of the non-TH containing cells. For the SNc it is known that about $45 \%$ of the cells are non-TH containing (Temel et al., 2006c). A change in the phenotype of a $\mathrm{TH}$ cell, while the cell is still functional, has been documented before in the substantia nigra of mice (Aumann et al., 2008) and rats (Paul et al., 2004).

There are two popular hypotheses for the consequences of a hyperdopaminergic status in HD: chorea induced by increased dopamine levels and higher dopamine leading to enhanced neurodegeneration. Evidence for the first hypothesis is mainly derived from Parkinson's disease (PD) and clinical observations in HD. In PD, one of the key symptoms is hypokinesia, this has been linked to dopaminergic neuron loss in the SNc, which can be treated successfully with dopamine-agonists and levo-dopa. In line with this, the chorea, which is a hyperkinesia, can be treated with dopamine-antagonists and dopamine-depleting drugs. We should keep in mind that HD patients can also suffer to, a certain extent, 
from bradykinesia and rigidity. The second hypothesis, which is mainly supported by experimental studies, is that higher concentrations of dopamine in the striatum lead to neurotoxicity and therefore plays a role in the pathogenesis of HD. Dopamine can auto-oxidize to form dopamine quinone, a reactive molecule which spontaneously decomposes to form additional reactive species that can induce cell damage (Jakel and Maragos, 2000; McLaughlin et al., 1998).

An interesting but provocative opinion is that increased dopamine plays a role in chorea, and not so much in neurodegeneration. Findings from transgenic mice models of HD support this. For instance in R6/2 (Ariano et al., 2002; Reynolds et al., 1999) and R6/1 (Petersen et al., 2002) mice, lower dopamine levels were found in the striatum, while these mice show neurodegeneration but no chorea. In line with this, the tgHD rats as demonstrated in this study, show neurodegeneration, but also chorea and have a hyperdopaminergic status.

We have not found a difference in the number of TH containing cells between the homozygous and hemizygous animals, while differences in behavioral performance exist at the age of 11 months (Nguyen et al., 2006). Interestingly, at this age there is also no difference in the number of choreiform movements, which arises at later ages (Cao et al., 2006; Temel et al., 2006a). This again supports the opinion expressed in the previous paragraph.

In conclusion, in a recently generated transgenic rat model of HD, exhibiting progressive neurodegeneration and chorea, we have found evidence for increased levels of dopamine in the striatum which is in line with post-mortem human studies. Furthermore, our results show that the origin of this hyperdopaminergic status lies in an increased number of dopaminergic cells in the VTA and $\mathrm{SNc}$, the two main nuclei providing the striatum with dopamine. 


\section{References}

Ariano, M.A., Aronin, N., Difiglia, M., Tagle, D.A., Sibley, D.R., Leavitt, B.R., Hayden, M.R., Levine, M.S., 2002. Striatal neurochemical changes in transgenic models of Huntington's disease. J Neurosci Res. 68, 716-29.

Augood, S.J., Faull, R.L., Emson, P.C., 1997. Dopamine D1 and D2 receptor gene expression in the striatum in Huntington's disease. Ann Neurol. 42, 215-21.

Aumann, T.D., Gantois, I., Egan, K., Vais, A., Tomas, D., Drago, J., Horne, M.K., 2008. SK channel function regulates the dopamine phenotype of neurons in the substantia nigra pars compacta. Exp Neurol. 213, 419-30.

Bauer, A., Zilles, K., Matusch, A., Holzmann, C., Riess, O., von Horsten, S., 2005. Regional and subtype selective changes of neurotransmitter receptor density in a rat transgenic for the Huntington's disease mutation. J Neurochem. 94, 639-50.

Bernheimer, H., Birkmayer, W., Hornykiewicz, O., Jellinger, K., Seitelberger, F., 1973. Brain dopamine and the syndromes of Parkinson and Huntington. Clinical, morphological and neurochemical correlations. J Neurol Sci. 20, 415-55.

Bird, E.D., 1980. Chemical pathology of Huntington's disease. Annu Rev Pharmacol Toxicol. 20, 533-51.

Bird, E.D., Spokes, E.G., Iversen, L.L., 1980. Dopamine and noradrenaline in postmortem brain in Huntington's disease and schizophrenic illness. Acta Psychiatr Scand Suppl. 280, 63-73.

Cao, C., Temel, Y., Blokland, A., Ozen, H., Steinbusch, H.W., Vlamings, R., Nguyen, H.P., von Horsten, S., Schmitz, C., Visser-Vandewalle, V., 2006. Progressive deterioration of reaction time performance and choreiform symptoms in a new Huntington's disease transgenic ratmodel. Behav Brain Res. 170, 257-61.

de la Monte, S.M., Vonsattel, J.P., Richardson, E.P., Jr., 1988. Morphometric demonstration of atrophic changes in the cerebral cortex, white matter, and neostriatum in Huntington's disease. J Neuropathol Exp Neurol. 47, 516-25.

Haber, S.N., Fudge, J.L., 1997. The primate substantia nigra and VTA: integrative circuitry and function. Crit Rev Neurobiol. 11, 323-42.

HuntingtonStudyGroup, 1993. A novel gene containing a trinucleotide repeat that is expanded and unstable on Huntington's disease chromosomes. The Huntington's Disease Collaborative Research Group. Cell. 72, 971-83.

Huot, P., Levesque, M., Parent, A., 2007. The fate of striatal dopaminergic neurons in Parkinson's disease and Huntington's chorea. Brain. 130, 222-32.

Jakel, R.J., Maragos, W.F., 2000. Neuronal cell death in Huntington's disease: a potential role for dopamine. Trends Neurosci. 23, 239-45.

Joel, D., Weiner, I., 2000. The connections of the dopaminergic system with the striatum in rats and primates: an analysis with respect to the functional and compartmental organization of the striatum. Neuroscience. 96, 451-74.

Levesque, M., Bedard, A., Cossette, M., Parent, A., 2003. Novel aspects of the chemical anatomy of the striatum and its efferents projections. J Chem Neuroanat. 26, 271-81.

Mann, D.M., 1989. Subcortical afferent projection systems in Huntington's chorea. Acta Neuropathol. 78, 551-4. 
Mason, S.L., Barker, R.A., 2009. Emerging drug therapies in Huntington's disease. Expert Opin Emerg Drugs. 14, 273-97.

McLaughlin, B.A., Nelson, D., Erecinska, M., Chesselet, M.F., 1998. Toxicity of dopamine to striatal neurons in vitro and potentiation of cell death by a mitochondrial inhibitor. J Neurochem. 70, 2406-15.

Nguyen, H.P., Kobbe, P., Rahne, H., Worpel, T., Jager, B., Stephan, M., Pabst, R., Holzmann, C., Riess, O., Korr, H., Kantor, O., Petrasch-Parwez, E., Wetzel, R., Osmand, A., von Horsten, S., 2006. Behavioral abnormalities precede neuropathological markers in rats transgenic for Huntington's disease. Hum Mol Genet. 15, 3177-94.

Paul, G., Meissner, W., Rein, S., Harnack, D., Winter, C., Hosmann, K., Morgenstern, R., Kupsch, A., 2004. Ablation of the subthalamic nucleus protects dopaminergic phenotype but not cell survival in a rat model of Parkinson's disease. Exp Neurol. 185, 272-80.

Petersen, A., Puschban, Z., Lotharius, J., NicNiocaill, B., Wiekop, P., O'Connor, W.T., Brundin, P., 2002. Evidence for dysfunction of the nigrostriatal pathway in the R6/1 line of transgenic Huntington's disease mice. Neurobiol Dis. 11, 134-46.

Ravikumar, B., Vacher, C., Berger, Z., Davies, J.E., Luo, S., Oroz, L.G., Scaravilli, F., Easton, D.F., Duden, R., O'Kane, C.J., Rubinsztein, D.C., 2004. Inhibition of mTOR induces autophagy and reduces toxicity of polyglutamine expansions in fly and mouse models of Huntington disease. Nat Genet. 36, 585-95.

Reiner, A., Albin, R.L., Anderson, K.D., D'Amato, C.J., Penney, J.B., Young, A.B., 1988. Differential loss of striatal projection neurons in Huntington disease. Proc Natl Acad Sci U S A. 85, 5733-7.

Reynolds, G.P., Dalton, C.F., Tillery, C.L., Mangiarini, L., Davies, S.W., Bates, G.P., 1999. Brain neurotransmitter deficits in mice transgenic for the Huntington's disease mutation. J Neurochem. 72, 1773-6.

Rosas, H.D., Salat, D.H., Lee, S.Y., Zaleta, A.K., Pappu, V., Fischl, B., Greve, D., Hevelone, N., Hersch, S.M., 2008. Cerebral cortex and the clinical expression of Huntington's disease: complexity and heterogeneity. Brain. 131, 1057-68.

Schmitz, C., Rub, U., Korr, H., Heinsen, H., 1999. Nerve cell loss in the thalamic mediodorsal nucleus in Huntington's disease. II. Optimization of a stereological estimation procedure. Acta Neuropathol. 97, 623-8.

Schmitz, C., Hof, P.R., 2000. Recommendations for straightforward and rigorous methods of counting neurons based on a computer simulation approach. J Chem Neuroanat. 20, 93-114.

Schmitz, C., Hof, P.R., 2005. Design-based stereology in neuroscience. Neuroscience. 130, 813-31.

Sharp, A.H., Loev, S.J., Schilling, G., Li, S.H., Li, X.J., Bao, J., Wagster, M.V., Kotzuk, J.A., Steiner, J.P., Lo, A., et al., 1995. Widespread expression of Huntington's disease gene (IT15) protein product. Neuron. 14, 1065-74.

Spokes, E.G., 1980. Neurochemical alterations in Huntington's chorea: a study of postmortem brain tissue. Brain. 103, 179-210.

Temel, Y., Blokland, A., Steinbusch, H.W., Visser-Vandewalle, V., 2005. The functional role of the subthalamic nucleus in cognitive and limbic circuits. Prog Neurobiol. $76,393-413$. 
Temel, Y., Cao, C., Vlamings, R., Blokland, A., Ozen, H., Steinbusch, H.W., Michelsen, K.A., von Horsten, S., Schmitz, C., Visser-Vandewalle, V., 2006a. Motor and cognitive improvement by deep brain stimulation in a transgenic rat model of Huntington's disease. Neurosci Lett. 406, 138-41.

Temel, Y., Visser-Vandewalle, V., Kaplan, S., Kozan, R., Daemen, M.A., Blokland, A., Schmitz, C., Steinbusch, H.W., 2006b. Protection of nigral cell death by bilateral subthalamic nucleus stimulation. Brain Res. 1120, 100-5.

Temel, Y., Visser-Vandewalle, V., Kaplan, S., Kozan, R., Daemen, M.A., Blokland, A., Schmitz, C., Steinbusch, H.W., 2006c. Protection of nigral cell death by bilateral subthalamic nucleus stimulation. Brain Res. 1120, 100-105.

von Horsten, S., Schmitt, I., Nguyen, H.P., Holzmann, C., Schmidt, T., Walther, T., Bader, M., Pabst, R., Kobbe, P., Krotova, J., Stiller, D., Kask, A., Vaarmann, A., Rathke-Hartlieb, S., Schulz, J.B., Grasshoff, U., Bauer, I., Vieira-Saecker, A.M., Paul, M., Jones, L., Lindenberg, K.S., Landwehrmeyer, B., Bauer, A., Li, X.J., Riess, O., 2003. Transgenic rat model of Huntington's disease. Hum Mol Genet. $12,617-24$.

Vonsattel, J.P., Myers, R.H., Stevens, T.J., Ferrante, R.J., Bird, E.D., Richardson, E.P., Jr., 1985. Neuropathological classification of Huntington's disease. J Neuropathol Exp Neurol. 44, 559-77.

Vonsattel, J.P., DiFiglia, M., 1998. Huntington disease. J Neuropathol Exp Neurol. 57, 369-84.

Walker, F.O., 2007. Huntington's disease. Lancet. 369, 218-28.

Weiss, A., Abramowski, D., Bibel, M., Bodner, R., Chopra, V., DiFiglia, M., Fox, J., Kegel, K., Klein, C., Grueninger, S., Hersch, S., Housman, D., Regulier, E., Rosas, H.D., Stefani, M., Zeitlin, S., Bilbe, G., Paganetti, P., 2009. Single-step detection of mutant huntingtin in animal and human tissues: a bioassay for Huntington's disease. Anal Biochem. 395, 8-15.

West, M.J., Slomianka, L., Gundersen, H.J., 1991. Unbiased stereological estimation of the total number of neurons in thesubdivisions of the rat hippocampus using the optical fractionator. Anat Rec. 231, 482-97.

Yang, W., Dunlap, J.R., Andrews, R.B., Wetzel, R., 2002. Aggregated polyglutamine peptides delivered to nuclei are toxic to mammalian cells. Hum Mol Genet. 11, 2905-17.

Yohrling, G.J.t., Jiang, G.C., DeJohn, M.M., Miller, D.W., Young, A.B., Vrana, K.E., Cha, J.H., 2003. Analysis of cellular, transgenic and human models of Huntington's disease reveals tyrosine hydroxylase alterations and substantia nigra neuropathology. Brain Res Mol Brain Res. 119, 28-36. 


\title{
CHHAPPTCEER 5,
}

\section{"Phenoconversion" in experimental and clinical Huntington's disease}

Jahanshahi A, Vlamings R, van Roon-Mom W, Faull R, Waldvogel H, Steinbusch HW

and Temel Y

\begin{abstract}
The predominant motor symptom in Huntington' disease (HD) is chorea. The patho-anatomical basis for the chorea is not well known, but a link with the dopaminergic system has been suggested by human postmortem studies and clinical therapy studies. In a previous study, utilizing the transgenic rat model of HD ( $\operatorname{tgHD}$ ), we have shown that this hyperdopaminergic status resulted from a substantial increase in the number of dopamine containing cells in both the substantia nigra pars compacta and ventral tegmental area. Since we found no clear evidence for changes in the total cell numbers in the investigated regions, we reasoned that this increase had to be the result of a change in phenotype of the non-dopamine containing cells. We decided to study the dorsal raphe nucleus, which houses dopaminergic and non-dopaminergic neurons which are mainly serotonergic. In tissue containing dorsal raphe nucleus obtained from tgHD rats and HD patients, we performed stereological and semi-quantitative counting methods, respectively, and analyzed the number of dopamine and serotonin containing cells. Our results show that the number of dopamine containing cells is substantially increased in the
\end{abstract}


DRN of tgHD rats. Importantly, we have found this hyperdopaminergic status also in the DRN tissue of HD patients, establishing a consistency of the finding across species. In addition, we found a reduced number of serotonin containing cells. Using confocal microscopy and double-staining methods, we found no coexpression between dopaminergic and serotonergic phenotype in HD. Interestingly, the absolute gain in the dopaminergic phenotype was less than the loss of the serotonergic phenotype. Our findings suggest that the mutation in HD causes neurons to switch phenotypes which may underlie the clinical neurological symptoms and provide a novel mechanism for therapy development.

Submitted 


\section{Introduction}

Huntington's disease (HD) is an autosomal dominantly inherited progressive disorder, eventually leading to death (Huntington Study Group, 1993; Vonsattel and DiFiglia, 1998). The main symptoms are neurological and include motor and non-motor features. The predominant motor symptom is chorea, and to a lesser extent hypokinesia. The nonmotor symptoms consist of cognitive dysfunction leading to dementia and emotional instability. The chorea can be defined as an abrupt, rapid, brief, irregular and unsustained movement. The patho-anatomical basis for the chorea is not well known, but a link with the dopaminergic system has been suggested by human post-mortem studies and clinical therapy studies. Early post-mortem studies showed that striatal dopamine levels, both in the dorsal and ventral striatum were significantly higher in HD patients compared to controls (Bird, 1980; Bird et al., 1980; Spokes, 1980). In addition, clinical studies have shown that chorea can be treated with dopamine antagonist or dopamine depleting drugs (Mason and Barker, 2009).

In a previous study, utilizing the transgenic rat model of HD (tgHD), which is one of the few experimental models of HD showing chorea-like movements (Cao et al., 2006), we have investigated the origin of elevated dopamine levels in the striatum (Jahanshahi et al., 2010). Using antibodies raised against tyrosine hydroxylase $(\mathrm{TH})$, the rate-limiting enzyme in the synthesis of dopamine, levels of expression of $\mathrm{TH}$ in the dorsal and ventral parts of the striatum, and the number of $\mathrm{TH}$ containing cells in the substantia nigra pars compacta $(\mathrm{SNc})$ and the ventral tegmental area (VTA) were analyzed. The latter two regions are the main source of the nigrostriatal and mesolimbic dopaminergic input to the striatum, respectively (Haber and Fudge, 1997; Joel and Weiner, 2000). We found increased expression of TH in both the dorsal and ventral striatum of $\operatorname{tgHD}$ rats, in line with post-mortem clinical studies (Spokes, 1980; Bird, 1980). The origin of this increase in striatal $\mathrm{TH}$ resulted from a substantial 
increase in the number of $\mathrm{TH}$ containing cells in both the SNc and the VTA. Since, we found no clear evidence for changes in the total cell numbers in the investigated regions, and since it has been demonstrated that the total number of cells in the substantia nigra in postmortem HD brains was not different from age-matched controls (Mann, 1989), we hypothesized that the increased number of TH containing cells in the SNc and VTA had to be the result of a change in phenotype of the non-TH containing cells.

Evidence suggests that genetic causes, transcription factors and calcium-dependent signaling can determine neuronal phenotype (Marek et al., 2010; Velazquez-Ulloa et al., 2011). Whether the development of neuronal phenotypes is influenced by the mutation in HD is unknown. Here, we tested the hypothesis that the increase in the number of dopamine containing cells, as reported earlier (Jahanshahi et al.), is accompanied by a decrease of another cell type in the same brain region. We decided to study the dorsal raphe nucleus (DRN), which is a prototypical brain region housing different types of monoaminergic cell types. The dopamine containing cells of the DRN, belonging to the A10 dopaminergic cell group, project mainly to the ventral and to a lesser extent to the dorsal striatum (Descarries et al., 1986; Stratford and Wirtshafter, 1990) and coexist with serotonin containing cells. The latter form the largest group of monoaminergic cells within the DRN. We reasoned that the number of dopamine containing cells would be increased and the number of serotonin containing cells would be decreased. But, we also considered the possibility of serotonin containing cells to coexpress the dopaminergic phenotype de novo due to the HD mutation (Dulcis and Spitzer), and checked for this as well.

In tissue containing DRN obtained from tgHD rats and HD patients, we performed stereological and semi-quantitative counting methods, respectively, and analyzed the number of dopamine and serotonin containing cells. The dopamine containing cells were detected by immuno 
-histochemical methods with antibodies raised against $\mathrm{TH}$, as reported previously (Jahanshahi et al., 2010). Serotonin containing cells were identified immunohistochemically with antibodies directed against phenylalanine hydroxylase subtype 8 ( $\mathrm{PH} 8$ ), which is known to be a reliable marker in paraffin-embedded post-mortem human tissue (Haan et al., 1987; Tork et al., 1992; Underwood et al., 2007). However, in tissue obtained from the tgHD rats, we performed both PH8 and serotonin staining to be certain that the staining profiles were identical. We used double staining to evaluate the presence of coexpression between the dopaminergic and serotonergic phenotype and at the same time checked for potential cross-reactivity of PH8 with TH (Haan et al., 1987; Tork et al., 1992).

\section{Materials and Methods}

We will describe this section in two parts, the animal model and post-mortem human tissue work, thereby explaining methods of tissue collection, processing and analysis.

\section{Animal model}

Two groups of male rats were investigated: homozygous transgenic HD (tgHD) and wildtype littermates $(n=4)$, approximately 11 months old. After genotyping, all rats were transferred from the Friedrich-AlexanderUniversity Animal Facilities (Erlangen-Nürnberg, Germany) to the Central Animal Facilities of Maastricht University (Maastricht, The Netherlands) and housed there during the experiments in standard Makrolon ${ }^{\mathrm{TM}}$ cages on sawdust bedding in an air-conditioned room (about $20{ }^{\circ} \mathrm{C}$ ). Food, standard laboratory chow (Hopefarms, Woerden, The Netherlands), and water were available ad libitum. All experimental procedures were approved by the Animal Experiments and Ethics Committee of Maastricht University, Maastricht, The Netherlands.

Tissue collection 
The subjects were sacrificed after deep anesthesia with Nembutal $(75 \mathrm{mg} / \mathrm{kg})$ and the brains were quickly removed, followed by immersionfixation with $4 \%$ paraformaldehyde in $0.1 \mathrm{M}$ sodium phosphate buffer ( $\mathrm{pH}$ : 7.6). The duration of immersion-fixation was 48 hours, followed by overnight immersion in $15 \%$ sucrose for cryoprotection. Hereafter, the DRN of the brains was cut in 10 series of $30-\mu$ m-thick coronal freefloating sections on a cryostat (MICROM HM 520, Neuss, Germany) and stored at $-80{ }^{\circ} \mathrm{C}$ until processing for immunohistochemistry.

\section{Immunohistochemistry and quantitative analysis}

Tyrosine hydroxylase

To evaluate the number of TH containing cells, we processed sections containing the DRN for immunohistochemistry. This was carried out using rabbit anti-TH (diluted 1:1000, Protos Biotech Crop, New York, USA) as primary antibody for 24 hours. After rinsing steps with Trisbuffered solution and Triton X-100, and incubation with the secondary antibody (diluted 1:400 donkey anti-rabbit biotin; Jackson Immunoresearch Laboratories, West Grove, USA), the sections were incubated with an avidin-biotin-peroxidase complex (diluted 1:800, Elite ABC-kit, Vestastatin, Burlingame, USA). To visualize the horseradish peroxide reaction product, the sections were incubated with 3,3' diaminobenzidine tetrahydrochloride with nickel chloride enhancement. Finally, the sections were mounted and coverslipped using Pertex (Histolab Products ab, Goteborg, Sweden).

\section{Phenylalanine hydroxylase subtype 8}

To evaluate the number of PH8 containing cells in the DRN, we performed an immunohistochemical staining using mouse anti-PH8 (diluted 1:1000, Santa Cruz Biotechnology Inc, Santa Cruz, USA). Incubation in the primary antibody was for three days. The remaining steps including the secondary antibody (diluted 1:400, donkey anti-mouse biotin; Jackson Immunoresearch Laboratories, West Grove, USA), ABCstep, and the visualization of the horseradish peroxide reaction product, 
were similar to the TH staining as described above. The sections were then mounted and coverslipped using Pertex.

\section{Serotonin}

In the animal tissue we also performed direct serotonin staining to ensure that PH8 was staining serotonergic neurons. Since in the human tissue (see below) direct staining of serotonin was impossible and only PH8 immunohistochemistry was performed to detect serotonin-containing cells. Sections containing the DRN were incubated for three days with a rabbit anti-serotonin antibody (diluted 1:50000) (Steinbusch, 1981). The staining was completed using the secondary antibody donkey anti-rabbit biotin (diluted 1:400, Jackson Immunoresearch Laboratories, West Grove, USA), ABC-kit and visualization of the horseradish peroxide reaction product. Finally, the sections were mounted and coverslipped using Pertex.

Quantitative analysis of TH, PH8 and serotonin containing cells in the rat $D R N$

The immunohistochemically stained sections were used to evaluate the total number and volumes of TH, PH8, and serotonin containing cells within the DRN. All stereological investigations were carried out with a stereological computer microscopy system (Stereo Investigator, Microbrightfield Bioscience, Williston, USA). In all sections containing the DRN, the region comprising the $\mathrm{TH}, \mathrm{PH} 8$, or serotonin containing cells, was delineated and total cell numbers and cell volumes were estimated with the optical fractionator and nucleator (Schmitz and Hof, 2000; Schmitz and Hof, 2004; West et al., 1991).

Double staining tyrosine hydroxylase and phenylalanine hydroxylase subtype 8

To evaluate the presence of a possible coexpression of $\mathrm{TH}$ and $\mathrm{PH} 8$, we performed an immunofluorescent double-labeling study. Sections containing the DRN were incubated with rabbit anti-TH and mouse anti- 
PH8 primary antibodies for 24 hours and three days, respectively. After washing steps, brain sections were incubated with the secondary anitibodies donkey anti rabbit alexa 594 (1:400, Invitrogen, Breda, the Netherlands) and donkey anti mouse Alexa 488 (1:400, Invitrogen, Breda, the Netherlands). Sections were then washed, mounted on gelatine coated slides and coverslipped with $80 \%$ glycerol in TBS.

\section{Confocal microscopy to evaluate coexpression}

To evaluate the presence of possible coexpression of $\mathrm{TH}$ and $\mathrm{PH} 8$, sections containing the DRN double-labeled with $\mathrm{TH}$ and PH8 were analysed using immunofluorescence spinning disk confocal microscope (Olympus DSU BX51WI, Pennsylvania, USA). We used this staining also to check for the presence of a potential cross-reactivity between $\mathrm{TH}$ and PH8 antibodies. We found no evidence for cross-reactivity in tgHD rats and wildtype littermates

\section{Human brain tissue}

Tissue Collection

Brain tissue from 4 Huntington's disease cases and 4 controls (Table 1) was obtained from the Neurological Foundation of New Zealand Human Brain Bank. The Huntington's disease cases included 2 males and 2 females, with a post-mortem interval prior to perfusion between 11 and 15h. The control cases included 3 males and 1 female with no known history of neurological disease, with a post-mortem interval between 17 and $>25 \mathrm{~h}$. Brains were perfused as described previously (Waldvogel et al., 2006), blocks containing the DRN were collected and kept in the same fixative for at least $24 \mathrm{~h}$. followed by paraffin embedding. Finally, $8 \mu \mathrm{m}$ sections were cut and processed for immunohistochemistry.

\section{Immunohistochemistry}

Tyrosine hydroxylase

Human sections on glass slides containing the DRN were first deparaffinized by washings steps in xylene and ethanol. The staining protocol was similar to the one described for the animal tissue above. The 
sections were incubated for 48 hours with the primary antibody rabbit antiTH (1:1000 dilution, Protos Biotech Crop, New York), and followed by a secondary antibody, ABC-step and visualization of the horseradish peroxidase complex. Slides were washed, dehydrated and coverslipped using Pertex (Histolab Products ab, Goteborg, Sweden).

\section{Phenylalanine hydroxylase subtype 8}

Since direct staining of serotonin in post-mortem paraffin-embedded human tissue is very difficult, we performed PH8 imunohistochemistry to detect serotonin-containing cells. For this first antigen retrieval was performed. Sections were microwaved in $10 \mathrm{mM}$ citrate buffer ( $\mathrm{pH}$ 6.00) for $7 \mathrm{~min}$ (650 watt). After $1 \mathrm{~min}$, sections were microwaved for another 5 $\min (350$ watt).

The slides were incubated with the primary antibody mouse antiPH8 (1:1000 dilution, Santa Cruz biotechnolog) for a period of 7 days. The following steps were similar to the ones described for the animal tissue above. Finally slides were washed, dehydrated and coverslipped using Pertex (Histolab Products ab, Goteborg, Sweden).

\section{Semi-quantitative analysis of TH and PH8 containing cells in the human DRN}

We performed a systematic counting of the number of TH and PH8 containing cells in the human DRN at one anatomical level. We could not perform a stereological cell count and reliably measure cell volumes because of the limited availability of well-documented post-mortem human HD tissue containing the DRN and the fact that the sections were cut at $8 \mu \mathrm{m}$.

Cell counting was carried out using the same computer-controlled microscopy system as used for the stereological quantification of the tissue of the rat model (Stereo Investigator, Microbrightfield Bioscience, Williston, USA). In all sections showing the DRN, the regions of interest were delineated and numbers of cells were counted. 


\section{Statistical analysis}

Data are presented as means and standard errors of means (S.E.M.). The quantitative data of the total number of $\mathrm{TH}$, PH8, and serotonin containing cells and the volumes of the cells were analyzed using the Independent Samples T-test for both the animal and human work. All statistical analyses were performed with SPSS 15.0 version for Windows. P-values lower than 0.05 were considered significant.

\section{Results}

In line with Materials and Methods section, we will report results in two parts with data obtained from our transgenic animal followed by human studies.

\section{Animal model}

\section{Dopaminergic phenotype}

Qualitative inspection of the stained sections of the rat DRN showed considerably more TH containing cells (Figure 1). The mean number of TH containing cells was 2563 in the wildtype littermates and 4622 in the homozygous tgHD rats (Figure 2). The number of TH containing cells in the homozygous tgHD rats were significantly higher than in wildtype littermates $(\mathrm{t}=-2.66, \mathrm{P}<0.05)$.

The mean volumes of TH containing cells in the rat DRN were $1047 \mu \mathrm{m}^{3}$ in the wildtype littermates and $1662 \mu \mathrm{m}^{3}$ in the homozygous tgHD rats. The mean volumes were significantly higher in the homozygous $\operatorname{tgHD}$ rats in comparison with the wildtype littermates $(\mathrm{t}=$ 3.72, $\mathrm{P}<0.01$, Figure 2).

\section{Serotonergic phenotype}

Qualitative inspection also revealed a clear-cut change. We found fewer serotonin containing cells in DRN sections of the tgHD rats (Figure 3). Stereological cell counts revealed 25441 PH8 containing cells in the 
DRN of homozygous tgHD rats and 11150 in the DRN of wildtype littermates (Figure 4).

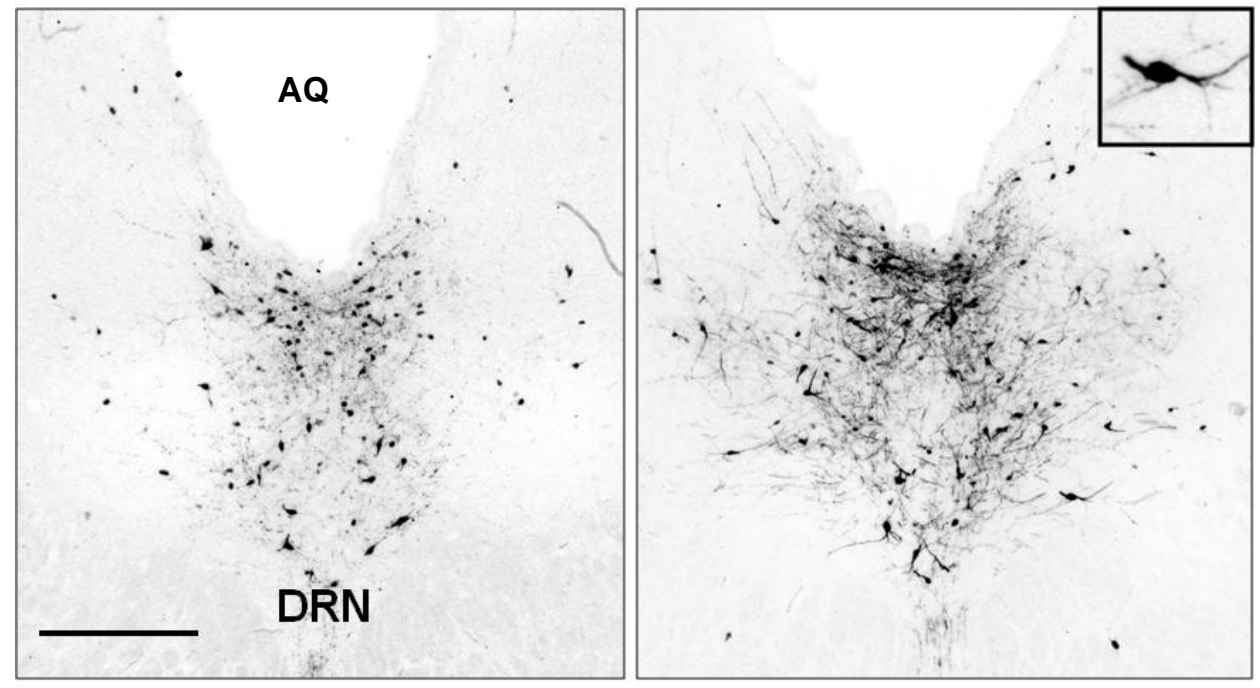

Figure 1. Representative low-power photomicrographs of coronal brain sections stained for tyrosine hydroxylase (TH) showing the dorsal raphe nucleus (DRN) and Aqueduct of Sylvius (AQ) of a wildtype littermate rat (left), and a transgenic HD homozygous (right) rat. Note the increased TH containing cell density in the DRN of the homozygous transgenic HD rats upon close inspection. The high power photomicrograph inset in the right upper corner shows a magnification of a TH containing cells of a transgenic homozygous rat. Scale bar is approximately $300 \mu \mathrm{m}$. The anatomical level is approximately anteroposterior $-8.0 \mathrm{~mm}$ from Bregma according to the Paxinos and Watson atlas of 1998.

The number of PH8 containing cells was substantially lower in the homozygous tgHD rats compared to wildtype littermates $(\mathrm{t}=6.19, \mathrm{P}<0.01)$. The mean volumes of PH8 containing cells in the DRN of homozygous tgHD rats was $2922 \mu \mathrm{m}^{3}$ and $3579 \mu^{3}$ in the DRN of wildtype littermates (Figure 4). These mean volumes were not significantly different between the two groups. 
In tissue from the rat model, we performed the direct serotonin staining. Although, the quality of this staining was less when compared to the PH8 staining, probably due to the fact that the rat tissue was not perfusion-fixed but immersion-fixed, we found a similar distribution pattern, cell count and cell volumes. This means that the PH8 staining reliably detects 5 -HT containing cells.
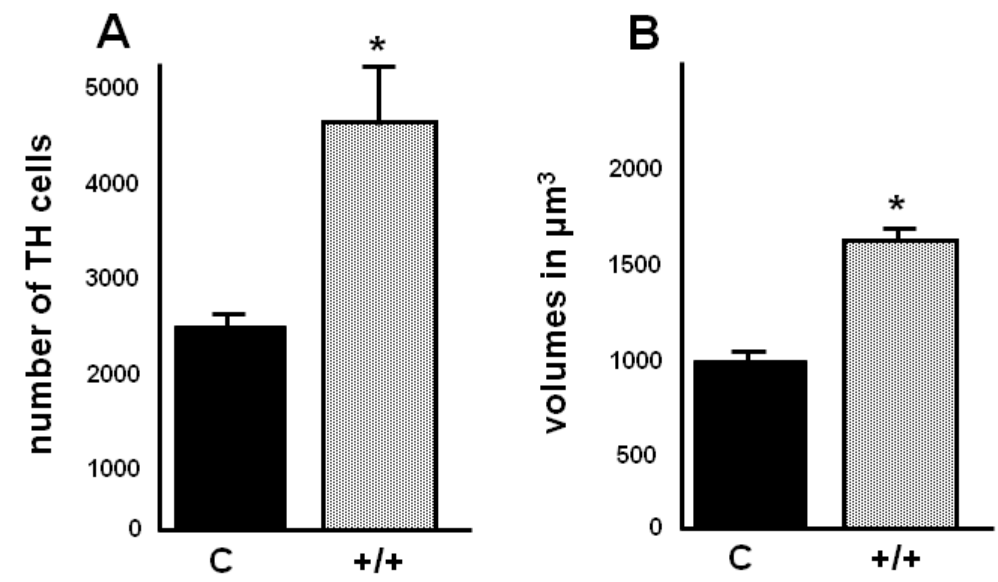

Figure 2. Cumulative data showing the means and SEM's of the number of TH containing cells (A) and of the cell volumes (B), in the rat dorsal raphe nucleus. Note that the homozygous $(+/+)$ transgenic HD rats have more TH containing neurons than the wildtype littermates and also greater cell volumes. Significant difference $(\mathrm{P}<0.05)$ is indicated by an $(*)$.

\footnotetext{
Coexpression between the dopaminergic and serotonergic phenotypes

Using double-labeling fluorescent immunohistochemical stainings and confocal microscopy, we evaluated qualitatively the existence of coexpression of PH8 and TH in the DRN of both wildtype littermates and homozygous tgHD rats. We found no evidence for coexpression of PH8 and TH (Figure 5).
} 


\section{Human brain tissue}

\section{Dopaminergic phenotype}

Qualitative inspection of the stained sections of the human DRN showed considerably more TH containing cells in the tissue from the HD patients (Figure 6). The mean number of $\mathrm{TH}$ containing cells was significantly higher in DRN of HD patients as compared to controls $(\mathrm{t}=$ 2.58, $\mathrm{P}<0.05$, Figure 7a).
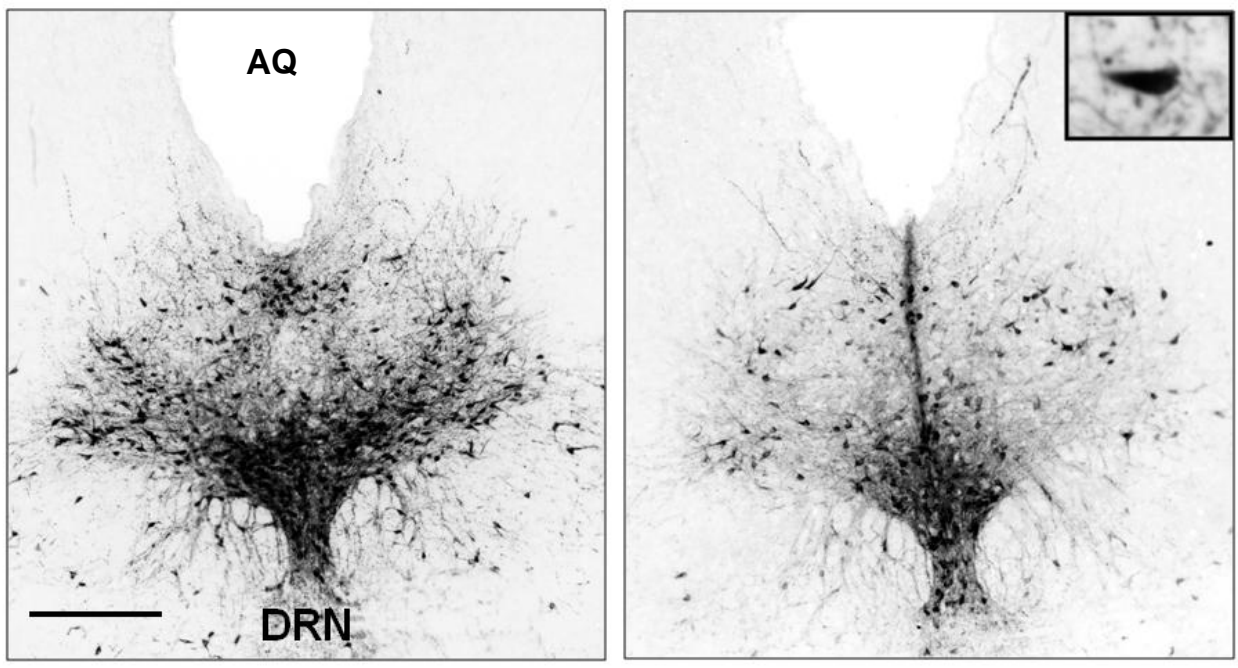

Figure 3. Representative low-power photomicrographs of coronal brain sections stained for phenylalanine hydroxylase subtype 8 (PH8), a reliable marker of serotonin containing cells, showing the dorsal raphe nucleus (DRN) and Aqueduct of Sylvius (AQ) of a wildtype littermate rat (right), and a transgenic HD homozygous (left) rat. Note the decreased PH8 containing cell density in the DRN of the homozygous transgenic HD rats. The high power photomicrograph inset in the right upper corner shows a magnification of a PH8 containing cells of a transgenic homozygous rat. Scale bar is approximately $300 \mu \mathrm{m}$. The anatomical level is approximately anteroposterior $-8.0 \mathrm{~mm}$ from Bregma according to the Paxinos and Watson atlas of 1998. 


\section{Serotonergic phenotype}

Qualitative inspection of the stained sections of the human DRN showed less PH8 containing cells in the tissue from the HD patients (Figure 8). The mean number of PH8 containing cells was substantially lower in DRN of HD patients than the controls $(t=-2.81, P<0.05$, Figure $7 b)$.
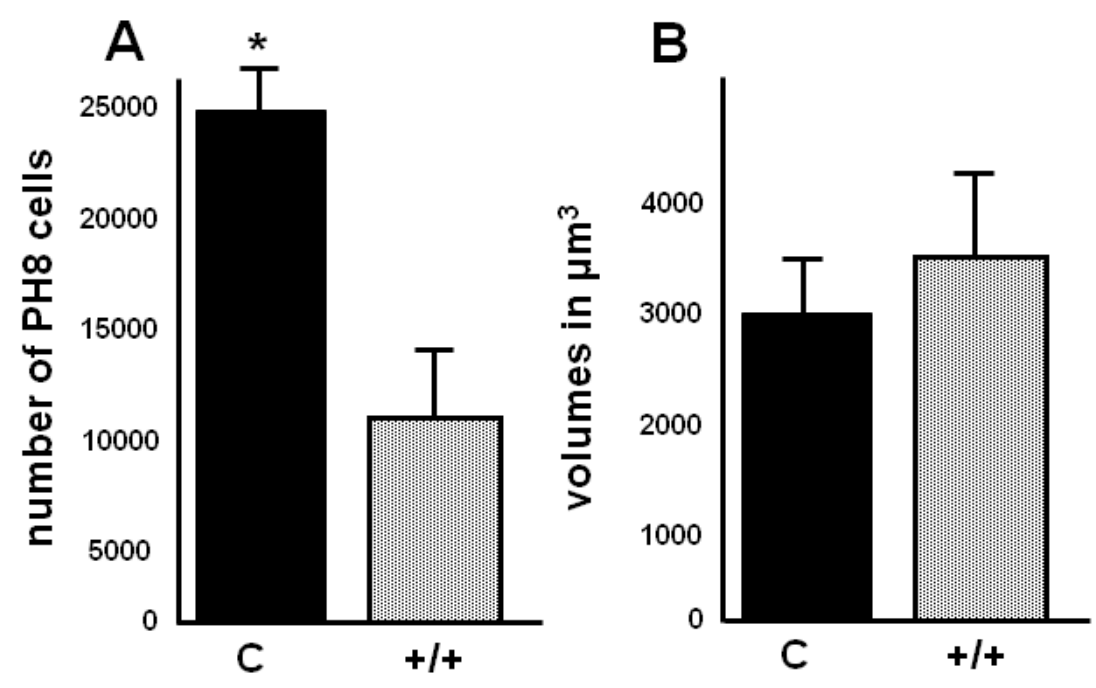

Figure 4. Cumulative data showing the means and SEM's of the number of PH8 containing cells (A) and of the cell volumes (B), in the rat dorsal raphe nucleus. Note that the homozygous $(+/+)$ transgenic HD rats have less PH8 containing neurons than the wildtype littermates, but similar cell volumes. Significant difference $(\mathrm{P}<0.05)$ is indicated by an $(*)$.

\section{Discussion}

Our results show that the number of $\mathrm{TH}$ containing cells is substantially increased in the DRN of tgHD rats. These data confirm our previously reported hyperdopaminergic status in this animal model of HD and extend these findings to a third dopaminergic cell group, besides the 
previously reported SNc and VTA (Jahanshahi et al., 2010). Importantly, we have found this hyperdopaminergic status also in the DRN tissue of HD patients, establishing a consistency of the finding across species. The consequence of increased number of dopamine containing neurons in the

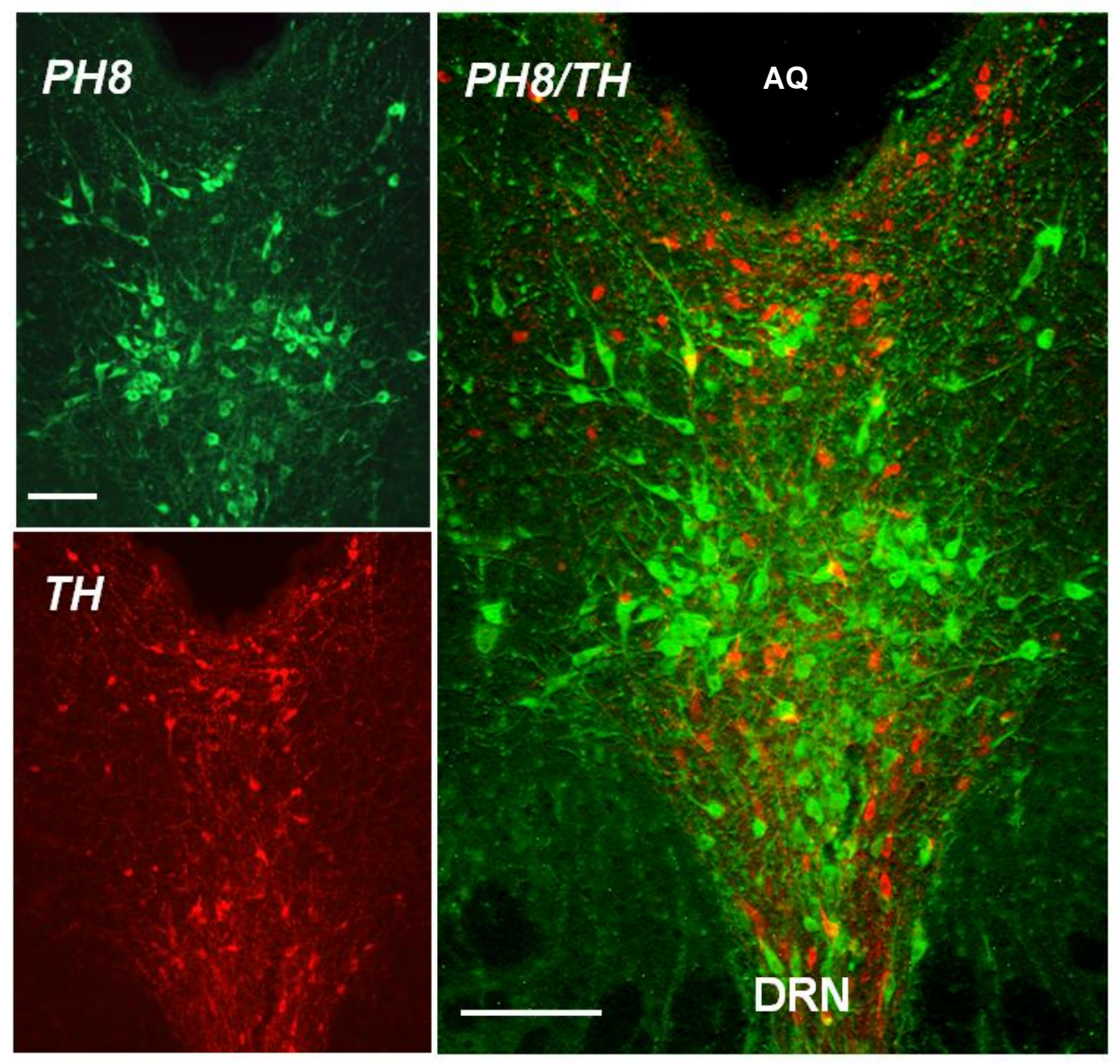

Figure 5. Representative low-power photomicrographs of coronal rat brain sections stained for PH8 and TH, and double-stained for PH8 and TH, showing the dorsal raphe nucleus (DRN) and Aqueduct of Sylvius (AQ.) of a transgenic HD homozygous $(+/+)$ rat. Note that we have not found any coexpression and cross-reactivity of PH8 and $\mathrm{TH}$ in the investigated cells of the DRN. Scale bar is approximately $100 \mu \mathrm{m}$. The anatomical level is approximately anteroposterior $-8.0 \mathrm{~mm}$ from Bregma according to the Paxinos and Watson atlas of 1998. 
DRN, which are known to project to both the dorsal and ventral striatum like the SNc and VTA, respectively, can be twofold. The first is that increased dopaminergic transmission in the striatum leads to hyperkinesias, so potentially to chorea. This hypothesis is supported by clinical data showing that the chorea can be treated with dopamineantagonists and dopamine-depleting drugs and that dopaminergic replacement therapy in Parkinson's disease patients leads to dyskinesias. The second consequence can be that higher concentrations of dopamine in the striatum lead to neurotoxicity and therefore plays a role in the pathogenesis of HD. Dopamine can auto-oxidize to form dopamine quinone, a reactive molecule which spontaneously decomposes to form additional reactive species that can induce cell damage (Jakel and Maragos, 2000; McLaughlin et al., 1998).
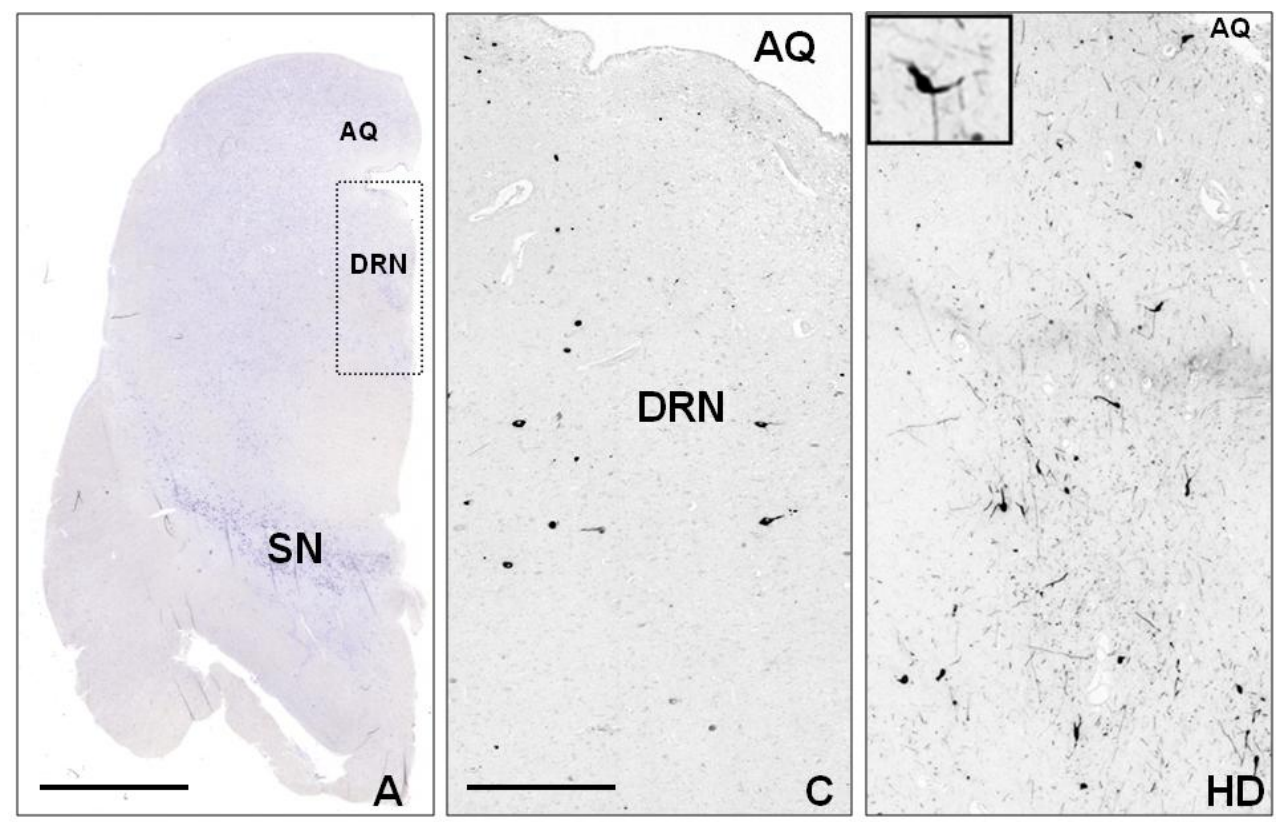
Figure 6. We performed a systematic counting of the number of cells in the human DRN at one anatomical level. This level is shown here with representative low-power photomicrographs of an axial brain section of half of the brainstem stained for Nissl (A) of a control patient (scale bar is approximately $4.2 \mathrm{~mm}$ ), including the dorsal raphe nucleus (DRN), Aqueduct of Sylvius (AQ), and substantia nigra (SN). In addition, we show representative low-power photomicrographs of axial brain sections stained for $\mathrm{TH}$ of a control ( $\mathrm{C}$, scale bar is approximately $0.5 \mathrm{~mm})$, and a HD specimen. In the HD specimen, only a small part of the AQ is shown in the right upper corner. Note the increased TH containing cell density in the DRN in the HD specimen. The high power photomicrograph inset in the left corner of the HD tissue shows a magnification of a TH containing cells from the DRN of the HD specimen.

We found an increased cell volume of $\mathrm{TH}$ containing cells in the DRN of tgHD rats. Generally, an increase in cell volume reflects either early stages of cell damage (cell swelling) or increased cell activity related hypertrophy. The latter would fit with the hypothesis of an increased dopaminergic output from the DRN towards the striatum. However, in our previous study examining the TH containing cells in the SNc and VTA, we found no increased cell volumes (Jahanshahi et al., 2010). Therefore, the relevance of this finding is unclear.
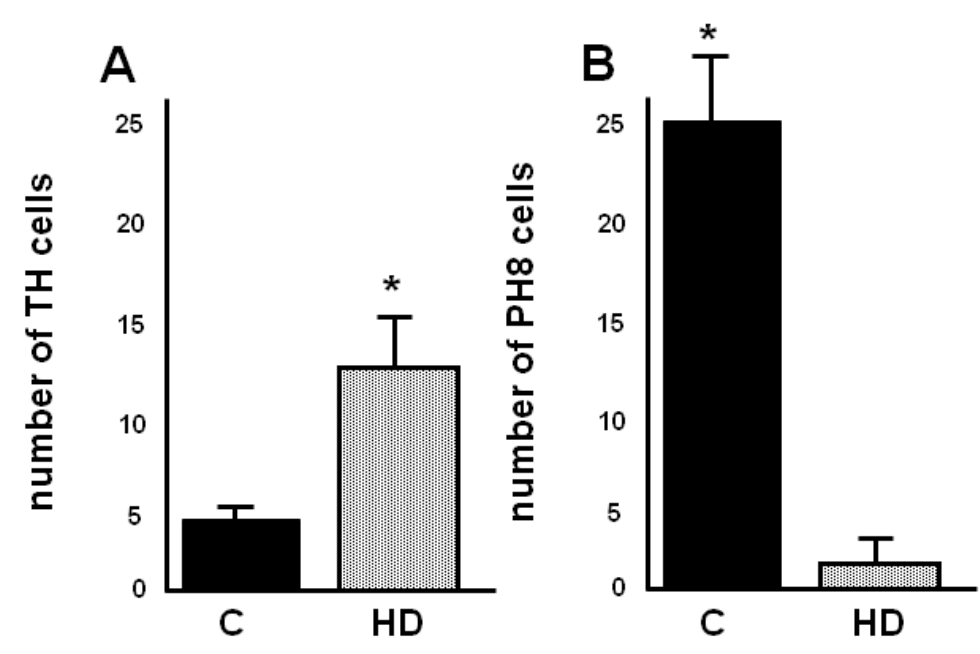
Figure 7. Cumulative data showing the means and SEM's of the number of TH containing cells (A) and the number of PH8 containing cells, in the dorsal raphe nucleus of controls and HD patients. Note that the DRN of the HD patients has more TH containing neurons and less PH8 containing neurons than the wildtype littermates. Significant difference $(\mathrm{P}<0.05)$ is indicated by an $(*)$.
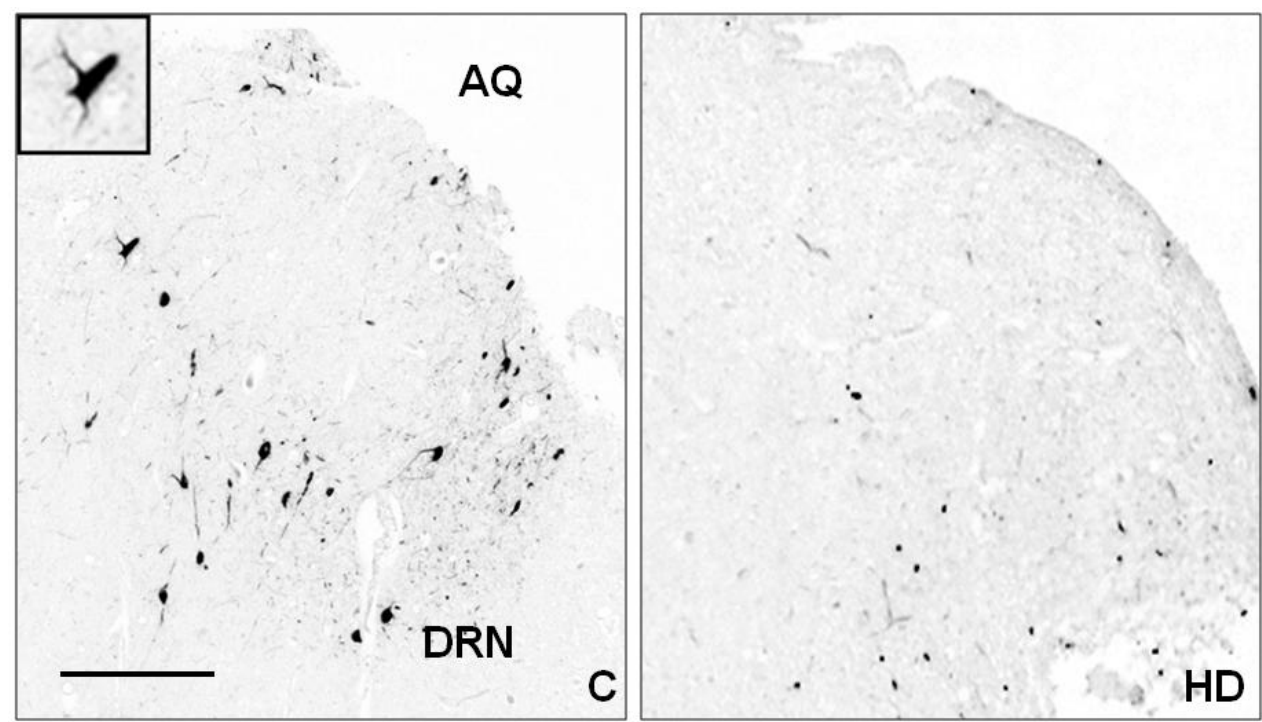

Figure 8. Representative low-power photomicrographs of axial brain sections stained for PH8 showing the half of the human dorsal raphe nucleus (DRN) and Aqueduct of Sylvius (AQ) of a control (C), and a HD specimen. Note the decreased PH8 containing cell density in the DRN in the HD specimen upon close inspection. The high power photomicrograph inset in the right upper corner shows a magnification of a $\mathrm{PH} 8$ containing cells from the DRN of the control specimen. Scale bar is approximately $0.5 \mathrm{~mm}$. The anatomical level is similar to the Nissl stained section shown in Figure 6.

Our results suggest that the increase in the number of dopaminergic cells in HD comes from a change in cell phenotype. We found in the DRN of tgHD rats and human post-mortem HD tissue, a reduced number of serotonergic and increased number of dopaminergic cells, in comparison to controls. Serotonin and dopamine containing cells coexist in the DRN and show no coexpression under physiological conditions. Using confocal 
microscopy and double-staining methods, we found no coexpression between dopaminergic and serotonergic phenotype in HD and control tissue. Interestingly, the absolute gain in the dopaminergic phenotype seems to be less than the loss of the serotonergic phenotype. This suggests that there is additional cell loss in serotonin containing cells in the DRN of $\operatorname{tgHD}$ animals. Since, the serotonin containing cells form the majority of the cells of the DRN (circa 60\%) (Fu et al., 2010), a substantial loss in this cell type should be obvious (Steinbusch, 1981). In a small study, we have quantitatively assessed the total number of cells in the DRN of tgHD rats and wildtype littermates using a Nissl staining. The total numbers were similar, approximately 40000 cells in both. This means there is no actual loss of cells in the DRN of tgHD rats. A provocative explanation can be that serotonin-containing cells are switching their phenotype not only to become dopamine-containing cells, but also to become another type of cell. This opens a new window for future investigation. Another explanation, which however seems unlikely, is the HD mutation may change the detection level of serotonin.

How can cells switch to the dopaminergic phenotype? There are generally two possible mechanisms: either a cell changes its phenotype entirely to a different phenotype, or a cell maintains its original phenotype but starts to coexpress de novo an unusual phenotype. Thus far, we have evidence for the first mechanism, but cannot rule out the second. Generally, dopaminergic neurons are a heterogeneous population expressing additional neurotransmitters such as GABA and/or neuropeptide Y (Velazquez-Ulloa et al., 2011). Using experimental models, several factors have been identified in the development of the dopaminergic phenotype such as Pax6 (Vitalis et al., 2000), Lim1,2 (Moreno et al., 2004), Nurr1 (Jankovic et al., 2005), and calcium spike activity (Velazquez-Ulloa et al., 2011). Calcium spike activity in turn controls the expression of the some of these factors. In recent studies transforming fibroblasts into dopaminergic neurons, the transcription factors Mash1, Lmx1a, FoxA2and Nurr 1 have been found to be critical (Caiazzo et al.; Pfisterer et al.). In experimental models or cell lines of 
$\mathrm{HD}$, evidence has been found for altered $\mathrm{Ca}^{2+}$ signaling, but this has been classically linked to striatal cell damage mechanisms (Bezprozvanny and Hayden, 2004; Tang et al., 2005; Zhang et al., 2008). It is possible that HD causes a change in the activity of one or more of these transcription factors encoding for dopaminergic neurotransmitter specification by a mechanism still to be unraveled.

\section{Conclusion}

In the transgenic rat model of HD and in postmortem human HD tissue, we found increased number of dopamine containing neurons and decreased number of serotonin neurons in the DRN. These findings suggest that the mutation in HD causes neurons to switch phenotypes which may underlie the clinical neurological symptoms and provide a novel mechanism for therapy development.

\section{Acknowledgements:}

YT received financial support by a grant from The Netherlands Organization for Scientific Research (NWO-Veni No: 016.096.032) and the Cure Huntington's disease Initiative. RF and HW have received financial support from the Neurological Foundation of New Zealand. WvRM received financial support from the Centre for Medical Systems Biology within the framework of the Netherlands Genomics Initiative/Netherlands Organization for Scientific Research and Dutch Centre for Biomedical Genetics. 


\section{References}

Bezprozvanny, I., Hayden, M.R., 2004. Deranged neuronal calcium signaling and Huntington disease. Biochem Biophys Res Commun. 322, 1310-7.

Bird, E.D., 1980. Chemical pathology of Huntington's disease. Annu Rev Pharmacol Toxicol. 20, 533-51.

Bird, E.D., Spokes, E.G., Iversen, L.L., 1980. Dopamine and noradrenaline in postmortem brain in Huntington's disease and schizophrenic illness. Acta Psychiatr Scand Suppl. 280, 63-73.

Caiazzo, M., Dell'anno, M.T., Dvoretskova, E., Lazarevic, D., Taverna, S., Leo, D., Sotnikova, T.D., Menegon, A., Roncaglia, P., Colciago, G., Russo, G., Carninci, P., Pezzoli, G., Gainetdinov, R.R., Gustincich, S., Dityatev, A., Broccoli, V., Direct generation of functional dopaminergic neurons from mouse and human fibroblasts. Nature.

Cao, C., Temel, Y., Blokland, A., Ozen, H., Steinbusch, H.W., Vlamings, R., Nguyen, H.P., von Horsten, S., Schmitz, C., Visser-Vandewalle, V., 2006. Progressive deterioration of reaction time performance and choreiform symptoms in a new Huntington's disease transgenic ratmodel. Behav Brain Res. 170, 257-61.

Descarries, L., Berthelet, F., Garcia, S., Beaudet, A., 1986. Dopaminergic projection from nucleus raphe dorsalis to neostriatum in the rat. J Comp Neurol. 249, 511-20, 484-5.

Dulcis, D., Spitzer, N.C., Reserve pool neuron transmitter respecification: Novel neuroplasticity. Dev Neurobiol.

Fu, W., Le Maitre, E., Fabre, V., Bernard, J.F., David Xu, Z.Q., Hokfelt, T., 2010. Chemical neuroanatomy of the dorsal raphe nucleus and adjacent structures of the mouse brain. J Comp Neurol. 518, 3464-94.

Haan, E.A., Jennings, I.G., Cuello, A.C., Nakata, H., Fujisawa, H., Chow, C.W., Kushinsky, R., Brittingham, J., Cotton, R.G., 1987. Identification of serotonergic neurons in human brain by a monoclonal antibody binding to all three aromatic amino acid hydroxylases. Brain Res. 426, 19-27.

Haber, S.N., Fudge, J.L., 1997. The primate substantia nigra and VTA: integrative circuitry and function. Crit Rev Neurobiol. 11, 323-42.

HuntingtonStudyGroup, 1993. A novel gene containing a trinucleotide repeat that is expanded and unstable on Huntington's disease chromosomes. The Huntington's Disease Collaborative Research Group. Cell. 72, 971-83.

Jahanshahi, A., Vlamings, R., Kaya, A.H., Lim, L.W., Janssen, M.L., Tan, S., VisserVandewalle, V., Steinbusch, H.W., Temel, Y., 2010. Hyperdopaminergic status in experimental Huntington disease. J Neuropathol Exp Neurol. 69, 910-7.

Jakel, R.J., Maragos, W.F., 2000. Neuronal cell death in Huntington's disease: a potential role for dopamine. Trends Neurosci. 23, 239-45.

Jankovic, J., Chen, S., Le, W.D., 2005. The role of Nurr1 in the development of dopaminergic neurons and Parkinson's disease. Prog Neurobiol. 77, 128-38.

Joel, D., Weiner, I., 2000. The connections of the dopaminergic system with the striatum in rats and primates: an analysis with respect to the functional and compartmental organization of the striatum. Neuroscience. 96, 451-74. 
Mann, D.M., 1989. Subcortical afferent projection systems in Huntington's chorea. Acta Neuropathol. 78, 551-4.

Marek, K.W., Kurtz, L.M., Spitzer, N.C., 2010. cJun integrates calcium activity and tlx3 expression to regulate neurotransmitter specification. Nat Neurosci. 13, 944-50.

Mason, S.L., Barker, R.A., 2009. Emerging drug therapies in Huntington's disease. Expert Opin Emerg Drugs. 14, 273-97.

McLaughlin, B.A., Nelson, D., Erecinska, M., Chesselet, M.F., 1998. Toxicity of dopamine to striatal neurons in vitro and potentiation of cell death by a mitochondrial inhibitor. J Neurochem. 70, 2406-15.

Moreno, N., Bachy, I., Retaux, S., Gonzalez, A., 2004. LIM-homeodomain genes as developmental and adult genetic markers of Xenopus forebrain functional subdivisions. J Comp Neurol. 472, 52-72.

Pfisterer, U., Kirkeby, A., Torper, O., Wood, J., Nelander, J., Dufour, A., Bjorklund, A., Lindvall, O., Jakobsson, J., Parmar, M., Direct conversion of human fibroblasts to dopaminergic neurons. Proc Natl Acad Sci U S A. 108, 10343-8.

Schmitz, C., Hof, P.R., 2000. Recommendations for straightforward and rigorous methods of counting neurons based on a computer simulation approach. J Chem Neuroanat. 20, 93-114.

Schmitz, C., Hof, P.R., 2004. Design-based stereology in neuroscience. Neuroscience. in press.

Spokes, E.G., 1980. Neurochemical alterations in Huntington's chorea: a study of postmortem brain tissue. Brain. 103, 179-210.

Steinbusch, H.W., 1981. Distribution of serotonin-immunoreactivity in the central nervous system of the rat-cell bodies and terminals. Neuroscience. 6, 557-618.

Stratford, T.R., Wirtshafter, D., 1990. Ascending dopaminergic projections from the dorsal raphe nucleus in the rat. Brain Res. 511, 173-6.

Tang, T.S., Slow, E., Lupu, V., Stavrovskaya, I.G., Sugimori, M., Llinas, R., Kristal, B.S., Hayden, M.R., Bezprozvanny, I., 2005. Disturbed Ca2+ signaling and apoptosis of medium spiny neurons in Huntington's disease. Proc Natl Acad Sci U S A. 102, 2602-7.

Tork, I., Halliday, G.M., Cotton, R.G., 1992. Application of antiphenylalanine hydroxylase antibodies to the study of the serotonergic system in the human brain. J Chem Neuroanat. 5, 311-3.

Underwood, M.D., Mann, J.J., Arango, V., 2007. Morphometry of dorsal raphe nucleus serotonergic neurons in alcoholism. Alcohol Clin Exp Res. 31, 837-45.

Velazquez-Ulloa, N.A., Spitzer, N.C., Dulcis, D., 2011. Contexts for dopamine specification by calcium spike activity in the CNS. J Neurosci. 31, 78-88.

Vitalis, T., Cases, O., Engelkamp, D., Verney, C., Price, D.J., 2000. Defect of tyrosine hydroxylase-immunoreactive neurons in the brains of mice lacking the transcription factor Pax6. J Neurosci. 20, 6501-16.

Vonsattel, J.P., DiFiglia, M., 1998. Huntington disease. J Neuropathol Exp Neurol. 57, 369-84.

West, M.J., Slomianka, L., Gundersen, H.J., 1991. Unbiased stereological estimation of the total number of neurons in thesubdivisions of the rat hippocampus using the optical fractionator. Anat Rec. 231, 482-97. 
CHAPTER 5

Zhang, H., Li, Q., Graham, R.K., Slow, E., Hayden, M.R., Bezprozvanny, I., 2008. Full length mutant huntingtin is required for altered $\mathrm{Ca} 2+$ signaling and apoptosis of striatal neurons in the YAC mouse model of Huntington's disease. Neurobiol Dis. $31,80-8$. 



\title{
CHHIA.PTTEER 6,
}

\section{Close communication between the subependymal serotonergic plexus and the neurogenic subventricular zone.}

\author{
Jahanshahi A, Temel Y, Lim LW, Hoogland G and Steinbusch HW
}

\begin{abstract}
Although many studies have appeared on the mechanisms of neurogenesis in the adult mammalian central nervous system, the challenge remains to identify the factors controlling this process. Among numerous factors, which have been described to influence neurogenesis, serotonin (5-hydroxytryptamine, 5-HT) has received considerable attention. 5-HT drug manipulations and their effects on neurogenesis have revealed that 5-HT contributes to adult neurogenesis. An interesting but relatively unexplored attribute is the presence of an extensive plexus of 5HT containing fibers in the subventricular zone, one of two main neurogenic brain structures. A dense layer of 5-HT fibers overlaps the subventricular zone, separating this region from the adjacent structures of the lateral ventricle. This close anatomical relationship suggests an important functional role for 5-HT in influencing cell proliferation in the subventricular zone. Here, we review the literature and propose that subependymal plexus is part of an intrinsic brain mechanism which controls the subventricular zone cell proliferative capacity by modulating 5-HT release.
\end{abstract}

Journal of Chemical Neuroanatomy, 2011 



\section{Introduction}

Neurogenesis is the process of generating new neurons from populations of stem and progenitor cells. Stem cells reside in distinct areas of the brain, and after the proliferation stage, their progeny migrate to target regions and eventually differentiate into specific neuronal cell types. Ultimately, these newly formed neuronal cells are incorporated into existing neuronal cell populations, and integrate into mature neuronal circuits (Alvarez-Buylla et al., 2001; Temple, 2001). For decades it was believed that only gliogenesis took place under certain conditions and generation of new neurons seemed to be unlikely in adult brain. However, the discovery of the method of labeling dividing cells with tritiated thymidine (Sidman et al., 1959) and few decades later with 5bromodihydroxyuridin (BrdU) provided new ways to trace dividing cells in the central nervous system (CNS) and presented evidence that neurons are continuously generated in the adult mammalian brain (Luskin, 1993). Neurogenesis plays a crucial role in the maintenance of brain functioning and is more and more targeted in the search for novel therapies for neurodegenerative diseases, like Parkinson's and Alzheimer's disease, and diseases with profound cell loss such as stroke or brain contusion (Abdipranoto et al., 2008; Arvidsson et al., 2002).

Neurogenesis occurs mainly at two sites in the mammalian brain, in the dorsolateral walls of the lateral ventricles, known as the subventricular zone (SVZ), and in the subgranular zone (SGZ) of the dentate gyrus (DG) of the hippocampal formation (Luskin 1993; Eriksson, 2007; van Praag et al., 2002). Interestingly, neurogenesis has been reported to be a more widespread phenomenon with progenitor cells giving rise to new neurons in other adult brain regions such as the CA1 area of the hippocampus (Rietze et al., 2000), amygdala (Bernier et al., 2002), substantia nigra (Zhao et al., 2008) hypothalamus (Kokoeva et al., 2005), third ventricle, and neocortex (Gould et al., 1999; Xu et al., 2005; Zhao et al., 2003) for review see also Migau et al. (2010). Although, it has been suggested that in certain conditions such as stroke, ischemia or exposure to growth 
factors, these apparently "dormant" progenitor cells may become activated and form new neuronal cells (Darsalia et al., 2005; Lichtenwalner and Parent, 2006), there is only few direct evidence showing the activation of neurnal progenitors out of adult germinal regions in pathological situation (Ohira et al., 2010). The functional significance of these multi-site phenomena are under debate. In this review, we will focus on the SVZ.

Many studies have appeared on the mechanism of the formation of new cells in the SVZ. However, the challenge remains to identify the factors controlling this process. In this respect, an interesting but relatively unexplored factor is the presence of 5-hydroxytryptamine (5-HT, serotonin). As demonstrated in Figure 1, the SVZ is densely innervated with 5-HT containing fibers. Therefore, this region is referred as the subependymal 5-HT complex. These 5-HT fibers originate from the dorsal raphe nucleus (DRN) and the median raphe nucleus (MNR) (Figure 2). In line with this, high levels of 5-HT have been measured in the SVZ (ChanPalay, 1976) and while 5-HT fibers are present along all ventricles, the highest densities have been found along the lateral ventricles neighboring the SVZ (Steinbusch, 1981). This close anatomical relationship predicts an important functional role for 5-HT to influence cell proliferation in the SVZ. Interestingly, lesioning the dorsal raphe nucleus 5-HT system using specific neurotoxin against 5-HT neurons reduces the proliferation of progenitor cells in the SVZ. These suggest a direct controlling role for 5HT from the subependymal 5-HT fibers on neurogenesis in this germinal region (Brezun and Daszuta, 1999). In addition, 5-HT has a direct effect on the survival of SVZ derived neuronal stem cells in vitro (Hitoshi et al., 2007). This hypothesis is indirectly supported by the results of pharmacological studies. Selective serotonin reuptake inhibitors (SSRIs) and other 5-HT active drugs, given to enhance central 5-HT levels, can induce neurogenesis in animal models (Nandam et al., 2007; Newton and Duman, 2007; Banasr and Duman, 2007). While these are extrinsic enhancers of 5-HT function, we hypothesize that the subependymal plexus is the brain's intrinsic 5-HT mechanism to control SVZ's cell proliferation capacity. While 5-HT drug manipulations and their effects on neurogenes- 


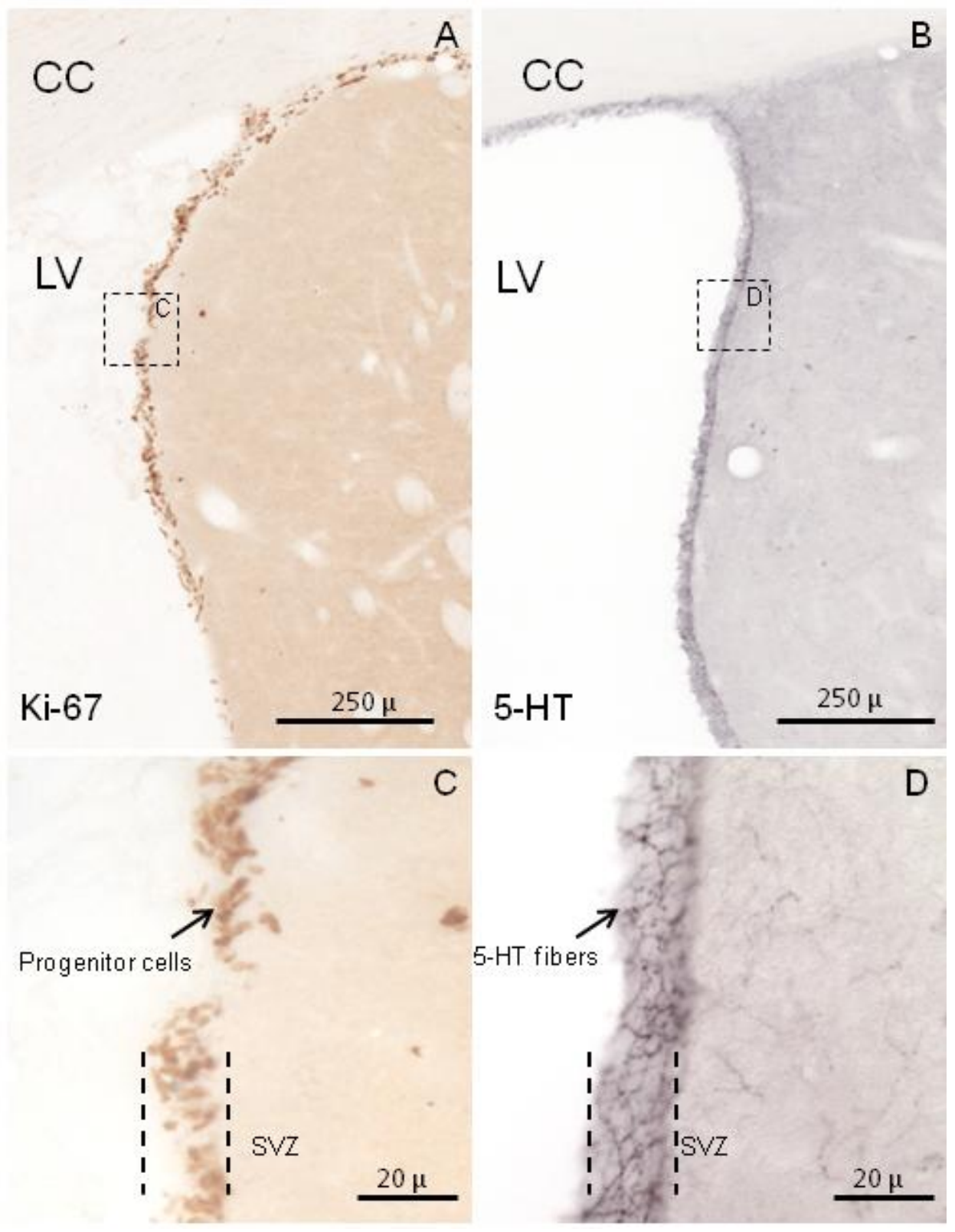

Figure 1. Representative photomicrographs of coronal sections of the rat brain showing the subventricular zone (SVZ) stained for Ki-67 (A and C), a widely used marker for cell proliferation, and 5-hydroxytryptamine (B and D). Figures A and B are low-power and figures $\mathrm{C}$ and $\mathrm{D}$ are high power photomicrographs. Figures $\mathrm{C}$ and $\mathrm{D}$ show 
the delineated areas in figures A and B, respectively, in detail. Note the dense 5-HT containing fiber network around the proliferating cells in the SVZ. Other surrounding anatomical structures are corpus callosum (CC) and lateral ventricle (LV).

-is have received much attention, the interaction between subependymal 5HT innervation and the SVZ has received little attention. Here, we review the latter interaction in detail.

\section{The neuroanatomy of the subependymal 5-HT plexus}

The brainstem DRN and MRN, cell groups B7 and B8, respectively according to Dahlstrom and Fuxe (1964), are the main source of forebrain 5-HT innervation (Michelsen et al., 2007 and 2008; Steinbusch et al., 1980 and 1981; Steinbusch, 1981). The SVZ forms a complex of cells topographically organized with respect to the lateral ventricles (Mikkelsen et al., 1997; Simpson et al., 1998; Aghajanian and Gallager, 1975; O'Hearn and Molliver, 1984). There is a fine network of varicose axons underneath the ependymal layer. Many of these fibers extend into the ependyma forming a plexus within the ventricular wall (Moore and Speh, 2004; Richards and Tranzer, 1974). During evolution mammals have lost their CSF-containing 5-HT cells in the ependymal wall. However, these 5HT cells have been replaced in mammals by the prominent 5-HT fiber and buttons complex along the ventricular wall (Smeets and Reiner, 1994; Steinbusch and Nieuwenhuys, 1983). The development of the 5-HT complex along the lateral ventricles takes place in first two weeks after birth. During this period, fibers become thinner, longer, expressing a high number of varicosities and get intermingled to form a dense plexus (Dinopoulos and Dori, 1995; Lidov and Molliver, 1982). This 5-HT plexus in primates is reported less dense in comparison to rodents (Richards and Tranzer, 1974). Interestingly, some of the 5-HT projections to the SVZ have a band-like pattern of innervation, which is different from the pattern of 5-HT projections to the neighboring striatum (Simpson et al., 1998). This pattern is thought to play an important role in creating a highly localized microenvironment, the so called niche (Hagg, 2005) (Figure 3). 
The SVZ 5-HT complex is a unique structure, but its exact functional significance still remains unclear. Naturally, some hypotheses exist. Besides its involvement in neurogenesis, its relation to the cerebro-spinal fluid (CSF) system is of interest. Varicosities of 5-HT fibers innervating the SVZ appear to regulate variety of ependymal activities. Secreted 5-HT from the fibers has been shown to increase intracellular metabolism in the ependymal epithelium (Prothmann et al., 2001) and in turn increases the frequency of ciliary beats (Nguyen et al., 2001). Ependymal cells have been observed to facilitate the "sink" action of CSF by removing various numbers of molecules including 5-HT when CSF passes through the parenchymal extracellular space into the ventricles (Verleysdonk et al., 2004).

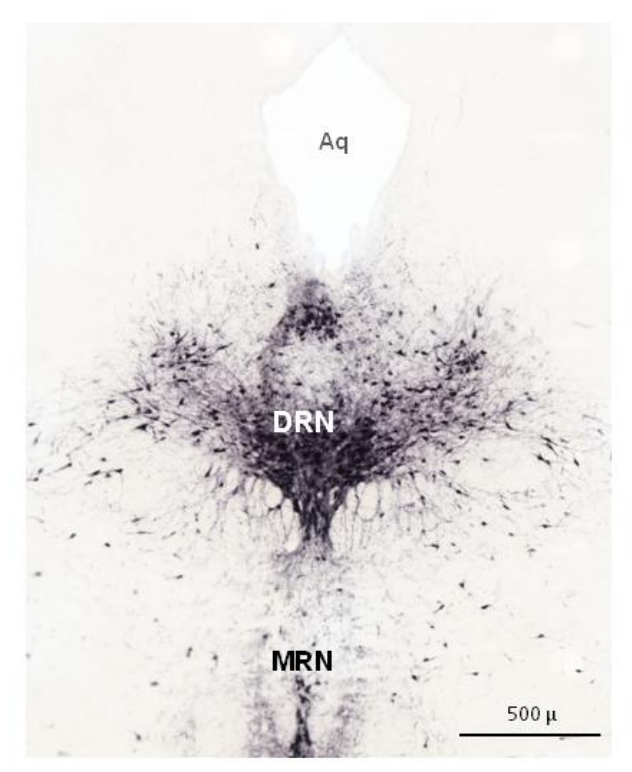

Figure $2 . \quad$ Representative
photomicrographs of frontal sections of
the rat brain stained for tryptophan
hydroxylase (TPH), the rate limiting
enzyme in 5-hydroxytryptamine (5-HT,
serotonin) production, showing the TPH
containing in the dorsal raphe (DRN) and
median raphe (MRN) nuclei.

Specific reuptake capacity of extracellular 5-HT has also been suggested for astrocytes in the SVZ (Del Bigio, 1995; Verleysdonk et al., 2004). Early observations showed that 5-HT fibers penetrate the ependymal layer to form a so-called supraependymal complex (Chan 
Palay, 1976; Matsuura et al., 1985; Sano et al., 1982; Richards et al., 1973), but in later studies this was not confirmed (Dinopoulos and Dori, 1995).

Whether the 5-HT fibers in SVZ make classical synaptic and/or synaptic contacts with stem cells, transit amplifying cells (type C) or with neuroblasts (type A), remains to be determined. An alternative route for the action of 5-HT can be diffusion. It has been shown that 5-HT released at varicosities and exocytotic release sites can be transported by diffusion to sites of action (Cloft and Mitchell, 1997; Descarries et al., 1975).

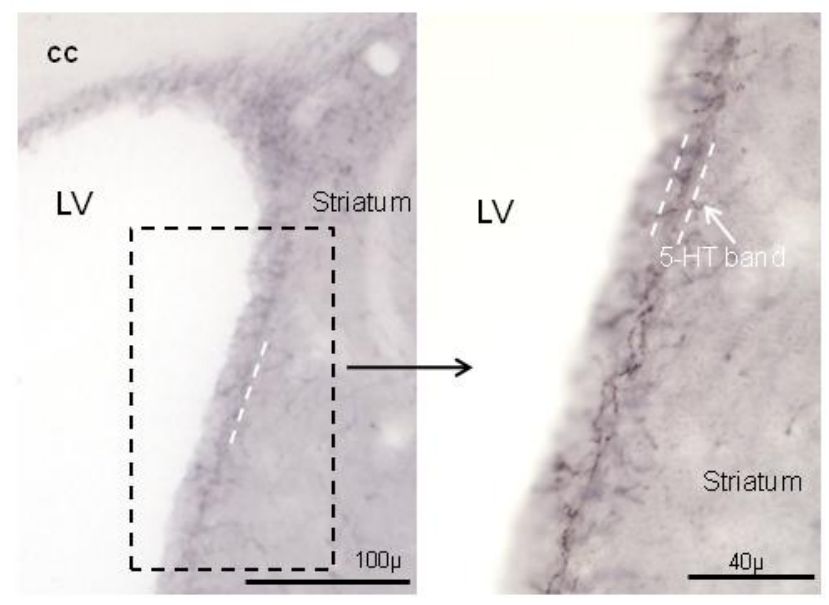

Figure 3. Low-power photomicrographs of rat coronal sections containing the subventricular zone (SVZ) stained for 5-HT. Figures show the presence of highly localized band like pattern of 5-HT containing fibers (dashed lines) aligning the SVZ.

\section{Neuronal proliferation in the SVZ}

Neuronal stem cells are primitive cells with multipotent properties possessing proliferation (self-renewal) and differentiation abilities to generate neuronal and non-neuronal cells in the central nervous system. Stem cells have been described to have the capacity to divide indefinitely. Due to the self-renewal ability of stem cells, they give rise to several orders of progeny magnitude and appear to be able to generate three main cell types including: neurons, astrocytes, and oligodendrocytes (Reynolds 
and Rietze, 2005). Progenitor cells are the intermediate daughter cells with limited capacity of self-renewal and proliferative characteristics and due to restricted properties, these cells can only give rise to a more limited variety of cell types (Bull and Bartlett, 2005; Seaberg and van der Kooy, 2002). Stem and progenitor cells in the SVZ consist of three major types (Doetsch et al., 1997) (Fig. 4). Type "A" cells are known as migratory neuroblasts which are mainly targeting the olfactory bulb. Type B cells are generally glial fibrilary acidic protein (GFAP) positive astrocytes, surrounding the migration channels. Type "B" cells which surround the migration channels resemble the ultrastructural morphology of astrocytes and generally express GFAP. Along this migration channel, young type A neuroblasts migrate rostrally in a chain shape pattern towards the rostral migratory stream (RMS) and from there continue towards the olfactory bulb (OB). Type B cells are self-renewing multipotent precursors of newly formed neurons. They are in fact regional neural stem cells that give rise to type $\mathrm{C}$ cells, which in turn develop into migratory type : A" neuroblasts (Taupin 2006; Lovell-Badge, 2001; Doetsch et al., 1999). According to Doetsch and Hen, (2005), the adult SVZ contains the highest number of stem and progenitor cells.

Type A neuroblasts gives rise to neurons by new immature neurons, the so-called neuroblasts. They migrate from the SVZ through the RMS till the $\mathrm{OB}$ as mentioned as "tangential migration" and then migrate radially to the most external OB layers including not only the glomerular layer (periglomerular cells), but also the granule cell layer, which accounts for the large majority of SVZ newborn neurons. These cells become integrated within the neuronal circuitry of the $\mathrm{OB}$ and become for instance interneurons expressing the inhibitory transmitter $\gamma$-aminobutyric acid (GABA) and/or the modulatory transmitter dopamine (Lledo et al., 2006 and 2008; Menezes et al., 1995). The ultrastructural architecture of the adult rodent RMS has been well described by Whitman and Greer, (2009). However the RMS appears not to be the only route for migration. Migration of progenitors into the overlying white matter and cortex and striatum has been reported in rodents as well (Zerlin et al., 1995). 
Moreover, studies have demonstrated migration of newly generated neurons from SVZ to the substantia nigra in mice (Zhao et al., 2003), and frontal cortex in macaque monkeys (Gould et al., 1999). Additionally, neuroblasts have been shown to migrate from the SVZ to the amygdala in the rabbit (Luzzati et al., 2003). In humans, the exact location of the neural stem cells is yet to be determined. However, the presence of stem cells has only been reported in the wall of the anterior horn and body of the lateral ventricles (Quinones-Hinojosa et al., 2006). Although, the migration of neuroblasts from SVZ to olfactory bulb has been reported in the human brain (Eriksson, 2007), in adult primates it is still debated whether the rostral migration of neuroblasts really exists (Curtis et al., 2007). Moreover, migratory neuroblasts in rodents form chains of migratory cells toward the $\mathrm{OB}$ and in primates they migrate more or less individually (Quinones-Hinojosa et al., 2006). It is important to note that under physiological conditions, SVZ cells in all mammals so far investigated (with few exceptions, i.e., humans) are fated to become exclusively OB interneurons.

An interesting but provocative opinion is that stem cells in SVZ underlie neurogenesis in DG, the other main neurogenic region of the adult brain. As evidence multipotent stem cells have been isolated from the subventricular zone of the posterior periventricular area $(\mathrm{pLV})$ near the vicinity of the hippocampus. Experimental data have demonstrated that these stem cells in the $\mathrm{pLV}$ divide and give rise to neuroblasts that migrate over a very short distance from the SVZ into the SGZ neurogenic site (Bull and Bartlett 2005; Doetsch et al., 1999; Seaberg et al., 2002). Moreover, tracing of the caudal SVZ neuronal stem cells has demonstrated that they reach the CA1 region of the hippocampus, and differentiate into pyramidal neurons (Nakatomi et al., 2002).

\section{5-HT and neuronal proliferation in the SVZ}

The role of 5-HT in the development and regulation of adult neurogenesis has generally received more attention than other 
monoamines (Djavadian, 2004; Gaspar et al., 2003). 5-HT neurotransmission appears to be among one of the earliest to be developed in the fetal brain (Djavadian, 2004; Lauder and Krebs, 1978; Vaidya et al., 2007) and has been described as a phylogenetically ancient neurotransmitter (Azmitia, 2001). 5-HT plays an essential role in the vertebrate brain development. It regulates its shape and patterns of neuronal connectivity (Lauder, 1990; Wesemann, 1978; Whitaker-Azmitia et al., 1996). 5-HT is also known to induce synaptogenesis (Lipton and Kater, 1989), electrogenesis (Lessmann and Dietzel, 1991) and neurite outgrowth (Lieske et al., 1999; Mercer et al., 1996). It also plays a pivotal relevant role in the survival of neuronal circuits and synapses in the adult brain (Moriizumi et al., 1994; Okado et al., 1993).

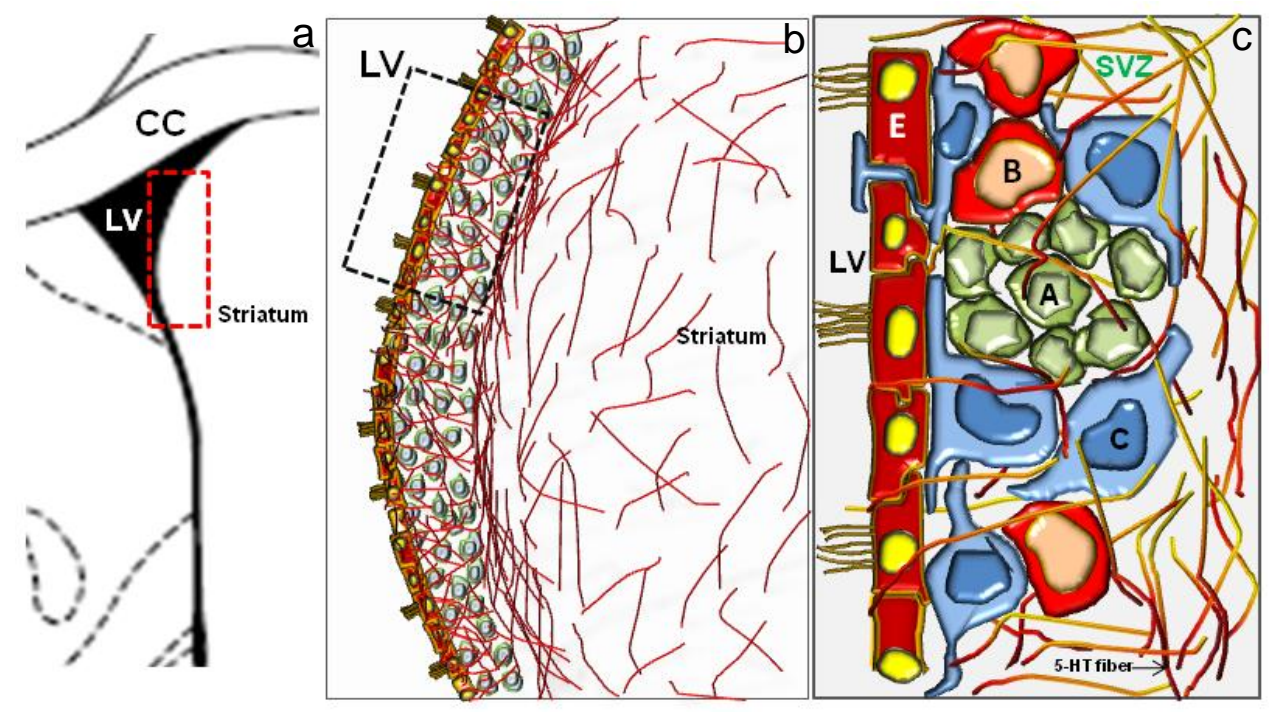

Figure 4. A schematic representation of the microstructure of the subventricular zone (SVZ); (a) the anatomical position of the SVZ from a coronal view. (b), a higher magnitude schematic view is given of the stem/progenitor cells, 5-hydroxytrytamine fibers and ependymal cells in the SVZ. (c), a detailed schematic overview is given of the relationship between the type " $\mathrm{A}$ " migratory neuroblasts (A), type " $\mathrm{B}$ " neuronal stem cell (B), type " $C$ " neuronal progenitor cell $(C)$, ependymal cell $(E)$, lateral ventricle (LV) and 5- hydroxytryptamine fibers (5-HT), (CC) corpus callosum". 
Lesion studies have shown that lesioning the raphe 5-HT neurons reduces the number of cells in the SVZ, suggesting a direct controlling role for 5-HT from the subependymal 5-HT fibers (Brezun and Daszuta, 1999). In a recent study, increase in proliferation of SVZ derived cells was found by administration of 5-HT (Cheng et al 2010). Interestingly, higher concentrations of 5-HT reduced the proliferative capacity, suggesting a potential fine-tuning effect for 5-HT. The influence of 5-HT on proliferation of cells has also been reported in in vivo studies (Lauder and Krebs, 1978, Gaspar et al., 2003).

Although the expression of functional 5-HT receptors in the SVZ cells is not entirely known yet, data from in vivo experiments using 5-HT receptor agonists and antagonists have shown the neurogenic effects to be (partly) mediated by the 5-HT1A and 5-HT2C receptors. Activation of the 5-HT1A and 5-HT2C receptors in the choroid plexus by systemic administration of agonists, 8-OH-DPAT (8-hydroxy-2-N-propylamino) tetralin and RO600175 respectively, caused a 50\% increase in cell proliferation in the rat SVZ (Banasr et al., 2004; Soumier et al., 2010). It has been shown that activation of 5-HT receptors in the choroid plexus, including the 5-HT2C receptor, by agonists or direct infusion of 5-HT into the ventricles, stimulates the secretion of growth factors such as FGF-2 (Hitoshi et al., 2007). These neurotrophins can enhance the proliferation in the SVZ. The notion that 5-HT2C receptors have distinct functional properties of inverse agonistic activity (Barker et al., 1994), may explain the observations concerning the fine-tuning effect of 5-HT on neuronal proliferation in the SVZ. This perhaps happens due to constitutive activity of the 5-HT2C receptors in the choroid plexus by ambient 5-HT released from serotonergic terminals in the SVZ into the CSF. The 5-HT1B antagonist GR127935 also enhanced SVZ cell proliferation, while the 5HT1B agonist sumatriptan exerted the opposite effect. In addition, systemic administration of the 5-HT2A agonist DOI (2,5-dimethoxy-4iodophenyl-2-aminopropane) increased cell proliferation in the SVZ (Banasr et al., 2004), the same was the case for buspirone, a 5HT1A receptor partial agonist (Grabiec et al., 2009). 
Selective serotonin reuptake inhibitors (SSRI), which are widely used to treat mood disorders, have been shown to enhance cell proliferation in animal models (Lau et al., 2007). Interestingly, atypical neuroleptics such as haloperidol, paliperidon and risperidone, which have the potential the block some 5-HT receptors, have the capacity to increase cell proliferation in the SVZ as well (Green et al., 2006; Nasrallah et al., 2010; Wakade et al., 2002). This makes the situation on the effect of 5-HT receptors rather complicated. In addition to experimental studies, in schizophrenic patients treated with olanzapine enhancement of cell proliferation was found in the forebrain (Lieberman et al., 2005).

\section{Conclusion}

The presence of a dense 5-HT fiber complex in the vicinity of the stem cells of the SVZ is an intriguing anatomical fact. This close anatomical relationship suggests an important functional role for 5-HT in influencing cell proliferation in the SVZ. It remains unsolved how 5-HT released by terminals in the subependymal complex reaches the cells in the SVZ. There are two possibilities: direct synaptic contact and diffusion. Synaptic contact has not been found, but we have to bear in mind that it has not been investigated in detail yet. Diffusion of 5-HT to the neighboring stem cells is a plausible mechanism. It might well be that both mechanism exist and are activated depending on the action required. In this respect, evidence suggest a fine-tuning effect of 5-HT on cell proliferation, enhanced by lower concentrations and decreased by higher levels.

Acknowledgements: This study was supported by grants from the FP6 Marie Curie Fellowship (MEST-CT-2005-020589), the Netherlands Organization for Scientific Research (NWO-Veni, grant no: 016.096.032) and Dutch Brain Foundation (Hersenstichting Nederland, grant no: 2009.2.26). We would like to bring special thanks for discussions to Prof. Dr. David Hopkins from Dalhousie University, Halifax, Canada. 


\section{References}

Abdipranoto, A., Wu, S., Stayte, S., Vissel, B., 2008. The role of neurogenesis in neurodegenerative diseases and its implications for therapeutic development. CNS Neurol Disord Drug Targets. 7, 187-210.

Aghajanian, G.K., Gallager, D.W., 1975. Raphe origin of serotonergic nerves terminating in the cerebral ventricles. Brain Res. 88, 221-31.

Alvarez-Buylla, A., Garcia-Verdugo, J.M., Tramontin, A.D., 2001. A unified hypothesis on the lineage of neural stem cells. Nat Rev Neurosci. 2, 28793.

Arvidsson, A., Collin, T., Kirik, D., Kokaia, Z., Lindvall, O., 2002. Neuronal replacement from endogenous precursors in the adult brain after stroke. Nat Med. 8, 963-70.

Azmitia, E.C., 2001. Modern views on an ancient chemical: serotonin effects on cell proliferation, maturation, and apoptosis. Brain Res Bull. 56, 413-24.

Banasr, M., Hery, M., Printemps, R., Daszuta, A., 2004. Serotonin-induced increases in adult cell proliferation and neurogenesis are mediated through different and common 5-HT receptor subtypes in the dentate gyrus and the subventricular zone. Neuropsychopharmacology. 29, 45060.

Banasr, M., Duman, R.S., 2007. Regulation of neurogenesis and gliogenesis by stress and antidepressant treatment. CNS Neurol Disord Drug Targets. 6, $311-20$

Barker, E.L., Westphal, R.S., Schmidt, D., Sanders-Bush, E., 1994. Constitutively active 5 hydroxytryptamine $2 \mathrm{C}$ receptors reveal novel inverse agonist activity of receptor ligands. J Biol Chem. 269, 1168711690.

Bernier, P.J., Bedard, A., Vinet, J., Levesque, M., Parent, A., 2002. Newly generated neurons in the amygdala and adjoining cortex of adult primates. Proc Natl Acad Sci U S A. 99, 11464-9.

Brezun, J.M., Daszuta, A., 1999. Depletion in serotonin decreases neurogenesis in the dentate gyrus and the subventricular zone of adult rats. Neuroscience. 89, 999-1002.

Bull, N.D., Bartlett, P.F., 2005. The adult mouse hippocampal progenitor is neurogenic but not a stem cell. J Neurosci. 25, 10815-21.

Chan-Palay, V., 1976. Serotonin axons in the supra- and subependymal plexuses and in the leptomeninges; their roles in local alterations of cerebrospinal fluid and vasomotor activity. Brain Res. 102, 103-30.

Cheng, A., Scott, A.L., Ladenheim, B., Chen, K., Ouyang, X., Lathia, J.D., Mughal, M., Cadet, J.L., Mattson, M.P., Shih, J.C., 2010. Monoamine oxidases regulate telencephalic neural progenitors in late embryonic and early postnatal development. J Neurosci. 30, 10752-62. 
Cloft, H.J., Mitchell, J.A., 1997. Serotonergic innervation of the supraependymal neuronal complex of the golden hamster. Brain Res. 761, 210-6.

Curtis, M.A., Kam, M., Nannmark, U., Anderson, M.F., Axell, M.Z., Wikkelso, C., Holtas, S., van Roon-Mom, W.M., Bjork-Eriksson, T., Nordborg, C., Frisen, J., Dragunow, M., Faull, R.L., Eriksson, P.S., 2007. Human neuroblasts migrate to the olfactory bulb via a lateral ventricular extension. Science. 315, 1243-9.

Dahlstrom, A., Fuxe, K., 1964. Localization of monoamines in the lower brain stem. Experientia. 20, 398-9.

Darsalia, V., Heldmann, U., Lindvall, O., Kokaia, Z., 2005. Stroke-induced neurogenesis in aged brain. Stroke. 36, 1790-5.

Del Bigio, M.R., 1995. The ependyma: a protective barrier between brain and cerebrospinal fluid. Glia. 14, 1-13.

Descarries, L., Beaudet, A., Watkins, K.C., 1975. Serotonin nerve terminals in adult rat neocortex. Brain Res. 100, 563-88.

Djavadian, R.L., 2004. Serotonin and neurogenesis in the hippocampal dentate gyrus of adult mammals. Acta Neurobiol Exp (Wars). 64, 189-200.

Doetsch, F., Alvarez-Buylla, A., 1996. Network of tangential pathways for neuronal migration in adult mammalian brain. Proc Natl Acad Sci U S A. 93, 14895-900.

Doetsch, F., Garcia-Verdugo, J.M., Alvarez-Buylla, A., 1997. Cellular composition and three-dimensional organization of the subventricular germinal zone in the adult mammalian brain. J Neurosci. 17, 5046-61.

Doetsch, F., Caille, I., Lim, D.A., Garcia-Verdugo, J.M., Alvarez-Buylla, A., 1999. Subventricular zone astrocytes are neural stem cells in the adult mammalian brain. Cell. 97, 703-16.

Doetsch, F., Hen, R., 2005. Young and excitable: the function of new neurons in the adult mammalian brain. Curr Opin Neurobiol. 15, 121-8.

Eriksson, P.S., 2007. Human neuroblasts migrate to the olfactory bulb via a lateral ventricular extension. Science. 315, 1243-9.

Gaspar, P., Cases, O., Maroteaux, L., 2003. The developmental role of serotonin: news from mouse molecular genetics. Nat Rev Neurosci. 4, 1002-12.

Grabiec, M., Turlejski, K., Djavadian, R.L., 2009. The partial 5-HT1A receptor agonist buspirone enhances neurogenesis in the opossum (Monodelphis domestica). Eur. Neuropsychopharmacol. 19, 431-439.

Green, W., Patil, P., Marsden, C.A., Bennett, G.W., Wigmore, P.M., 2006. Treatment with olanzapine increases cell proliferation in the subventricular zone and prefrontal cortex. Brain Res. 1070, 242-5.

Gould, E., Reeves, A.J., Graziano, M.S., Gross, C.G., 1999. Neurogenesis in the neocortex of adult primates. Science. 286, 548-52. 
Hitoshi, S., Maruta, N., Higashi, M., Kumar, A., Kato, N., Ikenaka, K., 2007. Antidepressant drugs reverse the loss of adult neural stem cells following chronic stress. J Neurosci Res. 85(16), 3574-85.

Hagg, T., 2005. Molecular regulation of adult CNS neurogenesis: an integrated view. Trends Neurosci. 28, 589-95.

Kokoeva, M.V., Yin, H., Flier, J.S., 2005. Neurogenesis in the hypothalamus of adult mice: potential role in energy balance. Science. 310, 679-83.

Lau, W.M., Qiu, G., Helmeste, D.M., Lee, T.M., Tang, S.W., So, K.F., Tang, S.W., 2007. Corticosteroid decreases subventricular zone cell proliferation, which could be reversed by paroxetine. Restor Neurol Neurosci. 25, 17-23.

Lauder, J.M., Krebs, H., 1978. Serotonin as a differentiation signal in early neurogenesis. Dev Neurosci. 1, 15-30.

Lauder, J.M., 1990. Ontogeny of the serotonergic system in the rat: serotonin as a developmental signal. Ann N Y Acad Sci. 600, 297-313; discussion 314.

Lessmann, V., Dietzel, I.D., 1991. Development of serotonin-induced ion currents in identified embryonic Retzius cells from the medicinal leech (Hirudo medicinalis). J Neurosci. 11, 800-9.

Lichtenwalner, R.J., Parent, J.M., 2006. Adult neurogenesis and the ischemic forebrain. J Cereb Blood Flow Metab. 26, 1-20.

Lidov, H.G., Molliver, M.E., 1982. An immunohistochemical study of serotonin neuron development in the rat: ascending pathways and terminal fields. Brain Res Bull. 8, 389-430.

Lieberman, J.A., Tollefson, G.D., Charles, C., Zipursky, R., Sharma, T., Kahn, R.S., Keefe, R.S., Green, A.I., Gur, R.E., McEvoy, J., Perkins, D., Hamer, R.M., Gu, H., Tohen, M., 2005. Antipsychotic drug effects on brain morphology in first-episode psychosis. Arch Gen Psychiatry. 62, 361-70.

Lieske, V., Bennett-Clarke, C.A., Rhoades, R.W., 1999. Effects of serotonin on neurite outgrowth from thalamic neurons in vitro. Neuroscience. 90, 96774.

Lipton, S.A., Kater, S.B., 1989. Neurotransmitter regulation of neuronal outgrowth, plasticity and survival. Trends Neurosci. 12, 265-70.

Lledo, P.M., Alonso, M., Grubb, M.S., 2006. Adult neurogenesis and functional plasticity in neuronal circuits. Nat Rev Neurosci. 7, 179-93.

Lledo, P.M., Merkle, F.T., Alvarez-Buylla, A., 2008. Origin and function of olfactory bulb interneuron diversity. Trends Neurosci. 31, 392-400.

Lovell-Badge, R., 2001. The future for stem cell research. Nature. 414, 88-91.

Luskin, M.B., 1993. Restricted proliferation and migration of postnatally generated neurons derived from the forebrain subventricular zone. Neuron. 11, 173-89. 
Luzzati, F., Peretto, P., Aimar, P., Ponti, G., Fasolo, A., Bonfanti, L., 2003. Gliaindependent chains of neuroblasts through the subcortical parenchyma of the adult rabbit brain. Proc Natl Acad Sci U S A. 100, 13036-41.

Matsuura, T., Takeuchi, Y., Kojima, M., Ueda, S., Yamada, H., Nojyo, Y., Ushijima, K., Sano, Y., 1985. Immunohistochemical studies of the serotonergic supraependymal plexus in the mammalian ventricular system, with special reference to the characteristic reticular ramification. Acta Anat (Basel). 123, 207-19.

Menezes, J.R., Smith, C.M., Nelson, K.C., Luskin, M.B., 1995. The division of neuronal progenitor cells during migration in the neonatal mammalian forebrain. Mol Cell Neurosci. 6, 496-508.

Mercer, A.R., Kirchhof, B.S., Hildebrand, J.G., 1996. Enhancement by serotonin of the growth in vitro of antennal lobe neurons of the sphinx moth Manduca sexta. J Neurobiol. 29, 49-64.

Michelsen, K.A., Schmitz, C., Steinbusch, H.W., 2007. The dorsal raphe nucleus-from silver stainings to a role in depression. Brain Res Rev. 55, 329-42.

Michelsen, K.A., Prickaerts, J., Steinbusch, H.W., 2008. The dorsal raphe nucleus and serotonin: implications for neuroplasticity linked to major depression and Alzheimer's disease. Prog Brain Res. 172, 233-64.

Mikkelsen, J.D., Hay-Schmidt, A., Larsen, P.J., 1997. Central innervation of the rat ependyma and subcommissural organ with special reference to ascending serotoninergic projections from the raphe nuclei. J Comp Neurol. 384, 556-68.

Moore, R.Y., Speh, J.C., 2004. Serotonin innervation of the primate suprachiasmatic nucleus. Brain Res. 1010, 169-73.

Migaud, M., Batailler, M., Segura, S., Duittoz, A., Franceschini, I., Pillon, D., 2010. Emerging new sites for adult neurogenesis in the mammalian brain: a comparative study between the

hypothalamus and the classical neurogenic zones. Erop J Neurosci. 32, 20422052.

Moriizumi, T., Tsukatani, T., Sakashita, H., Miwa, T., 1994. Olfactory disturbance induced by deafferentation of serotonergic fibers in the olfactory bulb. Neuroscience. 61, 733-8.

Nakatomi, H., Kuriu, T., Okabe, S., Yamamoto, S., Hatano, O., Kawahara, N., Tamura, A., Kirino, T., Nakafuku, M., 2002. Regeneration of hippocampal pyramidal neurons after ischemic brain injury by recruitment of endogenous neural progenitors. Cell. 110, 429-41.

Nandam, L.S., Jhaveri, D., Bartlett, P., 2007. 5-HT7, neurogenesis and antidepressants: a promising therapeutic axis for treating depression. Clin Exp Pharmacol Physiol. 34, 546-51. 
Nasrallah, H.A., Hopkins, T., Pixley, S.K., 2010. Differential effects of antipsychotic and antidepressant drugs on neurogenic regions in rats. Brain Res. 1354, 23-29.

Newton, S.S., Duman, R.S., 2007. Neurogenic actions of atypical antipsychotic drugs and therapeutic implications. CNS Drugs. 21, 715-25.

Nguyen, T., Chin, W.C., O'Brien, J.A., Verdugo, P., Berger, A.J., 2001. Intracellular pathways regulating ciliary beating of rat brain ependymal cells. J Physiol. 531, 131-40.

O'Hearn, E., Molliver, M.E., 1984. Organization of raphe-cortical projections in rat: a quantitative retrograde study. Brain Res Bull. 13, 709-26.

Okado, N., Cheng, L., Tanatsugu, Y., Hamada, S., Hamaguchi, K., 1993. Synaptic loss following removal of serotoninergic fibers in newly hatched and adult chickens. J Neurobiol. 24, 687-98.

Prothmann, C., Wellard, J., Berger, J., Hamprecht, B., Verleysdonk, S., 2001. Primary cultures as a model for studying ependymal functions: glycogen metabolism in ependymal cells. Brain Res. 920, 74-83.

Quinones-Hinojosa, A., Sanai, N., Soriano-Navarro, M., Gonzalez-Perez, O., Mirzadeh, Z., Gil-Perotin, S., Romero-Rodriguez, R., Berger, M.S., Garcia-Verdugo, J.M., Alvarez-Buylla, A., 2006. Cellular composition and cytoarchitecture of the adult human subventricular zone: a niche of neural stem cells. J Comp Neurol. 494, 415-34.

Reynolds, B.A., Rietze, R.L., 2005. Neural stem cells and neurospheres--reevaluating the relationship. Nat Methods. 2, 333-6.

Richards, J.G., Lorez, H.P., Tranzer, J.P., 1973. Indolealkylamine nerve terminals in cerebral ventricles: identification by electron microscopy and fluorescence histochemistry. Brain Res. 57, 277-88.

Richards, J.G., Tranzer, J.P., 1974. Ultrastructural evidence for the localization of an indolealkylamine in supra-ependymal nerves from combined cytochemistry and pharmacology. Experientia. 30, $287-9$.

Rietze, R., Poulin, P., Weiss, S., 2000. Mitotically active cells that generate neurons and astrocytes are present in multiple regions of the adult mouse hippocampus. J Comp Neurol. 424, 397-408.

Sano, Y., Takeuchi, Y., Yamada, H., Ueda, S., Goto, M., 1982. Immunohistochemical studies on the serotonergic innervation of the pia mater. Histochemistry. 76, 277-80.

Seaberg, R.M., van der Kooy, D., 2002. Adult rodent neurogenic regions: the ventricular subependyma contains neural stem cells, but the dentate gyrus contains restricted progenitors. J Neurosci. 22, 1784-93.

Sidman, R.L., Miale, I.L., Feder, N., 1959. Cell proliferation and migration in the primitive ependymal zone: an autoradiographic study of histogenesis in the nervous system. Exp Neurol. 1, 322-33. 
Simpson, K.L., Fisher, T.M., Waterhouse, B.D., Lin, R.C., 1998. Projection patterns from the raphe nuclear complex to the ependymal wall of the ventricular system in the rat. J Comp Neurol. 399, 61-72.

Smeets, W.J.A.J., Reiner, A., 1994. Phylogeny and Development of Catecholamine Systems in the CNS of Vertebrates., Vol., Cambridge University Press, Cambridge.

Steinbusch, H.W., van der Kooy, D., Verhofstad, A.A., Pellegrino, A., 1980. Serotonergic and non-serotonergic projections from the nucleus raphe dorsalis to the caudate-putamen complex in the rat, studied by a combined immunofluorescence and fluorescent retrograde axonal labeling technique. Neurosci Lett. 19, 137-42.

Steinbusch, H.W., 1981. Distribution of serotonin-immunoreactivity in the central nervous system of the rat-cell bodies and terminals. Neuroscience. $6,557-618$.

Steinbusch, H.W.M., Nieuwenhuys, R., 1983. The raphe nuclei of the rat brainstem: a cytoarchitectonic and immunohistochemical study. In: Chemical Neuroanatomy. Vol., P.C. Emson, ed.^eds. Raven Press, New York, pp. 131-207.

Taupin, P., 2006. Neurogenesis in the adult central nervous system. C R Biol. 2006 Jul;329(7):465-75. Epub 2006 May 26.

Temple, S., 2001. The development of neural stem cells. Nature. 414, 112-7.

Vaidya, V.A., Vadodaria, K.C., Jha, S., 2007. Neurotransmitter regulation of adult neurogenesis: putative therapeutic targets. CNS Neurol Disord Drug Targets. 6, 358-74.

van Praag, H., Schinder, A.F., Christie, B.R., Toni, N., Palmer, T.D., Gage, F.H., 2002. Functional neurogenesis in the adult hippocampus. Nature. 415, $1030-4$.

Verleysdonk, S., Hamprecht, B., Rapp, M., Wellard, J., 2004. Uptake and metabolism of serotonin by ependymal primary cultures. Neurochem Res. 29, 1739-47.

Wakade, C.G., Mahadik, S.P., Waller, J.L., Chiu, F.C., 2002. Atypical neuroleptics stimulate neurogenesis in adult rat brain. J Neurosci Res. 69, 72-9.

Wesemann, W., 1978. On the possible mode of action of serotonin in neurotransmission and brain dysfunction. J Neural Transm Suppl. 1-8.

Whitaker-Azmitia, P.M., Druse, M., Walker, P., Lauder, J.M., 1996. Serotonin as a developmental signal. Behav Brain Res. 73, 19-29.

Whitman, M.C., Greer, C.A., 2009. Adult neurogenesis and the olfactory system. Prog Neurobiol. 89,162-175.

Xu, Y., Tamamaki, N., Noda, T., Kimura, K., Itokazu, Y., Matsumoto, N., Dezawa, M., Ide, C., 2005. Neurogenesis in the ependymal layer of the adult rat 3rd ventricle. Exp Neurol. 192, 251-64. 
Zerlin, M., Levison, S.W., Goldman, J.E., 1995. Early patterns of migration, morphogenesis, and intermediate filament expression of subventricular zone cells in the postnatal rat forebrain. J Neurosci. 15, 7238-49.

Zhao, C., Deng, W., Gage, F.H., 2008. Mechanisms and functional implications of adult neurogenesis. Cell. 132, 645-60.

Zhao, M., Momma, S., Delfani, K., Carlen, M., Cassidy, R.M., Johansson, C.B., Brismar, H., Shupliakov, O., Frisen, J., Janson, A.M., 2003. Evidence for neurogenesis in the adult mammalian substantia nigra. Proc Natl Acad Sci U S A. 100, 7925-30. 


\title{
$\mathbb{C H}[\mathbb{A}] P(T] E \mathbb{R}$;
}

\section{In vivo brain repair? \\ Electrical fields attract newborn brain cells.}

\author{
Jahanshahi A, Janssen ML, Steinbusch HW and Temel Y
}

\begin{abstract}
The subventricular zone contains stem cells of the brain. After proliferation, these cells normally migrate towards different brain regions. Here, we report the discovery of a novel approach directing this migration. Epidurally applied electrical fields attracted newborn brain cells to the adult rat neocortex where they expressed neuronal marker. Interestingly, this process was accompanied by enhanced proliferation by a serotonin dependent mechanism.
\end{abstract}



Stem cells are present at specific sites in the mammalian brain, including the subventricular zone (SVZ) (Arvidsson et al., 2002). The SVZ contains the highest number of stem and progenitor cells (Doetsch and AlvarezBuylla, 1996). After proliferation in the SVZ, newborn cells migrate rostrally mainly towards the olfactory bulb (OB) (Curtis et al., 2007). Most of them become glia and small part neurons (Doetsch and AlvarezBuylla, 1996). Although specific factors influencing the rate of proliferation have been identified (Palmer et al., 1999), tools controlling the direction of migration of newborn cells are not available. Here, we report the discovery of a novel approach, namely, the epidural application of specific electrical fields to direct migration of newborn brain cells to the area of interest utilizing animal models. At the same time, we observed enhanced proliferation and increased differentiation into the neuronal cell phenotype.

We performed a set of experiments motivated by recent studies showing neurotrophic effects of high frequency electrical stimulation of the brain (Stone et al., 2011; Toda et al., 2008), and electrical fields (EFs) inducing movement of different cell types in vitro (Li et al., 2008; McCaig et al., 2005; Mycielska and Djamgoz, 2004).

First, we established a tool to apply EFs. We designed and manufactured an electrode with 2 rows with each 3 contacts for epidural placement above the rat sensorimotor cortex (supplementary material and Fig. 1H). The second step was the determination of stimulation parameters. We developed a theoretical framework to establish specific EFs. We applied cathodic current based on in vitro observations that stem and progenitor cells show mobility responses to cathodic stimulation instead of anodic ( $\mathrm{Li}$ et al., 2008). In addition, we used a monopolar setting to reduce the risk of tissue damage (Temel et al., 2004). The stimulation frequencies were low (30 Hz) (Jeong et al., 2009; Nguyen et al., 1999; Tsubokawa et al., 1993) or high $(330 \mathrm{~Hz})$ (Salimi et al., 2008), based on findings on cell mobility and regenerative processes, respectively. We applied low amplitude current, approximately $80 \mu \mathrm{A} /$ contact, in the range, which is observed in 
physiological conditions in neuronal networks in vivo (Borgens and Shi, 1995).
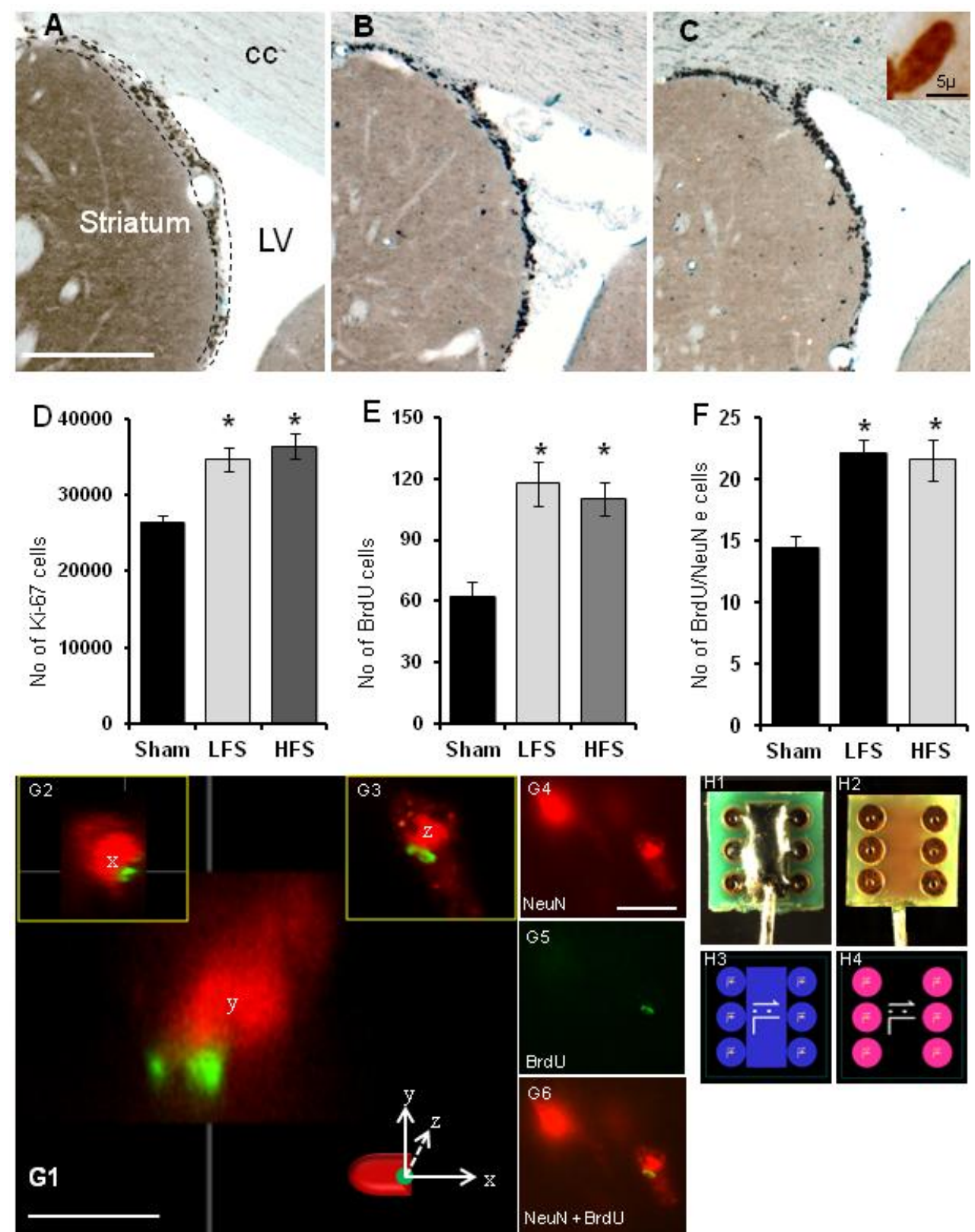
Figure 1. Representative photomicrographs of coronal brain sections showing the proliferating (Ki-67 containing) cells in the SVZ in an animal with sham treatment (A), low frequency EFs (B), and high frequency EFs (C). The scale bar is $400 \mu \mathrm{m}$. A high power photomicrograph of one cell is shown in the inset in $(\mathrm{C})$, scale bar $=5 \mu \mathrm{m}$. Note the presence of more cells in the SVZ in the animals with EFs. cc= corpus callosum, LV= lateral ventricle. (D) Shows the cumulative data of the Ki-67 and * indicates a statistically significant difference in comparison to sham treatment.

(E) Graph shows the cumulative data for the BrdU cell counts. Note that in animals with the application of EFs, more new born cells were found in the cortex below the electrode. Interestingly, these cells expressed more often the neuronal marker NeuN in the stimulated animals (F). Figure $G$ shows photomicrographs of such a newborn neuron migrated towards the EFs in more detail. This cell is contains both BrdU and NeuN. In G1 (x-view, scale bar $=10 \mu \mathrm{m}$.), G2 (y-view, scale bar $=10 \mu \mathrm{m})$ and G3 (z-view, scale bar $=10 \mu \mathrm{m}$ ), we show a 3-D reconstruction of such cell and in G4 (scale bar $=20 \mu \mathrm{m})$, G5, and G6 shows the evidence for double-labeling of NeuN and BrdU in the same cell.

(H) Figures illustrate the electrode construction designed and manufactured by us. It consists of one central rectangular part for the connection of a wire and 6 round electrode contacts. H1 shows the view from the top and $\mathrm{H} 2$ from the bottom.

Third, we applied these EFs epidurally to the right sensorimotor cortex of rats after implanting the electrodes using microsurgical techniques (supplementary material). In a behavioral analysis task, we observed no motor responses with currents of mentioned above. Higher currents (> $150 \mu \mathrm{A} /$ contact) clearly induced contralateral limb movements. Subjects were rats and were divided into the following three groups: high frequency EFs, low frequency EFs, and controls receiving sham treatment. All animals were connected to the stimulators for approximately 4 hours per day, and only animals of the high frequency and low frequency groups received stimulation. We found no effects of these EFs on the general well-being and physiological behavior of the subjects. The animals were treated for 31 days.

Fourth, we evaluated the influence of epidurally applied EFs on proliferation, migration and differentiation. 

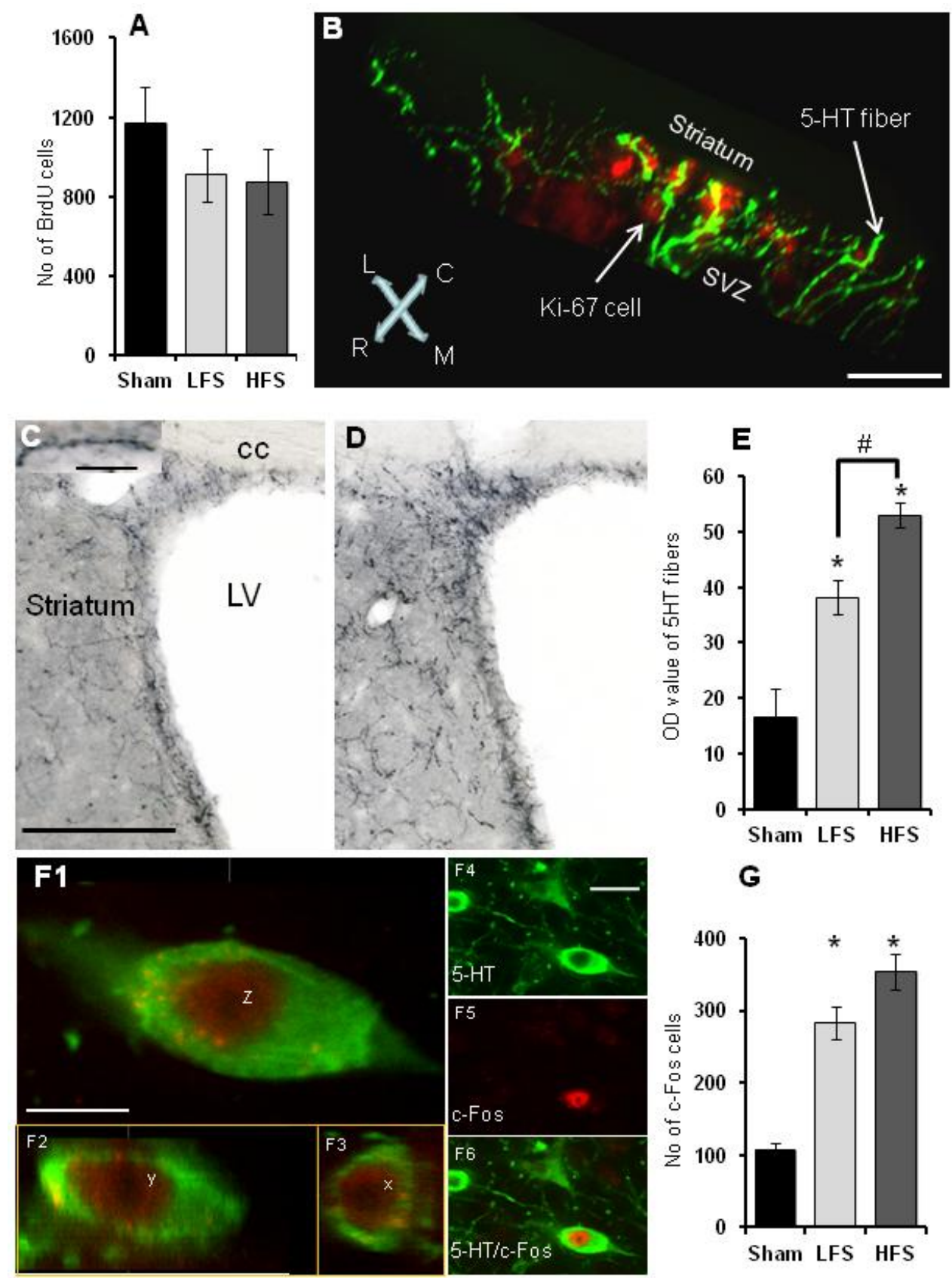

G

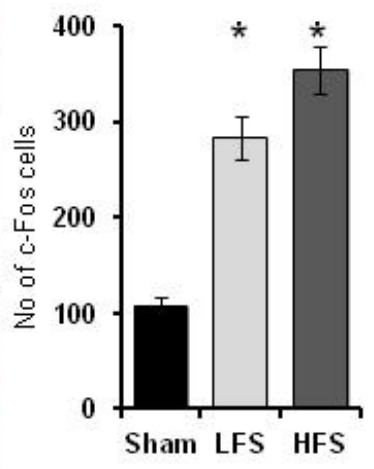


Figure 2. (A). Graph shows the cumulative data for the BrdU cell counts in the olfactory bulb. Note that in animals with the application of EFs, more new born cells were found in the cortex below the electrode.

(B). Proliferating (Ki-67 containing) cells are in close contact with 5-HT containing fibers in the SVZ as demonstrated here by a double-labeling study, scale bar $30 \mu \mathrm{m}$. In animals with epidurally applied EFs (D, this is a rat from the HF group), fibers showed more 5-HT when compared to controls $(\mathrm{C})$, scale bar $=400 \mu \mathrm{m}$. The inset in C shows a high power photomicropgraph of a 5-HT containing fiber, scale bar $10 \mu \mathrm{m}$. cc= corpus callosum, LV= lateral ventricle. (E) Shows the cumulative data of the optical density measurements of 5-HT containing fibers in the SVZ and * indicates a significant difference.

(F) Photomicrographs of an activated (c-Fos) 5-HT containing cell in the DRN in three dimensions (F1, z-axis; F2, y-axis, F3, z-axis), scale bar 10 $\mu \mathrm{m}$. F4 (scale bar $=25 \mu \mathrm{m})$, F5 and F6 photomicrographs show the evidence for double-labeling of c-Fos with 5-HT in the same cell. In graph $(\mathrm{G})$, the cumulative data on the number of c-Fos containing cells in the DRN are shown.

We injected all animals with thymidine analog 5bromo-2deoxyuridine (BrdU) five days before stimulation started (supplementary material). After the last stimulation session, we sacrificed all animals, removed their brains and processed them for further analysis.

Analysis of proliferation in the SVZ was performed by determining the number of dividing cells using Ki-67 immunocytochemistry, a marker of proliferating cells (supplementary material) (Scholzen and Gerdes, 2000). In animals with epidurally applied EFs, we found a striking increase in the number of proliferating cells in the ipsilateral $\mathrm{SVZ}(\mathrm{F}=17.845, \mathrm{P}$ 's $<0.01$ : Fig. 1A-D) and no effects on the contralateral side $(\mathrm{F}=3.532, \mathrm{P}=$ n.s. $)$. Interestingly, in animals with EFs, the proliferating cells showed a clear migration, already at the level of the SVZ, moving from the ventral towards the dorsal parts. To evaluate whether the migration continued towards the cortical area below the electrode, we determined the number of BrdU labeled cells there (supplementary material). We found a remarkable increase in the number of BrdU cells in the cortical area below the electrodes, in the animals with epidurally applied EFs $(F=8.714$, 
$\mathrm{P}$ 's $<0.05$ : Fig. 1E). In the contralateral cortex, we found no increase $(\mathrm{F}=0.003, \mathrm{P}=\mathrm{n} . \mathrm{s}$.). We double-labeled these migrated newborn cell with $\mathrm{NeuN}$, a marker for neuronal phenotype (supplementary material). We found significantly more cells with a neuronal phenotype in animals with epidurally applied EFs (F=7,642, $\mathrm{P}<0.05$; Fig. 1F-G).

The fifth step was to control for the possibility that migration of newborn cells from the SVZ to the area with EFs goes at the cost of the physiological migration towards the olfactory bulb. We assessed the number of newborn cells in the olfactory bulb, and found no differences between groups ( $\mathrm{F}=1.906, \mathrm{P}=$ n.s.; Fig. 2A).

The mechanism responsible for effects described here certainly need further investigation, but at the moment can be discussed in at least three domains, proliferation, migration and differentiation. Although the latter two are largely unknown, effects of stimulation on proliferation have been described (Toda et al., 2008). Based on our interest in the subependymal 5-HT (5-hydroxytryptamine, serotonin) fiber plexus (Jahanshahi et al., 2011) distributed within areas of the SVZ with stemand progenitor cells and the well-known effects of 5-HT on neurogenesis (Banasr et al., 2004; Brezun and Daszuta, 1999), we reasoned here that enhanced 5-HT in the SVZ would be responsible for the boost in proliferation. In our final experiment, using a double-labeling study (supplementary material), we found clearly enhanced 5-HT fibers in the SVZ in animals with epidurally applied EFs (F=27.473, P's $<0.01$ : Fig. 2BD). Since 5-HT innervation of the SVZ, comes mainly from the 5-HT cells in the dorsal raphe nucleus (DRN) (Jahanshahi et al., 2011), we investigated its neuronal activity (supplementary material) and found a substantial increase ( $\mathrm{F}=27.992, \mathrm{P}$ 's $<0.01$ : Fig. $2 \mathrm{~F}-\mathrm{G})$.

Our findings demonstrated the in vivo existence of electrotaxis (McCaig et al., 2005) (ie. attracting cells with electrical currents), which can apparently occur the normal migration. It was accompanied by an 
increased production of new cells and enhanced differentiation into neurons. This mechanism offers new perspectives for brain repair.

\section{Materials and methods}

\section{Electrode construction}

The electrodes were designed and manufactured by us with the assistance of our medical engineering department. The total size of the construction is $3 \mathrm{~mm} \times 3 \mathrm{~mm}$ and made up of a base material and two layers of copper. The base material has a thickness of $0.36 \mathrm{~mm}$ and both copper layers have a thickness of $18 \mu \mathrm{m}$. The copper layers are covered with a Ni/Au coating. It consists of one central rectangle part $(2,5 \mathrm{mmx} 1 \mathrm{~mm})$ for the connection of a wire and 6 round electrode contacts $(0,75 \mathrm{~mm}$ in diameter).

\section{Subjects and experimental groups}

Male Sprague Dawley weighing approximately $300 \mathrm{~g}$ at the time of surgery were housed individually (Central Animal Facility of Maastricht University, Maastricht, The Netherlands) under a 12-h reversed light/dark cycle, with food and water freely available. All experimental procedures were approved by the Animal Experiments and Ethics Committee of Maastricht University.

Rats were randomly assigned to one of the following groups: Sham $(n=6)$, low frequency stimulation (LFS, $n=6$ ) or high frequency stimulation (HFS, $n=6)$.

\section{Surgical procedure}

The surgical procedures were performed under general anesthesia using isoflurane. Body temperature was controlled and supported. Rats underwent craniotomy $(3.5 \mathrm{~mm} \times 3.5 \mathrm{~mm})$ on the right hemisphere above the sensorimotor cortex (M1 and M2 cortices), coordinates from Bregma: AP $0.0 \mathrm{~mm}$ to $3.5 \mathrm{~mm}$ and ML $0.0 \mathrm{~mm}$ to $3.5 \mathrm{~mm}$ (Paxinos and Watson, 1998). All animals received implantation of the electrode construction 
epidurally and a monopolar reference electrode was placed in the skull above the left hemisphere (Paxinos and Watson, 1998). Stainless steel screws were also positioned in the skull above the parietal and occipital bones and served as anchoring arms. All electrodes were connected to pins of a lightweight miniature socket as a head-stage and fixed to the skull with dental acrylic. Afterwards, animals received a 2-week recovery period.

\section{Stimulation parameters}

For a period of 31 days, each animal was stimulated in a freely moving condition $4 \mathrm{~h}$ per day. During the stimulation rats had free access to food and water. We applied a pulse width of $60 \mu \mathrm{s}$, LFS $(30 \mathrm{~Hz})$ and HFS (330 $\mathrm{Hz}$ ). The pulse amplitude was $50 \%$ of the amplitude inducing a contralateral motor response. A World Precision Instruments accupulser (A310, WPI, Berlin, Germany) and a stimulus isolator (A360, WPI, Berlin, Germany) were used to deliver the stimuli. Sham operated animals, were connected to the stimulator but not stimulated spent the same time in the cage.

\section{BrdU administration and tissue processing}

For a period of five days before the stimulation started, all rats received twice daily with a minimum interval of $6 \mathrm{~h}$, intraperitoneal injections of the thymidine analog 5bromo-2deoxyuridine (BrdU, $50 \mathrm{mg} / \mathrm{kg}$, Sigma, St. Louis, MO, U.S.A.), $2 \mathrm{mg} / \mathrm{ml}$ in $0.9 \%$ saline (pH 7.6). At the end of the stimulation period, animals received an overdose of Nembutal $^{\circledR}$, and underwent perfusion-fixation with tyrode $(0.1 \mathrm{M})$ and fixative containing $4 \%$ paraformaldehyde, $15 \%$ picric acid, $0,05 \%$ glutaraldehyde in $0.1 \mathrm{M}$ phosphate buffer ( $\mathrm{pH}$ 7.6). Brains were removed and post-fixed for $2 \mathrm{~h}$ followed by overnight immersion in $15 \%$ sucrose at $4{ }^{\circ} \mathrm{C}$. Brain tissue was then quickly frozen with $\mathrm{CO} 2$, stored at $-80{ }^{\circ} \mathrm{C}$ and later cut serially using a cryostat. 


\section{Immunohistochemical staining}

To assess cell proliferation one series of brain sections was processed immunohistochemicaly for $\mathrm{Ki}-67$, a well characterized protein extensively used as a proliferation marker (Scholzen and Gerdes, 2000). In addition, to evaluate the density of 5-HT-immunoreactive (5HT-IR) neuronal fibers in the SVZ and motor cortex, two series of sections containing the SVZ and motor cortex were processed for 5-HT immunohistochemistry. Another series of sections containing the olfactory bulbs (OB) were processed immunohistochemicaly for BrdU. Finally, to test the effect of EFs on DRN cells, we carried out c-Fos (K-25) immunohistochemistry. C-Fos (K-25) is known to be a marker for neuronal activation (Budzikowski et al., 1998).

The stainings were carried out using primary antibodies; rabbit anti-Ki-67 (diluted 1:1000, Vector laboratories, Inc, USA), rabbit anti-5-TH antibody (Steinbusch, 1981), (diluted 1:20000) mouse anti-BrdU (1:400, Roche, IN, USA) and polyclonal rabbit anti-c-Fos (K-25) (1:10,000; Santa Cruz Biotechnology Inc, Santa Cruz, USA). After the incubation period (three days for 5-HT and overnight for the rest) and rinsing steps with TBS and Tris-buffered solution containing Triton X-100 (TBS-T), and incubation with the secondary antibody (1:800 donkey anti-rabbit biotin and donkey anti-mouse biotin, Jackson Immunoresearch Laboratories, West Grove, USA), the sections were incubated for two hours with an avidin-biotinperoxidase complex (1:800, Vector laboratories, Inc, USA). To visualize the horseradish peroxide reaction product, the sections were incubated with 3,3' -diaminobenzidine tetrahydrochloride. Finally, the sections were mounted and coverslipped.

To evaluate neuronal differentiation, another series of tissue sections containing the motor cortex were processed for BrdU and NeuN double staining. Staining was performed using the primary antibodies mouse antiBrdU (1:400) and mouse anti-NeuN (biotin-conjugated; 1:100, Temecula, California, USA). After overnight incubation and washing steps, brain sections were incubated with the secondary anitibodies donkey-anti-mouse alexa 488 (1:200, Invitrogen, Oregon, USA) and streptavidin alexa 594 
(1:1000, Invitrogen, Oregon, USA). Sections were washed, mounted on gelatine coated glasses and coverslipped with $80 \%$ glycerol in TBS.

\section{Quantification of immunohistochemical data}

Ki-67 cells in the SVZ

The number of $K i-67$ containing cells in the SVZ was quantified using designed based stereology. Stereological investigations were carried out with a stereological computer microscopy system (Stereo Investigator, Microbrightfield Bioscience, Williston, VT). In all sections showing the SVZ, the region comprising the $K i-67$ containing cells in the SVZ, was delineated and total numbers of $\mathrm{Ki}$ - 67 containing cells was estimated with the optical fractionator method (Schmitz and Hof, 2000; Schmitz and Hof, 2005; West et al., 1991). Our stereological counting method has been previously described (Temel et al., 2006).

\section{BrdU/NeuN double-labeled cells in the cortex}

Double-stained sections were evaluated using a spinning disk confocal microscope (Olympus DSU BX51WI, Pennsylvania, USA) connected to a computer with analysis software (Stereo Investigator, Microbrightfield Bioscience, Williston, VT). Per brain, three sections from three bregma levels $(+3.20,+2.20$ and +1.20 , according to the atlas of the rat brain (Paxinos and Watson, 1998), were used for cell counting. After delineating the M1/M2 cortex, all BrdU-labeled cells were assessed and also the number of double labeled cells with NeuN.

\section{BrdU cells in the olfactory bulb}

Three sections per rat were quantified at the right and left mid-olfactory bulb levels using an image analysis system (analySIS Imaging System, Munster, Germany) from digital photos taken by an Olympus U-CMAD-2 digital camera connected to an Olympus AX-70 microscope. Four olfactory bulb areas (dorsal, ventral, medial, lateral) from the granular layer of each section were randomly chosen from each side using the $20 x$ magnification (Fig; 5-C). Cells were counted in each photomicrograph using ImageJ software (version 1.38x; National Institutes of Health, 
Bethesda, MD, USA). Quantification method for OB was adopted from an earlier publication (Sundholm-Peters et al., 2005).

Density of 5-TH containing fibers in the SVZ

The optical density of 5-TH containing fibers in the in the SVZ were quantified using an image analysis system (f-view; Olympus, Tokyo, Japan) connected to an Olympus AX70 brightfield microscope (analySIS; Imaging System, Münster, Germany) from digital photos taken by an Olympus U-CMAD-2 digital camera connected to an Olympus AX 70 microscope. Densitometric measurements using the ImageJ software were obtained at 3 anteroposterior levels for in the right and left hemispheres. The coordinates were from bregma for the $\mathrm{SVZ}+0.48,+0.20$ and -0.40 (Paxinos and Watson, 1998). Data are expressed as optical density ratios.

c-Fos cells in the DRN

Images of the area of interest were taken. The number of c-Fos containing cells were counted using a previously described method (Tan et al., 2011). 


\section{References}

Arvidsson, A., Collin, T., Kirik, D., Kokaia, Z., Lindvall, O., 2002. Neuronal replacement from endogenous precursors in the adult brain after stroke. Nat Med. 8, 963-70.

Banasr, M., Hery, M., Printemps, R., Daszuta, A., 2004. Serotonin-induced increases in adult cell proliferation and neurogenesis are mediated through different and common 5-HT receptor subtypes in the dentate gyrus and the subventricular zone. Neuropsychopharmacology. 29, 450-60.

Borgens, R.B., Shi, R., 1995. Uncoupling histogenesis from morphogenesis in the vertebrate embryo by collapse of the transneural tube potential. Dev Dyn. 203, 456-67.

Brezun, J.M., Daszuta, A., 1999. Depletion in serotonin decreases neurogenesis in the dentate gyrus and the subventricular zone of adult rats. Neuroscience. 89, 9991002.

Budzikowski, A.S., Vahid-Ansari, F., Leenen, F.H., 1998. Chronic activation of brain areas by high-sodium diet in Dahl salt-sensitive rats. Am J Physiol. 274, H204652.

Curtis, M.A., Kam, M., Nannmark, U., Anderson, M.F., Axell, M.Z., Wikkelso, C., Holtas, S., van Roon-Mom, W.M., Bjork-Eriksson, T., Nordborg, C., Frisen, J., Dragunow, M., Faull, R.L., Eriksson, P.S., 2007. Human neuroblasts migrate to the olfactory bulb via a lateral ventricular extension. Science. 315, 1243-9.

Doetsch, F., Alvarez-Buylla, A., 1996. Network of tangential pathways for neuronal migration in adult mammalian brain. Proc Natl Acad Sci U S A. 93, 14895-900.

Jahanshahi, A., Temel, Y., Lim, L.W., Hoogland, G., Steinbusch, H.W., 2011. Close communication between the subependymal serotonergic plexus and the neurogenic subventricular zone. J Chem Neuroanat. 42, 297-303.

Jeong, S.H., Jun, S.B., Song, J.K., Kim, S.J., 2009. Activity-dependent neuronal cell migration induced by electrical stimulation. Med Biol Eng Comput. 47, 93-9.

Li, L., El-Hayek, Y.H., Liu, B., Chen, Y., Gomez, E., Wu, X., Ning, K., Chang, N., Zhang, L., Wang, Z., Hu, X., Wan, Q., 2008. Direct-current electrical field guides neuronal stem/progenitor cell migration. Stem Cells. 26, 2193-200.

McCaig, C.D., Rajnicek, A.M., Song, B., Zhao, M., 2005. Controlling cell behavior electrically: current views and future potential. Physiol Rev. 85, 943-78.

Mycielska, M.E., Djamgoz, M.B., 2004. Cellular mechanisms of direct-current electric field effects: galvanotaxis and metastatic disease. J Cell Sci. 117, 1631-9.

Nguyen, J.P., Lefaucheur, J.P., Decq, P., Uchiyama, T., Carpentier, A., Fontaine, D., Brugieres, P., Pollin, B., Feve, A., Rostaing, S., Cesaro, P., Keravel, Y., 1999. Chronic motor cortex stimulation in the treatment of central and neuropathic pain. Correlations between clinical, electrophysiological and anatomical data. Pain. 82, 245-51.

Palmer, T.D., Markakis, E.A., Willhoite, A.R., Safar, F., Gage, F.H., 1999. Fibroblast growth factor-2 activates a latent neurogenic program in neural stem cells from diverse regions of the adult CNS. J Neurosci. 19, 8487-97.

Paxinos, G., Watson, C., 1998. The rat brain in stereotaxic coordinates., Vol., Academic Press San Diego. 
Salimi, I., Friel, K.M., Martin, J.H., 2008. Pyramidal tract stimulation restores normal corticospinal tract connections and visuomotor skill after early postnatal motor cortex activity blockade. J Neurosci. 28, 7426-34.

Schmitz, C., Hof, P.R., 2000. Recommendations for straightforward and rigorous methods of counting neurons based on a computer simulation approach. J Chem Neuroanat. 20, 93-114.

Schmitz, C., Hof, P.R., 2005. Design-based stereology in neuroscience. Neuroscience. $130,813-31$.

Scholzen, T., Gerdes, J., 2000. The Ki-67 protein: from the known and the unknown. J Cell Physiol. 182, 311-22.

Steinbusch, H.W., 1981. Distribution of serotonin-immunoreactivity in the central nervous system of the rat-cell bodies and terminals. Neuroscience. 6, 557-618.

Stone, S.S., Teixeira, C.M., Devito, L.M., Zaslavsky, K., Josselyn, S.A., Lozano, A.M., Frankland, P.W., 2011. Stimulation of entorhinal cortex promotes adult neurogenesis and facilitates spatial memory. J Neurosci. 31, 13469-84.

Sundholm-Peters, N.L., Yang, H.K., Goings, G.E., Walker, A.S., Szele, F.G., 2005. Subventricular zone neuroblasts emigrate toward cortical lesions. J Neuropathol Exp Neurol. 64, 1089-100.

Tan, S.K., Janssen, M.L., Jahanshahi, A., Chouliaras, L., Visser-Vandewalle, V., Lim, L.W., Steinbusch, H.W., Sharp, T., Temel, Y., 2011. High frequency stimulation of the subthalamic nucleus increases c-fos immunoreactivity in the dorsal raphe nucleus and afferent brain regions. J Psychiatr Res.

Temel, Y., Visser-Vandewalle, V., van der Wolf, M., Spincemaille, G.H., Desbonnet, L., Hoogland, G., Steinbusch, H.W., 2004. Monopolar versus bipolar high frequency stimulation in the rat subthalamic nucleus: differences in histological damage. Neurosci Lett. 367, 92-6.

Temel, Y., Visser-Vandewalle, V., Kaplan, S., Kozan, R., Daemen, M.A., Blokland, A., Schmitz, C., Steinbusch, H.W., 2006. Protection of nigral cell death by bilateral subthalamic nucleus stimulation. Brain Res. 1120, 100-5.

Toda, H., Hamani, C., Fawcett, A.P., Hutchison, W.D., Lozano, A.M., 2008. The regulation of adult rodent hippocampal neurogenesis by deep brain stimulation. $\mathrm{J}$ Neurosurg. 108, 132-8.

Tsubokawa, T., Katayama, Y., Yamamoto, T., Hirayama, T., Koyama, S., 1993. Chronic motor cortex stimulation in patients with thalamic pain. J Neurosurg. 78, 393401.

West, M.J., Slomianka, L., Gundersen, H.J., 1991. Unbiased stereological estimation of the total number of neurons in thesubdivisions of the rat hippocampus using the optical fractionator. Anat Rec. 231, 482-97. 

CIHIAPPTIER \&

\section{CONCLUSION}


In the present thesis, we first investigated the plasticity of the intracellular contents (phenotype) of different neurotransmitters in the dorsal raphe nucleus (DRN) following pharmacological modulation. Secondly, we aimed to find the consequence of genetic modulation on the serotonergic and dopaminergic systems. In addition, we provided a review of the histology, anatomy, and chemistry of the subventricular zone (SVZ). In this chapter, we outlined the involvement of the neurogenic SVZ serotonergic system in neurogenesis, which can be considered as structural plasticity. Following this, we developed a new method to influence neurogenesis by a 5-HT related mechanism. The experimental data presented in this thesis are, in summary, as follows;

Pharmacological modulation, using buspirone, a 5-HT1A partial agonist, administered intra-peritoneal, resulted in neurochemical changes in the DRN. We have shown that buspirone has an effect on different neurotransmitter systems in the DRN, while the mechanism of action is explained by an effect on the serotonergic (5-hydroxytryptamine- 5-HT) system. Here, we investigated the effect of acute and chronic buspirone treatment on the 5-HT and non-5-HT cells, the neuronal nitric oxide synthase (nNOS) and tyrosine hydroxylase (TH) cells, in the DRN. Our findings suggest that buspirone treatment affects not only the phenotype of 
5-HT but also of nNOS and TH. Taken together, our findings provide additional evidence that the 5-HT and dopamine systems are remarkably interrelated in the DRN. In addition, our findings of acute and chronic effects of nNOS, suggest that this enzyme responsible for NO production can be activated during any moment of physiological response. Therefore, the cellular effects of buspirone are more complex than thought.

Although the abnormalities in serotonergic neurotransmission are known to be associated with depressive and anxiety symptoms, other neurotransmitter systems have also been shown to be involved. Using three genetically modified mouse models, all characterized by altered behaviors in depression-related paradigms, our results show quantitative differences in tryptophan hydroxylase-2 (TPH2) mRNA expression in the three main subregions of the DRN as well as in the median raphe nucleus $(\mathrm{MRN})$. These changes are related to serotonergic or glutamatergic neurotransmission and to endocannabinoid systems. It appears that $\mathrm{TPH} 2$ mRNA levels and activity can be regulated by the end-product 5-HT. In particular; higher extracellular 5-HT levels result in lower TPH mRNA expression in 5-HT transporter knock-out mice (5-HTT-/-). In addition, we found that cannabinoid receptor knock out (CB1R -/-) and vesicular glutamate transporter-1 (VGLUT1) genetic manipulation could lead to distributions in the excitatory and inhibitory effect exerted throughout different receptor types not only in the DRN and MRN 5-HT neurons, but also in target brain regions, possibly leading to impaired serotonergic negative feedback. These can enhance the expression of TPH2 mRNA in the DRN. Based on the findings of the present study, we suggest that TPH2 mRNA expression is under the influence of multiple messenger systems in relation with presynaptic and/or postsynaptic feedback control of serotonin synthesis. 5-HTT, VGLUT1 and CB1R seem to be involved in the execution of these feedback mechanisms. Finally, our data are consistent with previous reports suggesting that $\mathrm{TPH} 2$ activity, within different raphe subregions are differentially regulated under specific conditions. 
In another set of experiments we studied the effect of genetic modulation on dopaminergic system neuroplasticity. In this respect, using a recently generated transgenic rat model of Huntington's disease (tgHD), which shows progressive striatal neurodegeneration and chorea, we have found evidence for increased levels of dopamine in the striatum, which is in line with post-mortem human studies. In addition, we have demonstrated that the origin of increased levels of dopamine is the presence of more dopaminergic cells in the ventral tegmental area (VTA) and the substantia nigra pars compacta $(\mathrm{SNc})$ of transgenic Huntington's disease rats, the two main nuclei providing the striatum with dopamine. Here we suggested that the increased number of tyrosine hydroxylase (TH) containing cells in the SNc and VTA is possibly due to the change in phenotype of the non-TH containing cells. Our finding provides additional evidence for the observations concerning the treatment of the chorea with dopamine-antagonists and dopamine-depleting drugs. In addition, these findings are in line with previous experimental studies showing that high concentration of dopamine in the striatum leads to neurotoxicity and may play a role in the neurodegeneration in HD.

To further investigate the mechanism(s) underling the hyperdopaminergic status in $\mathrm{HD}$, we studied the DRN, the main area of dopaminergic and non-dopaminergic neurons outside the SNc and VTA, which could contribute to the dopaminergic input to the basal ganglia. Since we found no clear evidence for changes in the total cell numbers in the investigated regions, we hypothesized that this increase may be due to the change in the phenotype of the non-dopamine containing cells. Importantly, in addition to the tgHD rats, we found this hyperdopaminergic status also in the DRN tissue of HD patients, establishing a consistency of the finding across species. Based on these findings we suggest that the mutation in HD causes neurons to switch phenotypes, which may underlie the clinical neurological symptoms and provide a novel mechanism for therapy development. 
Altered neurogenesis is among the most prominent forms of neuroplasticity, which has been shown to be regulated by serotonergic inputs. The presence of a dense 5-HT fiber complex in the vicinity of the stem/progenitor cells of the SVZ is an intriguing anatomical fact. This close anatomical relationship suggests an important functional role for 5HT in influencing cell proliferation in the SVZ. However, it remains unsolved how 5-HT released by terminals in the subependymal complex reaches the cells in the SVZ. There are two possibilities: direct synaptic contact or diffusion. Synaptic contact has not been found, but we have to bear in mind that it has not been investigated in detail yet. Diffusion of 5HT to the neighboring stem cells is a plausible mechanism. It might well be that both mechanisms exist and are activated depending on the action required. In this respect, evidence suggest a fine-tuning effect of 5-HT on cell proliferation, enhanced by lower concentrations and decreased by higher levels.

During the last decades electrical modulation of central nervous system (CNS) has attracted great deal of interest in symptomatical treatment of a variety of neurological disorders. However, the mechanism by which electrical stimulation of CNS exerts therapeutic effects is not known yet. Here, we successfully developed a new tool to influence adult brain plasticity using electrical stimulation. We aimed to enhance the migration of neuronal progenitor cells towards the motor cortex, so called "electrotaxis". We found that epidural electrical stimulation of the motor cortex induced an increase in SVZ neurogenesis and migration. We found that these effects were accompanied by an enhanced 5-HT system.

The results obtained from the experiments as outlined in this thesis show that the serotonergic and dopaminergic systems undergo various plastic changes following pharmacological, genetic and electrical neuromodulation. Beside the conventional form of synaptic plasticity, which is achieved through enhancing communication at the synaptic site between existing neurons, for a long time the notion of structural forms of 
neuronal plasticity in the adult brain were considered heretic. In recent years, the existence of neurogenesis has become scientifically established. In this thesis, we have found evidence for radical forms of neuronal plasticity, namely the change in the phenotype of neurons and electrotaxis of neuronal stem cells in the adult brain. Based on these findings we suggest that in the presence of disease-related deficits and impaired synaptic plasticity, seen in behavioral disorders, the brain once again manifests its multi-source plasticity by re-organizing its resources. The challenge is to find tools to enhance this capacity, which ultimately can be a remedy for (degenerative) brain disorders. 




\section{Acknowledgments}

I want to thank the following people for their support and help in the completion of this thesis.

Prof. Dr. Harry W. M. Steinbusch

Dear Harry, during my last year of master training, I contacted you to ask about the possibility to perform research at your department; you gave me this opportunity and opened the doors to science for me. Ever since, you have provided me continuous guidance and support throughout this period of scientific research. You played and are still playing a very important role in my academic development. I consider this as a great privilege and cannot thank you enough for your support.

Prof. Dr. Y. Temel

Dear Yasin, my heartfelt gratitude for your sustained guidance, patience and supports you have provided throughout my time as your PhD student. I consider myself extremely fortunate for being able to work with you and having a supervisor who cared so much, not only about my research over this $\mathrm{PhD}$ period, but also about my future research career. Yasin: I will always keep this in my mind that "good scientist needs to be a good writer as well”.

Prof. Dr. T. Hokfelt

Dear Tomas, you gave me the opportunity to learn in-situ hybridization in your laboratory and enjoy the great scientific atmosphere of the Karolinska Institute. You and your group taught me wonderful things. I would like to express my sincere appreciation to you and the members of your group. I am looking forward to future collaborations.

Prof. Dr. D. Hopkins

My acknowledgments of gratitude would also be mentioned to Prof. Dr. David Hopkins, for your inspiration, guidance and careful perusal of this thesis. 
Dr. Hoogland

Dear Govert, many thanks to you for your supports and consistent attention when I was faced with a challenge. You always helped me in exchanging any ideas and gave me invaluable comments and critiques on the improvement of my work.

\section{My homeland mentors}

A word of thank-you would also be expressed to Mr. Hossein Radmard; enjoying your lessons in high school led me to my love of biology. Dr. Komaki: with you, I experienced my first in-vivo and ex-vivo experiments using old fashioned physiograph equipment during my bachelor studies! Prof. Mirnajafi-zadeh, Prof. Javan, Prof. Semnanian and Prof. Fathollahi: I feel deeply honored to start studying neuroscience with you.

Dr. L. Lee Wei

Dear Anthony, you were my first friend in Maastricht. You helped me out enormously in my research. Without your commitment, it was not possible to accomplish this project in the way we did. I want to thank you for your help and wish you good luck with your career.

HE. Steinbusch, M. Philippens and D. hermes

Dear Hellen, Denise and Marjan, I believe that without your technical supports the lab would not work. I thank you very much for your help and support.

\section{Colleagues}

The acknowledgements would not be complete without thanking my colleagues (as well as my sub-family members) of the experimental neurosurgery group. Rinske, Sonny, Mark, Youssef, Thibaut, Dagmar, Sarah, Mujzgan, Ehsan, Ingeborg, Maartje, Syenna, Frederic, Thank you for your unconditional support and help not only for my research but also for our excellent and wonderful relationship. I really appreciate everything you have done for me and 
my gratitude to all of you is beyond description! Rinske and Mark, thank you once again for being my 'Paranimfen' in organizing this successful event. Besides, I would like to thank Ahmet and Ersoy for your contribution in creating an ideal and interactive environment of science in the experimental neurosurgery group.

I would like to thank my colleagues and friends of the department for maintaining a good research environment. Here, my heartfelt gratitude to Prof. Marc De Baets, Prof. Fred van Leeuwen, Dr. Jos Prickaerts, Dr. Arjan Blokland, Dr. Jodi Pawluski, Prof. Bert Joosten, Dr. Ronald Deumens, Dr. Daniel van den Hove, Dr. Mario Losen, Dr. Pilar Martinez, Dr. Bart Rutten, Wiel, Sajjad, Shahed, Frank, Bart, Gerard, Pablo, Leonidas, Marlien, Marisela, Anna, Marijke, Annerieke, Natalia, Chiara, Alejandro, Tim, Sven and others. A special thank is also extended Marjanne Markerink for your excellent technical support in the laboratory. My sincere gratitude is also owed to Dr. Nicole Senden, Marie-Therese Moers, Liza pizuto, Anja de Bruin, for your wonderful secretary works in the department; as well as Ankie Hochstenbach, Laurent Louwies, and Marko van Hertrooy for your financial coordination. A word of thank-you would also be expressed to Richard Frijnts, Dr. Saskia Seeldrayers, Rik Tinneman, Clarice Soogelee and all CPV members.

On a more personal note, my acknowledgment of gratitude would also be mentioned to my parents and my brothers. They have always loved me and supported every choice of me. For sure, they are the happiest and the most proud persons, when seeing me getting this degree, I indeed dedicate this book to them.

A special thank is extended to the board of evaluation committee and corona of my dissertation defense for asking insightful questions and providing useful comments on the presentation of this scientific report. 
Many people in one way or another contributed to this thesis. It may be that I'm forgetting some people. I want to thank everyone who contributed. All deserve my deepest heartfelt gratitude. 


\section{Biography}

Ali Jahanshahi was born on $23^{\text {nd }}$ of September, 1978 in Bahar, a small city located in the mountainous province of Hamedan in western Iran.

He studied nursing at Hamedan University of Medical Sciences. Thereafter, he worked as a nurse in the trauma emergency unit from June 2002 to September 2005. Being interested in biology urged him to continue his academic education in the field of basic sciences. During his master study, he worked as a student-assistant at the department of cellular neurosciences under the supervision of Prof. Dr. Harry Steinbusch and Dr. Yasin Temel. In 2007, he received his master degree in medical physiology (with specialization in neurophysiology) at the Tarbiat Modares University in Tehran, Iran. In December 2008, he was awarded with Marie Curie fellowship to carry out his $\mathrm{PhD}$ research at the department of Neuroscience, Maastricht University, the Netherlands. Within this period he spent four months as a guest researcher under the supervision of Prof. Dr. Tomas Hokfelt at the department of neuroscience, Karolinska Institute, Stockholm, Sweden. 



\section{List of publications}

1. Temel Y, Zeef DH, Janssen ML, Oosterloo M, Schaper F, Jahanshahi A, Vlamings R. Lessons learned from the transgenic Huntington's disease rats. Neural Plast, 2012

2. Janssen ML, Zwartjes DG, Tan SK, Vlamings R, Jahanshahi A, Heida T, Hoogland G, Steinbusch HW, Visser-Vandewalle V, Temel Y. Mild dopaminergic lesions are accompanied by robust changes in subthalamic nucleus activity. Neurosci Lett, 2011

3. Jahanshahi A, Temel Y, Steinbusch HW. Dissecting the projections of different groups of raphe serotonergic neurons (Commentary on Beng et al.). EUR $J$ Neurosci, 2011

4. Zeef DH, van Goethem NP, Vlamings R, Schaper F, Jahanshahi A, Hescham S, von Hörsten S, Prickaerts J, Temel Y. Memory deficits in the transgenic rat model of Huntington's disease. Behav Brain Res. 2011 Nov 15

5. Zeef DH, Vlamings R, Lim LW, Tan S, Janssen ML, Jahanshahi A, Hoogland G, Prickaerts J, Steinbusch HW, Temel Y. Motor and non-motor behaviour in experimental Huntington's disease. Behav Brain Res. 2011

6. Jahanshahi A, Temel Y, Lim LW, Hoogland G, Steinbusch HW; Close communication between the subependymal serotonergic plexus and the neurogenic subventricular zone. Journal of Chem neuroanat, 2011

7. Jahanshahi A, Le Maitre E, Temel Y, Lanfumey L, Hamonf M, Lesch P, Tordera, RM, Del Río J, Aso E, Maldonado R, Hökfelt T, Steinbusch HW; Altered expression of neuronal tryptophan hydroxylase- 2 mRNA in the dorsal and median raphe nuclei of three genetically modified mouse models relevant to depression and anxiety. Journal of Chem neuroanat, $2011 \mathrm{Jul}$; 41(4):227-33

8. Tan SK, Janssen ML, Jahanshahi A, Chouliaras L, Visser-Vandewalle V, Lim LW, Steinbusch HW, Sharp T, Temel Y; High frequency stimulation of the subthalamic nucleus activates dorsal raphe afferent nuclei and inhibits dorsal raphe nucleus activity; a combined morphological and behavioural study. $J$ Psychiatr Res, 2011

9. Lim LW, Blokland A, Duinen M, Tan S, Vlamings S, Janssen M, Jahanshahi A, Aziz-Mohammadi M, Steinbusch H, Schruers K,Temel Y; Increased plasma corticosterone levels after periaqueductal gray stimulation-induced escape reaction or panic attacks in rats. Behav Brain Res, 2010 15; 218(2):301-7 
10. Jahanshahi A, Vlamings R, Hilmi Kaya A, Lim LW, Janssen M.L.F, Tan S.K, Visser-Vandewalle V, Steinbusch H.W.M, Temel T; Hyperdopaminergic status in experimental Huntington's disease. J Neuropath Exp Neurol, 2010 Sep; 69 (9): 910-7

11. Jahanshahi A, Lim LW, Steinbusch HWM, Visser-Vandewalle V, Temel Y; Buspirone-induced changes in the serotonergic and non-serotonergic cells in the dorsal raphe nucleus of rats. Neuroscience Letters, 2010 Apr 5; 473(2):136-40

12. Mehregan H, Sadeghizadeh M, Zarrindast MR, Jahanshahi A, Shirzad H, Saadati M; Effect of Morphine-Sensitization in D2 Receptor Gene Expression in the Mice Brain in the Absence and Presence of Lithium Chloride. Yakhteh Medical Journal, Vol 12, No 3, 2010, Pages: 395-404

13. Jahanshahi A, Mirnajafi-Zadeh J, Javan M, Mohammad-Zadeh M, Rohani R;The antiepileptogenic effect of electrical stimulation at different low frequencies is accompanied with change in adenosine receptors gene expression in rats. Epilepsia. 2009 Apr 24.

14. Mohammad-Zadeh M, Mirnajafi-Zadeh J, Fathollahi Y, Javan M, Jahanshahi A, Noorbakhsh SM, Motamedi F; The role of adenosine A(1) receptors in mediating the inhibitory effects of low frequency stimulation of perforant path on kindling acquisition in rats. Neuroscience. 2009 Feb 18; 158(4): 1632-43.

15. Sadegh M, Mirnajafi-Zadeh J, Javan M, Fathollahi Y, Mohammad-Zadeh M, Jahanshahi A, Noorbakhsh SM; The role of galanin receptors in anticonvulsant effects of low-frequency stimulation in perforant path-kindled rats. Neuroscience. 2007 Dec 5; 150(2): 396-403.

\section{Submitted manuscripts}

1. Jahanshahi A, Janssen ML, Steinbusch HW and Temel Y. In vivo brain repair? Electrical fields attract newborn brain cells.

2. Jahanshahi A, Vlamings A, van Roon-Mom W. Faull R.L.M, Waldvogel H.J, Steinbusch H.W.M, Temel Y. "Phenoconversion" in experimental and clinical Huntington's disease 